\title{
Basic theory and experimental approach to characterize flow and fracture properties of fine powder bulk body
}

\author{
Wiratni Wiratni \\ West Virginia University
}

Follow this and additional works at: https://researchrepository.wvu.edu/etd

\section{Recommended Citation}

Wiratni, Wiratni, "Basic theory and experimental approach to characterize flow and fracture properties of fine powder bulk body" (2003). Graduate Theses, Dissertations, and Problem Reports. 2547.

https://researchrepository.wvu.edu/etd/2547

This Dissertation is protected by copyright and/or related rights. It has been brought to you by the The Research Repository @ WVU with permission from the rights-holder(s). You are free to use this Dissertation in any way that is permitted by the copyright and related rights legislation that applies to your use. For other uses you must obtain permission from the rights-holder(s) directly, unless additional rights are indicated by a Creative Commons license in the record and/ or on the work itself. This Dissertation has been accepted for inclusion in WVU Graduate Theses, Dissertations, and Problem Reports collection by an authorized administrator of The Research Repository @ WVU.

For more information, please contact researchrepository@mail.wvu.edu. 


\title{
Basic Theory and Experimental Approach to Characterize Flow and Fracture Properties of Fine Powder Bulk Body
}

\author{
Wiratni Wiratni \\ Dissertation to be submitted to the \\ College of Engineering and Mineral Resources \\ at West Virginia University \\ in partial fulfillment of the requirements \\ for the degree of \\ Doctor of Philosophy \\ in \\ Chemical Engineering
}

Hisashi O. Kono, Dr. Engineering, Chair Rakesh K. Gupta, Ph.D. John R. Loth, Ph.D.

Peter G. Stansberry, Ph.D. Alfred H. Stiller, Ph.D.

Department of Chemical Engineering

Morgantown, West Virginia 2003

Keywords : Fine Powder Fluidization, Powder Rheology, Elevated Temperature 


\title{
ABSTRACT
}

\section{Basic Theory and Experimental Approach to Characterize Flow and Fracture Properties of Fine Powder Bulk Body}

\author{
Wiratni Wiratni
}

This dissertation comprised two parts, which were Part I for the development of a method to characterize the fine powder flow at ambient temperature and Part II for the application of the method in fine powder aeration at elevated temperature.

The analysis conducted on fine powder aeration in Part I was based on the theory of homogeneously-aerated-expanded (HAE) emulsion phase, which viewed a system of aerated fine powders as a quasi-solid single phase.

The original aeration data from an aeration experiment (gas velocity, pressure drop, and bed height) were transformed into the new variables specifically defined for aerated fine powder (powder strain and powder tensile stress). The plots of powder tensile stress against powder strain indicated a consistent tendency for all experimental data. Based on this fact, a parameter called elastic deformation coefficient $(Y)$ was determined from those plots and defined as the characterization parameter for fine powder aeration behaviors.

The point of intrinsic $U_{m b}$ could be accurately determined as the point of sudden change of $Y$ value on the plot of $Y$ against powder strain. These $Y$ values also provided a quantitative tool to compare the aeration quality of several different systems of fine powders.

In Part II, to study the effect of temperature on aeration quality, the $\mathrm{Y}$ method was applied on aerated FCC catalyst at temperatures ranged from $26^{\circ} \mathrm{C}$ to $600^{\circ} \mathrm{C}$.

At ambient temperature, the aeration quality of FCC catalyst was very poor and it was indicated by an initially high $Y$ which kept increasing through the whole range of strain until the maximum expansion. In contrast to that, at elevated temperature, a region of constant $Y$ was observed in the plot of $Y$ against strain. This fact indicated that at high temperature, an ideal HAE emulsion phase could be maintained over a wide range of strain before the first fractures occurred. These results showed that $Y$ value served as a general characterization parameter that could be applied consistently at both ambient and elevated temperature. 
gox

This dissertation

is dedicated to my daughter,

Dewanggani Kirana,

who has to spend her first 4 years without me by her side,

yet in her very special ways,

has given me the courage to start this adventure

and

the strength

to accomplish it.

8003 


\section{ACKNOWLEDGMENTS}

I would like to express my gratitude to Dr. Kono for his advice and patience in our long discussions and also for his constant enthusiasm to work with me on my experiments. I also deeply thank the members of my examining committee, Dr. Gupta, Dr. Loth, Dr. Stiller, and Dr. Stansberry, for their constructive questions and suggestions that were very helpful in completing this dissertation.

I would like to recognize QUE Project in Chemical Engineering Department, Gadjah Mada University, Indonesia, for providing me with the financial support to pursue my PhD program in West Virginia University.

I am very grateful to my husband for his sincere support and understanding on my ups and downs during my work on this dissertation. The same things go to my family and friends as well. In particular, I would like to thank Kuzilati Kushaari for her time to proof-read the dissertation draft and moreover, for being a family far away from home during my stay in Morgantown.

My special thank is going to Jim Hall, whose ingenuity helped me a lot to set up and run my experiments smoothly. I also thank Bonita Helmick, Linda Rogers, and Linda Cox for their patience and help in my paperwork. 


\section{TABLE OF CONTENT}

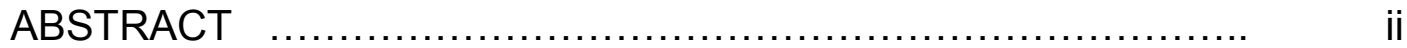

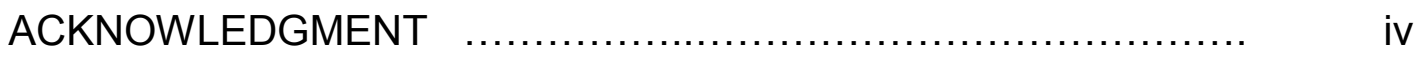

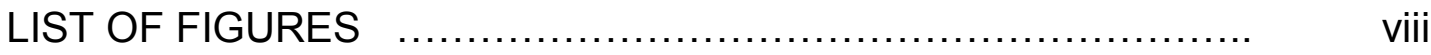

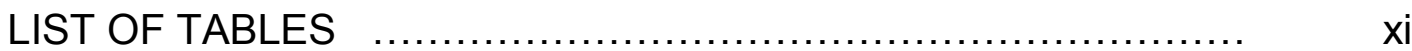

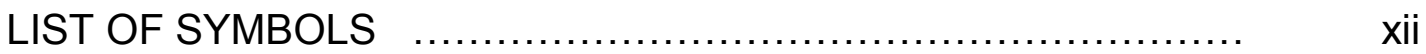

PART I : Characterization of Fine Powder Aerations at Ambient

Temperature

Chapter I.1. Introduction

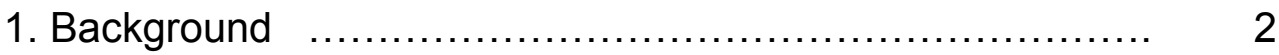

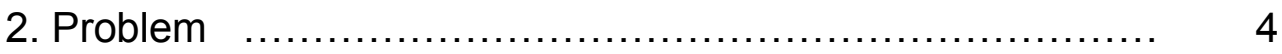

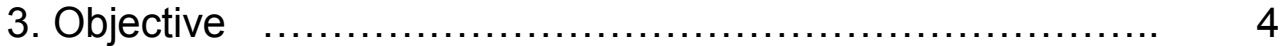

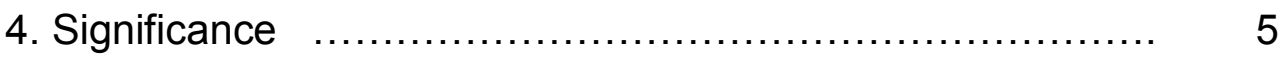

Chapter I.2. Literature Review

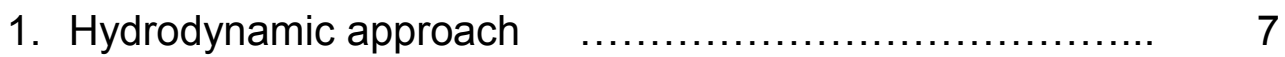

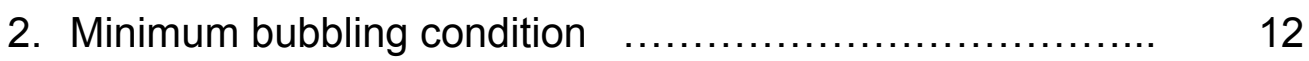

3. The nature of interparticle forces in fine powder aeration ... 14

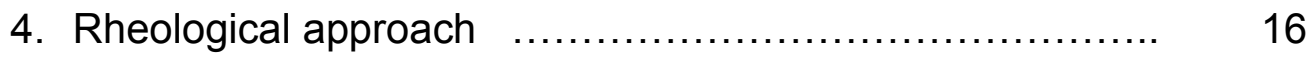

5. Homogeneously-aerated-expanded (HAE) emulsion phase 21 
Chapter I.3. Basic Consideration

1. The concept of 'excess pressure drop' .................... 23

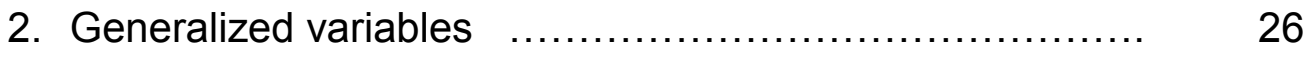

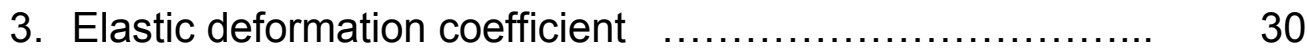

Chapter I.4. Experimental Procedures

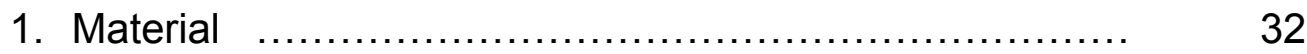

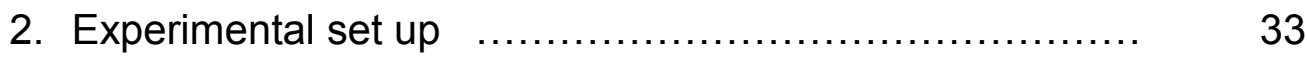

a. Powder bed retained under a fixed screen

b. Regular aeration experiment

Chapter I.5. Results

1. Verification of excess pressure drop concept $\ldots \ldots \ldots \ldots \ldots . . . . . \quad 39$

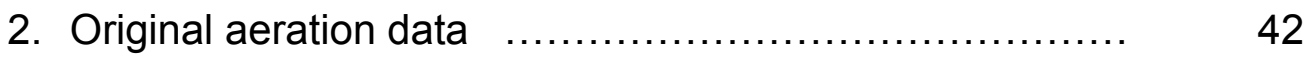

3. Transformation to generalized variables $\quad \ldots \ldots \ldots \ldots \ldots \ldots \ldots . \ldots \ldots$

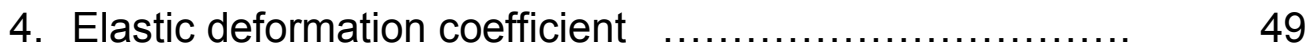

Chapter I.6. Conclusion and Significance .......................... $\quad 59$

PART II : Characterization of Fine Powder Aerations at Elevated

Temperature

Chapter II.1. Introduction

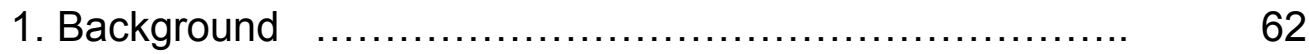

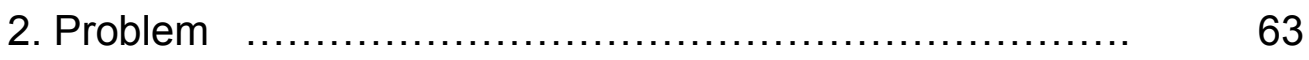

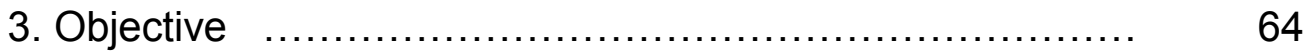




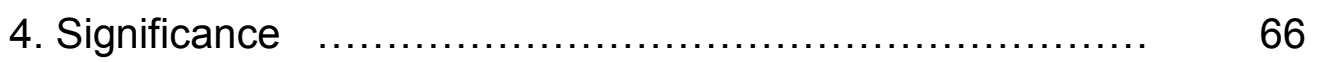

Chapter II.2. Literature Review

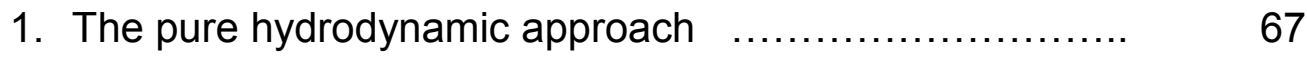

2. Effect of temperature on fine powder aeration behaviors 68

3. Minimum bubbling point at elevated temperature $\ldots \ldots \ldots . . . \quad 71$

4. Effect of temperature on HAE emulsion phase ............. 74

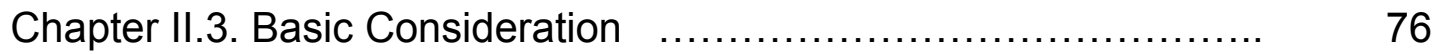

Chapter II.4. Experimental Procedures

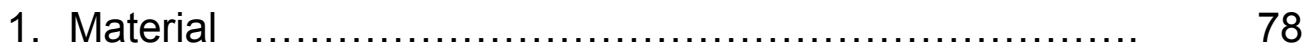

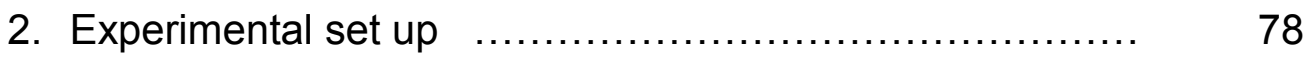

Chapter II.5. Results

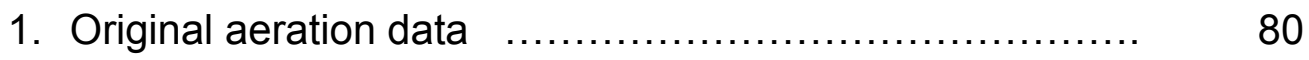

2. Transformation to generalized variables $\ldots \ldots \ldots \ldots \ldots \ldots \ldots . \ldots . \ldots$

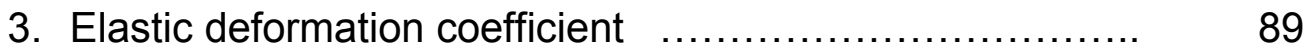

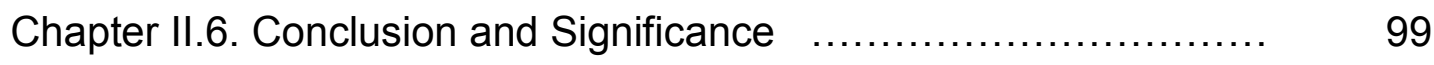

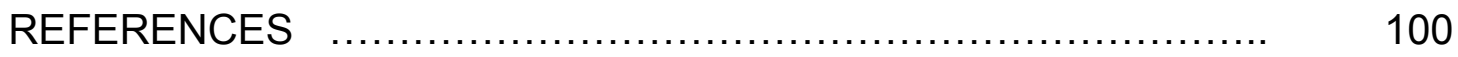

APPENDIX A. Calculation of original aeration data $\ldots \ldots \ldots \ldots \ldots \ldots \ldots . . . . . . . .108$

APPENDIX B. Calculation of elastic deformation coefficient $\quad . . . \ldots \ldots . . . \quad 114$

APPENDIX C. Procedure to determine $U_{m b}$ from Y-S plot $\ldots \ldots \ldots \ldots . . . . . \quad 117$

APPENDIX D. Analysis of variance on Y data ........................ 120 


\section{LIST OF FIGURES}

Figure No. Figure caption

Page

$\begin{array}{lll}\text { I.2.1 Illustration of fine powder aeration } & 8\end{array}$

$\begin{array}{lll}\text { I.2.2. Illustration of the difference between hydrodynamic } & 17\end{array}$

approach and rheological approach

1.2.3. Suggested cavity structure by Donsi and Massimilla (1973)

$\begin{array}{lll}\text { I.3.1. Typical plot of fine powder aeration data } & 24\end{array}$

$\begin{array}{lll}\text { I.3.2. The concept of powder layer unit } 28 & 28\end{array}$

I.3.3. Force balance on each powder layer unit 29

I.4.1. Equipment for excess pressure drop measurement 34

$\begin{array}{lll}\text { I.4.2. Regular aeration experiment } 38 & 38\end{array}$

I.5.1. Comparison between the data from actual aeration 41 experiment and the data from experiment using screen to prevent bed expansion

1.5.2. Bed height against gas velocity at various bed aspect ratios (Starch 1, ambient condition)

1.5.3. Pressure drop against gas velocity at various bed aspect ratios (Starch 1, ambient condition)

I.5.4. Excess pressure drop against powder strain at various bed aspect ratios (Starch 1, ambient condition) 
Figure No. Figure caption

1.5.5. Powder strain against gas velocity at various bed aspect ratio (Starch 1, ambient condition)

I.5.6. Powder tensile stress against powder strain (Starch

1 , ambient condition)

I.5.7. Elastic deformation coefficient (Starch 1, ambient condition)

I.5.8. Illustration of the physical meaning of the change in Y value

I.5.9. Comparison of $Y$ values among Starches 1, 2, 3

I.5.10. Effect of mixing of starches with different sizes on the aeration behavior

II.4.1. Experimental set up for experiment at elevated temperature (Su, 1995)

II.5.1. Bed height against gas velocity (FCC catalyst aerated by dry air)

II.5.2. Pressure drop against gas velocity (FCC catalyst aerated by dry air)

II.5.3. Excess pressure drop against gas velocity (FCC catalyst aerated by dry air)

II.5.4. Powder strain against gas velocity (FCC catalyst 86 aerated by dry air) 
$\begin{array}{lll}\text { Figure No. Figure caption } & \text { Page }\end{array}$

II.5.5. Powder tensile stress against powder strain (FCC 87 catalyst aerated by dry air)

II.5.6. Elastic deformation coefficient against powder strain 88 (FCC catalyst aerated by dry air)

II.5.7. Photographs of FCC catalyst aeration experiments 92

II.5.8. Comparison between FCC catalyst at ambient and 93 elevated temperature and Starch 1 at ambient temperature

II.5.9. Elastic deformation coefficient as a function of temperature (FCC catalyst aerated by dry air)
A.1.
Pressure drop data (EXP1-17)
B.1.
Powder tensile stress curve
C.1. The plot of elastic deformation coefficient against
powder strain
C.2. The plot of powder strain against gas velocity
D.1.
The output of two-way ANOVA from MATLAB 6.5
D.2. Box plot for Starch 1 data from MATLAB 6.5 


\section{LIST OF TABLES}

$\begin{array}{lll}\text { Table No. Table caption } & \text { Page }\end{array}$

I.4.1. The amount of starch used in experiments 32

I.5.1. $U_{m b}$ values for Starch 1, 2, and 3 aerated at ambient 54 temperature

II.5.1. $U_{m b}$ values for FCC catalyst aerated at 26,400 , and 95 $600{ }^{\circ} \mathrm{C}$

A.1. Original data from EXP1-17 110

B.1. Determination of elastic deformation coefficient for 116

data from EXP1-17

D.1. Y data on Starch 1

120 


\section{LIST OF SYMBOLS}

$$
\begin{aligned}
& \text { A }=\text { cross-sectional area of the aeration column }\left(\mathrm{cm}^{2}\right) \\
& \text { BAR = bed aspect ratio (-) } \\
& \mathrm{d}_{\mathrm{p}} \quad=\text { particle diameter }(\mu \mathrm{m}) \\
& \text { D = internal diameter of aeration column }(\mathrm{cm}) \\
& \text { g = gravity acceleration }\left(\mathrm{cm} / \mathrm{s}^{2}\right) \\
& \mathrm{H} \quad=\text { powder bed height }(\mathrm{cm}) \\
& \mathrm{H}_{\mathrm{mf}} \quad=\text { powder bed height at } \mathrm{U}_{\mathrm{mf}}(\mathrm{cm}) \\
& \mathrm{H}_{\max } \quad=\text { maximum powder bed height }(\mathrm{cm}) \\
& \mathrm{M} \quad=\text { total particle mass }(\mathrm{g}) \\
& \mathrm{N} \quad=\text { number of powder layer unit (-) } \\
& \Delta \mathrm{P}_{\mathrm{eq}} \quad=\text { observed pressure drop in the range of } \mathrm{U}_{\mathrm{mf}}<\mathrm{U}<\mathrm{U}_{\mathrm{mb}}(\mathrm{Pa}) \\
& \Delta \mathrm{P}_{\mathrm{h}} \quad=\text { hypothetical pressure drop }(\mathrm{Pa}) \\
& \Delta \mathrm{P}^{*} \quad=\text { excess pressure } \operatorname{drop}(\mathrm{Pa}) \\
& \Delta \mathrm{P}^{* *} \quad=\text { excess pressure drop per powder layer unit }(\mathrm{Pa}) \\
& \mathrm{S} \quad=\text { powder } \operatorname{strain}(-) \\
& \mathrm{S}_{\mathrm{mf}} \quad=\text { powder strain at } \mathrm{U}_{\mathrm{mf}}(-) \\
& \mathrm{S}_{\max } \quad=\text { maximum powder strain (-) } \\
& \mathrm{U} \quad \text { = superficial gas velocity }(\mathrm{cm} / \mathrm{s}) \\
& \mathrm{U}_{\mathrm{mb}} \quad=\text { minimum bubbling velocity }(\mathrm{cm} / \mathrm{s}) \\
& \mathrm{U}_{\mathrm{mf}} \quad=\text { minimum fluidization velocity }(\mathrm{cm} / \mathrm{s}) \\
& \mathrm{Y}=\text { = elastic deformation coefficient }(\mathrm{Pa})
\end{aligned}
$$




$\begin{array}{ll}\varepsilon & =\text { bed porosity }(-) \\ \mu & =\text { gas viscosity }(\text { Pa s }) \\ \sigma^{*} & =\text { powder tensile stress }(\mathrm{Pa}) \\ \Phi_{\mathrm{s}} & =\text { sphericity }(-)\end{array}$


PART I

CHARACTERIZATION OF FINE POWDER

AERATIONS AT AMBIENT TEMPERATURE 


\section{CHAPTER I.1. INTRODUCTION}

\section{Background}

Powders are very frequently met both in daily life and in industry. For example, the food industry produces many different powders, such as starches, milk powder, and many other spray-dried products. In pharmaceutical industry, many medicines are produced in tablets by compression of powders. The chemical industry is probably the largest user of powders with its widespread use of catalyst powders; while on the other hand, many of the final chemical products, such as polymers, are delivered as powders.

There are numerous operations carried out with powders in industries, such as:

1. Storage of powders in hoppers and bins.

2. Transportation of powders from storage to the process area.

3. Grinding or milling of the powder to improve its accessibility to the next process.

4. Mixing of different powders to make a product with higher quality.

5. Compression of powders in moulds to obtained a preformed solid product.

6. Granulation of powders to obtain larger grains which can be more easily transported and processed. 
7. Aeration by blowing gas upwardly through a powder bed in order to improve the contact between the powder particles and the aerating gas, such as in catalytic reactors or coal combustors. A famous example is the utilization of aerated silica alumina catalyst in FCC unit to produce high octane number gasoline from heavy distillates.

Besides being a commercially important powder-operation, an aeration system is also a perfect tool to study the behavior of powders. Aeration experiments are relatively easy to perform because simply by varying gas velocity, pressure, and temperature, various powder behaviors can be observed. Phenomena of aeration can be well visualized by a simple experiment in which a bed of solid is supported by a porous plate as gas distributor and gas is then forced to flow upwards through the bed. When the pressure drop caused by this gas flow is sufficient to support the weight of the particles, the bed will expand.

In general, the quality of aeration is visually distinguished by the homogeneity of expansion. Most of fluidizing reaction systems favors a homogeneous expansion without too many bubbles (particulate systems) because bubble existence reduces the effective contacts between gas and solid particles. A fluidization process with bubbling and fluctuating heterogeneous expansion (aggregative system) is usually avoided for its mechanical destructive tendency. 


\section{Problem}

Although the distinction between particulate and aggregative fluidization has drawn great attention for decades, relatively little has been discussed as to the transition condition. Among several attempts done in the past, the criterion of this transition condition required visual observations, such as the observation of the first bubble appearance (e.g. Davidson and Harrison, 1963, Verloop and Hertjes, 1970, Foscolo and Gibilaro, 1984, Bouillard and Gidaspow, 1991, Loezos et al., 2002), which could be very subjective and associated with high uncertainty. The methods available so far have not yet provided a satisfactory characterization parameter for aeration behavior, especially in the case of fine powder aeration.

On the other hand, in the age of computerization, it is always desirable to describe everything in numerical measures in order to perform a quantitative optimization. For these reasons, it is necessary to develop such a quantitative variable that can very well define fine powder aeration quality.

\section{Objective}

The aim of this present work is to address the importance of a specific parameter called 'elastic deformation coefficient' to quantitatively describe the quality of fine powder aeration. This current work is based on the concept of fine powder aerated bed assumed as a quasi-solid material then known as a 'homogeneously aerated expanded (HAE) emulsion phase' first introduced by 
Kono's research group in West Virginia University (Kono et al, 1994). In this theory, aerated fine powders are treated as a group of particles that forms a homogeneous single phase with the aerating gas instead of acting as individual particles. In this dissertation, while applying HAE emulsion phase basic theory, a new detail in data analysis is presented to improve the previous theory proposed by Kono's research group. Determination of the elastic deformation coefficient is conducted incrementally at various 'powder strain' in the range of homogeneous expansion of the bed without necessarily assuming the linearity in the relation of the bed height against the superficial gas velocity in the whole range of $U_{m f}<U<U_{m b}$ as the work published previously by Kono et al. (1994). Experimental data has shown that such an assumption oversimplifies real situations so that elimination of this assumption will have a significant impact on the usefulness of the model and potentially provides a better insight about fine powder behavior.

\section{Significance}

An understanding about the variables governing a homogeneous fine powder aeration is of great importance because in most powder handling operations such as catalytic reaction (fluidized bed hydrocarbon cracking using FCC for example), transportation, mixing, grinding, agglomeration, and separation, powders are continuously in an expanded state to some extent, either by applying gas or simply by turning over the powders so that gas is entrapped among the powder particles. A set of conditions that lead to homogeneous 
aeration of a powder bed is then recognized as the conditions that will result in good powder flow ability in any other powder handling operations. This homogeneity is always desirable because it guarantees excellent flow and gas-solid contacts required to achieve the desirable yield. Therefore, a study about the conditions limiting the prevalence of a homogeneous aeration needs to be conducted, mainly in order to find the characterization parameters to quantify the aeration quality of fine powders, which will be useful either in the scale-up or scale-down projects of fine powder aeration, or in applying aeration data to predict powder behavior in other powder handling operations.

The new approach based on the concept of elastic deformation coefficient of HAE emulsion phase can be used to infer one of the most challenging problems in fine powder aeration, i.e. accurate determination of minimum bubbling condition. Most importantly, this method solely needs regular aeration data without the necessity to insert any measuring devices into the aeration column so that the structure of the aerated powder is kept undisturbed. The elastic deformation coefficient is proposed to be a quantitative characterization parameter of a homogeneously aerated fine powder, which combines all crucial process conditions such as particle and gas physical properties, superficial gas velocity, pressure, and temperature into several simple correlations. 


\section{CHAPTER I.2. LITERATURE REVIEW}

\section{Hydrodynamic approach}

The famous pioneering work in powder aeration was conducted by Davidson (Davidson and Harrison, 1963). Davidson categorized powder aeration into two classes; those were 'aggregative fluidization' and 'particulate fluidization'. Aggregative fluidization was a condition in which the gas velocity was greater than the minimum fluidization velocity, $\mathrm{U}_{\mathrm{mf}}$, and some of the gas might pass through the bed as bubbles (Figure I.2.1. d). The bed height would remain constant although its surface was fluctuating due to the bursting bubbles (Figure I.2.1. $\mathrm{d}$ and e). The size and frequency of the bubbles did not affect the height of the bed because the bubbles pushed the surrounding particles closer to each other. Therefore, it is important to note that a portion of the incoming gas which passed through the bed as bubbles would not contribute to the bed expansion.

On the other hand, in particulate fluidization, with the gas velocity above $U_{m f}$, the bed height increased with velocity and there were no bubbles formed until the gas velocity reached the minimum bubbling point, $\mathrm{U}_{\mathrm{mb}}$ (Figure I.2.1. $\mathrm{b}$ and c). The particles were assumed to space themselves evenly so that the gas passed smoothly through the interstices. With this assumption, Davidson based the analysis to predict $U_{m f}$, bubble formation, particle motion, and bubble stability on the assumption of isolated or free-floating spheres in a 
uniform stream of gas. In the case of particulate fluidization, $\cup_{m b}$ could be far beyond $U_{m f}$ so that in between, a homogeneous powder expansion was observed. In the case of aggregative fluidization, however, the point of $U_{m b}$ was equal to the $U_{m f}$. In other words, the bed would immediately form bubbles as soon as it started being aerated. Aerated fine powders would most likely behave as particulate bed while aerated coarse particles always formed an aggregative bed.

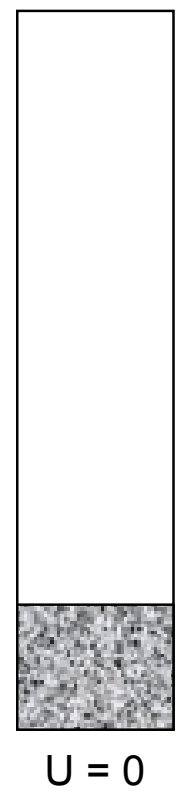

(a)

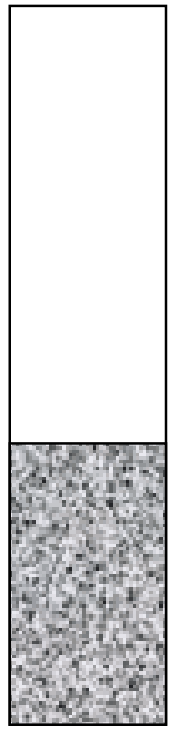

$\mathrm{U}_{\mathrm{mf}}<\mathrm{U}<\mathrm{U}_{\mathrm{mb}}$

(b)

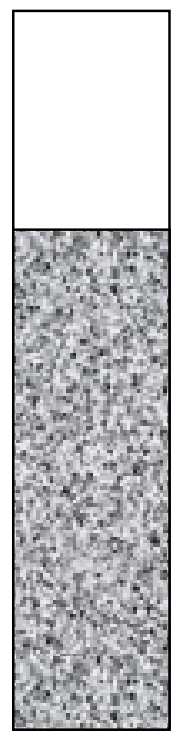

(c)

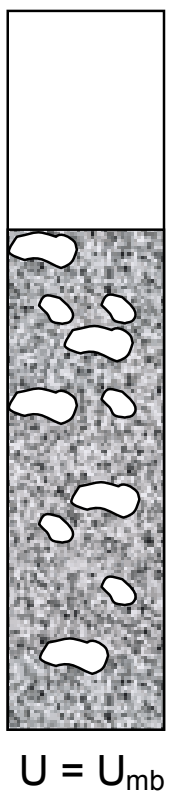

(d)

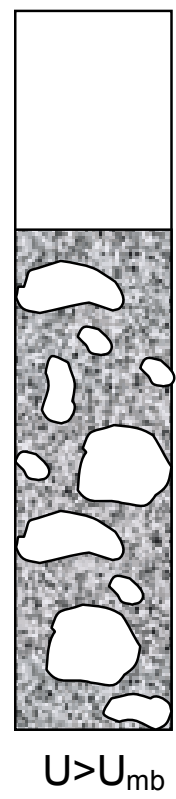

(e)

Figure I.2.1. Illustration of fine powder aeration

Davidson's theory might work well on the system of coarse particles on which he conducted the experiments to verify his theory. Nevertheless, this 
approach could not explain many phenomena encountered in fine powder aeration. Free-floating assumption could be reasonable for coarse particles because their sizes were much larger than the particle size that might cause strong interactions among particles. However, when people start dealing with much smaller particles in the order of $100 \mu \mathrm{m}$ or less, they found that these tiny particles behaved very differently from their coarser counterparts (Seville et al., 2000) and Davidson's theory could not explain the reasons behind this fact.

Another theory stated that aerated powders were always unstable in the sense that small disturbances in the distribution of the particles would rise through the bed and would become more pronounced as they rose. In most aerated systems, the rate of growth of those disturbances was very rapid so that a smoothly aerated state could not survive (Anderson and Jackson, 1964). However, these authors admitted that the detailed treatment to explain the origin of the disturbances appeared to be prohibitively difficult. Besides, this instability theory was only proven true for the coarse particle system. For fine powders, one can expect a smooth aeration under 'certain conditions'. The challenge is how to quantitatively define these 'certain conditions'.

On the basis of extensive observations of powder aeration, Geldart (1973) proposed a classification of powders as A, B, C, and D-powders. An A- 
powder was characterized by its homogeneous expansion when aerated with gas velocity not too far above $U_{m f}$. On the contrary, B-powder, which was coarser in size than the A-powder, can never be able to be aerated homogeneously. As soon as the gas velocity reached $U_{m f}$, bubbles appeared and grow larger as the gas velocity increased. Powders finer than A-powder were classified as C-powder and they were characterized by having strong cohesion among them so that they were said to be 'unfluidizable'. An attempt to aerate this type of powder would only result in horizontal fractures or vertical channels of gas flow. The coarsest powders fell into D-powder class. The excess gas formed a vertical channel through which the particles were spouted upwards. In a diagram of solid density against the average particle size, Geldart had indicated the boundaries between those classes. This practical classification was often referred to in powder handling practices.

Geldart's classification has been satisfactory to classify the 'conventional powders', i.e. those obtained from conventional process in making powders, such as by grinding. Nowadays, people often encounter more sophisticated type of powders, for example those whose particle surface has been modified to improve the flow ability. The modification can be done by applying a certain coating material or grinding the powder with finer particles by a method called 'mechanofusion' to create a 'spacer' that can overcome the excessive cohesiveness of the original powder (Geldart, 1989). With such a surface modification, a powder which is conventionally classified as the unfluidizable 
Geldart's C-powder due to its size can actually expand as homogeneously as the behavior of the aeratable Geldart's A-powder. This fact underscores the complexity of fine powder systems and also shows that conventional variable such as particle diameter and physical properties of both gas and the particles are not satisfactory to describe the aeration behavior of fine powders. For fine powders, surface characteristics matter more than those conventional variables used in Geldart's classification method.

Many attempts have been made in the past to develop deterministic models of aerated powder. Most of the work treated the particulate phase and the aerating fluid as two interpenetrating continua, such as the work of Anderson and Jackson (1964), Gidaspow (1994), and Kwauk et al. (2000). This approach required very large computing resources for actual cases where ones had to deal with thousands particles and bubbles. Given that a powerful computer is available, the computing issues may not be a problem at all. However, only few of the operational difficulties encountered in fine powder processing in industries can actually be solved using sophisticated computer models due to the lack of their generalization capability to handle the unique characteristics of various fine powders (Geldart, 1989). In addition to the complicated calculations, this hydrodynamics approach still leaves us with many unexplained aspects in fine powder aeration. 
The aforementioned citations imply that the technologies of the flow of aerated powders still present many scientific, engineering, and conceptual problems because the basic parameters in fine powder systems are not easily defined. Decades of research in aeration behaviors have inclined people to believe that hydrodynamic effects alone cannot characterize the aeration data of fine powders. Moreover, many researches suggested that such a characterization can be better developed by taking interparticle forces into account (Clift, 1993).

\section{Minimum bubbling condition}

Fine powders show an appreciable bubble-free expansion between certain values of gas velocities. The lower limit of homogeneous powder expansion is the minimum fluidization velocity $\left(\mathrm{U}_{\mathrm{mf}}\right)$, at which the initially packed powder starts to expand, and the upper limit is the minimum bubbling velocity $\left(\mathrm{U}_{\mathrm{mb}}\right)$ which is conventionally indicated by the 'first' appearance of bubbles. For fine powder aeration, the value of $U_{m b}$ is considerably higher than $U_{m f}$ and it is important to determine the $U_{m b}$ point as accurately as possible because many design correlations will need an input of $U_{m b}$ value. Generally, minimum bubbling velocity used to be determined by visual observation of the initial formation of bubbles (e.g. Bi and Grace, 1995). However, this method still needs reconsideration due to its subjectivity and high uncertainty associated with it. 
Despite many attempts already done in the past (e.g. Abrahamsen and Geldart, 1980, Sciazko and Bandrowski, 1985, Jacob and Weimer, 1987, Gibilaro et al., 1988, Wong, 2002), it is always difficult to precisely identify an exact value of $U_{m b}$ based on its conventional definition because the transition from a homogeneous expansion to a bubbling one is never visually obvious (Lim et al., 1995, Loezos et al., 2002). Some occasional bubbles can appear in the aerated bed even when the gas velocity is only slightly above $U_{m f}$ and the overall expansion still seems to be smooth and stable.

Bubble formation is closely related to the aeration stability. By defining a criterion for bubbling, one can manage to maintain the aeration condition in the stable region that can be expected to be homogeneous and smooth. It is not only important for achieving high yield but also in minimizing the mechanical destruction due to the bed fluctuations.

Verloop and Heertjes (1970) proposed a criterion for bubble formation by assuming that bubbles were in fact shock waves. The transition condition was defined as shock wave that occurred at the point when the rising velocity of a porosity fluctuation $\left(\mathrm{U}_{\varepsilon}\right)$ was equal to the longitudinal propagation velocity of an equilibrium disturbance $\left(U_{e}\right)$. The value of $U_{\varepsilon}$ could be determined experimentally but $U_{e}$ was unknown. The $U_{e}$ value was then estimated by assuming an aerated system as an elastic substance. This created another problem because there was no device to measure the elasticity modulus of 
aerated powders. Similar approach was also used by Foscolo and Gibilaro (1984) and Bouillard and Gidaspow (1991) in their criterion for minimum bubbling point.

All of the work cited above were done based on larger particle systems (the particles were in the order of $100 \mu \mathrm{m}$ or larger), although these particles could still be categorized into particulate systems based on the occurrence of bubble-free expansion. For the case of finer powders, Rietema (1984) suggested that the effect of interparticle forces had to be incorporated into the shock wave criterion. Rietema further stated that this interparticle effect would affect the value of elasticity modulus but still he admitted that a method for measuring this modulus directly was not yet available.

\section{The nature of interparticle forces in fine powder aeration}

The concept of interparticle forces in fine powders was first proposed by Rumpf (1958). Rumpf introduced the idea of powder structure by developing a theoretical equation to predict the strength of granules. Later, this theory was also widely applied by other researchers to characterize dry bulk powders as well.

According to Rumpf, interparticle force at each contact point of the powders depended upon the diameter of particle, the porosity among the powders, and the particle's coordination number. The effect of particle diameter dominated 
the other factors and smaller particle diameter would result in stronger interparticle forces.

Furthermore, Rumpf stated that for dry powders, even though there might not be any material-bridges (such as water bridge) existing between the particles, binding forces could still exist in the form of:

a. Van der Waals force. This force would be more significant in the case of powder aeration in which the gravitational force was already counterbalanced by the drag force from the aerating gas.

b. Binding due to electrostatic charging. Fine powder particles might be electrostatically charged by contacting or rolling friction with each other. The amount of electrostatic developed would depend on the material properties and the motion characteristics.

c. Interlocking binding. This occurred when the powders were plate-like so that it could be twisted and entangled with the neighboring particles.

Among several possibilities of the origin of interparticle forces in aerated powder bed, researchers believed that the dominant interaction force was the van der Waals force of attraction (Baerns, 1966, Visser, 1989). Van der Waals forces were effective up to a distance of $100 \AA$, while the distance between two particles in a bed of particulate materials near the $U_{m f}$ point was on the order of about $5 \mathrm{~A}$ between the point of contact (Baerns, 1966). From extensive researches on fine powder aeration, the interparticle forces 
apparently depended more on particle surface properties than on the powder bulk property. Spherical particles of diameter of order $100 \mu \mathrm{m}$ should exhibit interparticle van der Waals forces to equal their single particle weight (Seville et al., 2000).

It had been proven that gas adsorption had the most significant effect on the magnitude of interparticle forces compared with the effect of surface asperities. In the case of FCC particles, adsorption of gases on the particle surface would enhance the interaction among particles and had been known to increase the van der Waals forces by one to two orders of magnitude, corresponding to pressure from one to fifteen bar at room temperature (Xie, 1997). On the other hand, the interactions between surface asperities, rather than the parent particles, only began to dominate the interaction when the surface asperities were more than $0.1 \mu \mathrm{m}$ in size, which was seldom the case for the powders commonly encountered in practice.

\section{Rheological approach}

Because of the insufficiency of the pure hydrodynamic approach to explain many specific behaviors of fine powders, powder technologists turn to an alternative approach to address fine powder aeration. While pure hydrodynamic approach pictures each particle entirely surrounded by fluid and completely separated from each other, this alternative approach, which is then labeled as 'rheological approach', pictures the particles as being in 
dynamic contact all the time. Figure 1.2.2. illustrates the difference between these two approaches.
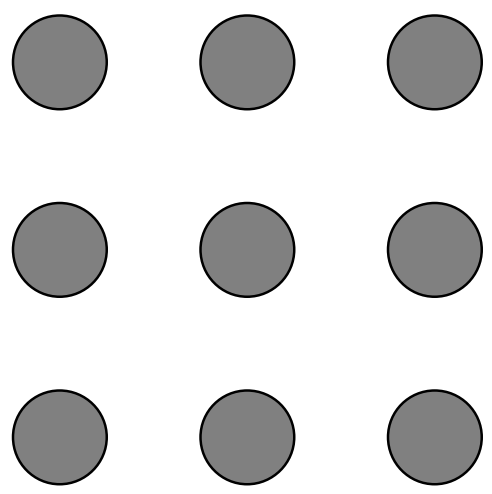

Hydrodynamic approach

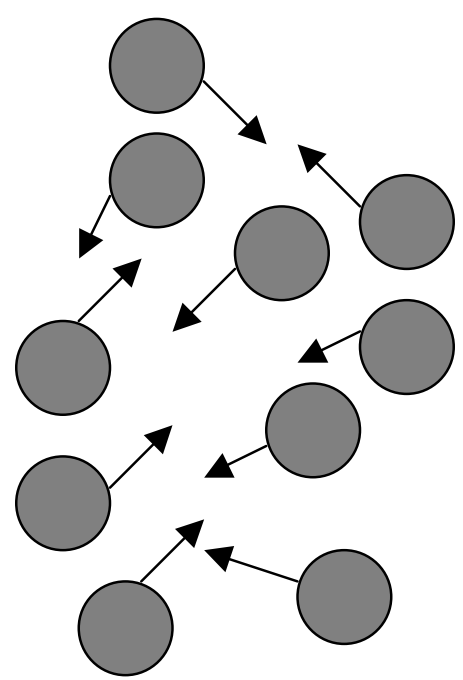

Rheological approach

Figure 1.2.2. Illustration of the difference between hydrodynamic approach and rheological approach

Taking interparticle forces into consideration, Molerus (1982) derived limiting conditions of powder classification which were equivalent to the conventional Geldart's classification. The borders between each class of powder were determined as the ratio between hydrodynamic force to the interparticle force on each single particle. The hydrodynamic force was estimated by the drag on one particle while the interparticle force was assumed to be van der Waals force. Although these correlations might be oversimplifying, those criteria 
provided a better physical interpretation than the empirical Geldart's classification.

With regard to aerated fine powders, in line with Rumpf's theory, Rietema (1967) pointed out that gas-solid and solid-solid interaction contributed an important effect to the behavior of the aerated powders. According to Rietema, powder aeration was the result of a balance between hydrodynamic forces on one hand and gravitational and interparticle forces on the other hand. It was the sum of all interparticle forces relative to the hydrodynamic forces which determined how an aerated bed of fine powders would behave. However, much controversy still held because the relative importance of the interparticle forces and hydrodynamic forces on the flow behavior of powders remained undefined. Many factors might contribute to the total interparticle force experienced by an assembly of fine particles and most were difficult to evaluate, in either absolute or relative terms.

Based on the existence of those interparticle forces, Donsi and Massimilla (1973) suggested that the dense phase in the expanded state of homogeneous aeration formed a 'cavity structure' that would react to compression or expansion as an elastic body. This thought has lead researchers to study the behavior of aerated powder by taking analogies to the well-established theories of polymer rheology. Nevertheless, many 
parameters have to be specifically redefined for fine powders because of their specific nature which is different from polymer materials.

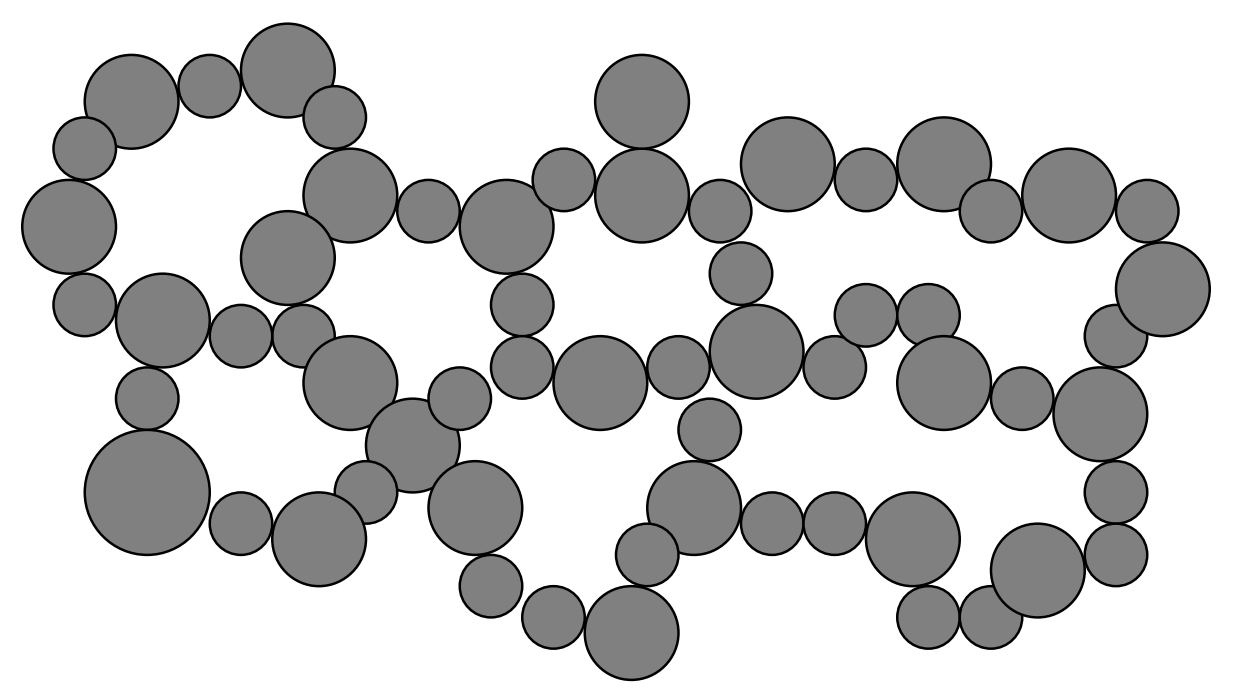

Figure I.2.3. Suggested cavity structure by Donsi and Massimila (1973)

Inspired by the idea of fine powder bed elasticity, Mutsers and Rietema (1977) proposed a hypothesis that the interparticle forces created a mechanical structure in the powder body as a network of particle chains with many cross links. When the powder was deformed by external forces without breaking these particle contacts, the powder structure generated a compensating force which always tried to restore the powder bed to its original condition. The consequence of this situation was a hypothesis that powders had elasticity, and its expansion characteristics could be represented by its elasticity modulus which implicitly took into account the effects contributed by both solid particles and gas. Under this school of 
thought, elasticity modulus was the intrinsic characteristic that governed the behavior of a particular powder under aeration. The determination of the mean elasticity of particulate phase is necessary to explain the distinction between particulate and aggregative behaviors (Clift, 1993). Furthermore, the values of elasticity modulus, which describes the macroscopic properties of the particulate phase, can give a range of stable expansion.

Some authors had incorporated powder elasticity modulus into their proposed stability criteria for homogeneous aerated powder bed. Mutsers and Rietema (1977) introduced a new dimensionless number $N_{F}$ to predict the limits to where homogeneous aeration was possible. This criterion involved the elasticity modulus $(E)$, but due to not being able to directly measure this $E, N_{F}$ was calculated using an equation with the maximum possible porosity at bubbling point as its sole variable. Poletto and Massimilla (1992) compared various theoretical approaches in defining the transition from bubble free to bubbling beds by considering the values of elasticity modulus of the dispersed phase using each approach. They found that the available theories, on which constitutive equations for elasticity modulus were based, were not satisfactory.

The determination of powder elasticity modulus remains challenging. Unlike the case of actual continuous solids, such as metals, on which elasticity modulus can readily be obtained as the slope on their measured stress-strain 
diagram from a standard tensile test, powder structure is actually composed by discrete particles interconnected by only very loose and weak interparticle forces. Therefore, there is no direct tensile stress measurement device available for aerated powder bed.

\section{Homogeneously-aerated-expanded (HAE) emulsion phase}

In 1994, Kono et al. showed that particle and gas physical properties were not good enough to define a condition of fine powder homogeneous expansion (Kono et al., 1994). They encountered some special treated powders whose particle size and other aeration conditions belonged to the 'unfluidizable' Geldart's C-powder group, but in fact those powders could be aerated homogeneously like an A-powder. In contrast to Davidson's theory of freefloating particles in an aerated powder bed, Kono's group viewed a homogeneous expanded powder as a quasi-solid body called 'homogeneously-aerated-expanded (HAE) emulsion phase' in which the particles were always in dynamic contact during the homogeneous expansion.

Although Kono's research group also applied the rheological approach to study the behavior of fine powders, this approach was not exactly the same as those established by other researchers in this field. Kono's approach treated the aerated fine powder bed as a unity of gas and particles behaved as a single phase instead of being a two-phase system of gas phase and 
solid phase separately like the assumption taken by the majority of other researchers. Therefore, Kono's HAE emulsion phase theory was more concerned on the macroscopic data obtained in the aeration experiment rather than the microscopic information about each single particle.

Kono's research group also concluded that elasticity and viscosity simultaneously affected the behavior of HAE emulsion phase so that both of them should be considered together in studying aeration behaviors. Their novel interpretation of experimental aeration data showed that the HAE emulsion phase behaved as a viscoelastic body and was well fitted by VoightKelvin model (Kono et al., 2002). Based on this concept, a method was proposed to characterize the emulsion phase in term of aerated powder tensile strength, elastic deformation coefficient, and viscosity. Those quantities were determined by performing an aeration experiment. From the standard data of superficial gas velocity, equilibrium bed height, and equilibrium pressure drop obtained in aeration experiments, Kono et al. (1994) introduced a new variable called 'excess pressure drop' as a basic quantity for tensile strength calculation. The method assumed a linear correlation between bed height and superficial gas velocity. This assumption was not always true because in many cases of fine powder aeration between its minimum fluidization velocity $\left(\mathrm{U}_{\mathrm{mf}}\right)$ and its minimum bubbling velocity $\left(\mathrm{U}_{\mathrm{mb}}\right)$, the bed height was experimentally observed to increase in a non-linear curve with increasing gas velocity (this will be shown in Figure 1.5.2). 


\section{CHAPTER I.3. BASIC CONSIDERATIONS}

\section{The concept of 'excess pressure drop'}

In an aeration experiment, gas flowing upwardly through a bed of fine powder causes the bed to expand. Flow of the aerating gas through the aerated particles will be accompanied by friction loss along its path so that a significant pressure drop will be observed. Figure I.3.1 shows a typical plot of pressure drop and bed height as a function of superficial gas velocity.

In Figure I.3.1, $\Delta \mathrm{P}_{\mathrm{eq}}$ is defined as the actual observed pressure drop in an aeration experiment. It is a measure of how much energy goes into drag force to counterbalance the weight of the particles in the bed. In the range of aerating gas velocity between its minimum fluidization velocity $\left(\cup_{\mathrm{mf}}\right)$ and the gas velocity corresponding to its maximum expansion (conventional $U_{m b}$ ), the bed expands from its initial height $\left(H_{m f}\right)$ to its maximum height $\left(H_{\max }\right)$. Consequently, the value of $\Delta \mathrm{P}_{\mathrm{eq}}$ is constant because friction loss is also constant due to increasing porosity with increasing gas velocity.

On the other hand, $\Delta P_{h}$ is the pressure drop across the bed IF the bed does not expand at superficial gas velocity in the range of $U_{m f}<U<U_{m b}$. In this situation, the bed will act as a packed bed with a constant porosity so that the pressure drop will increase linearly with gas velocity at relatively low gas velocity. 


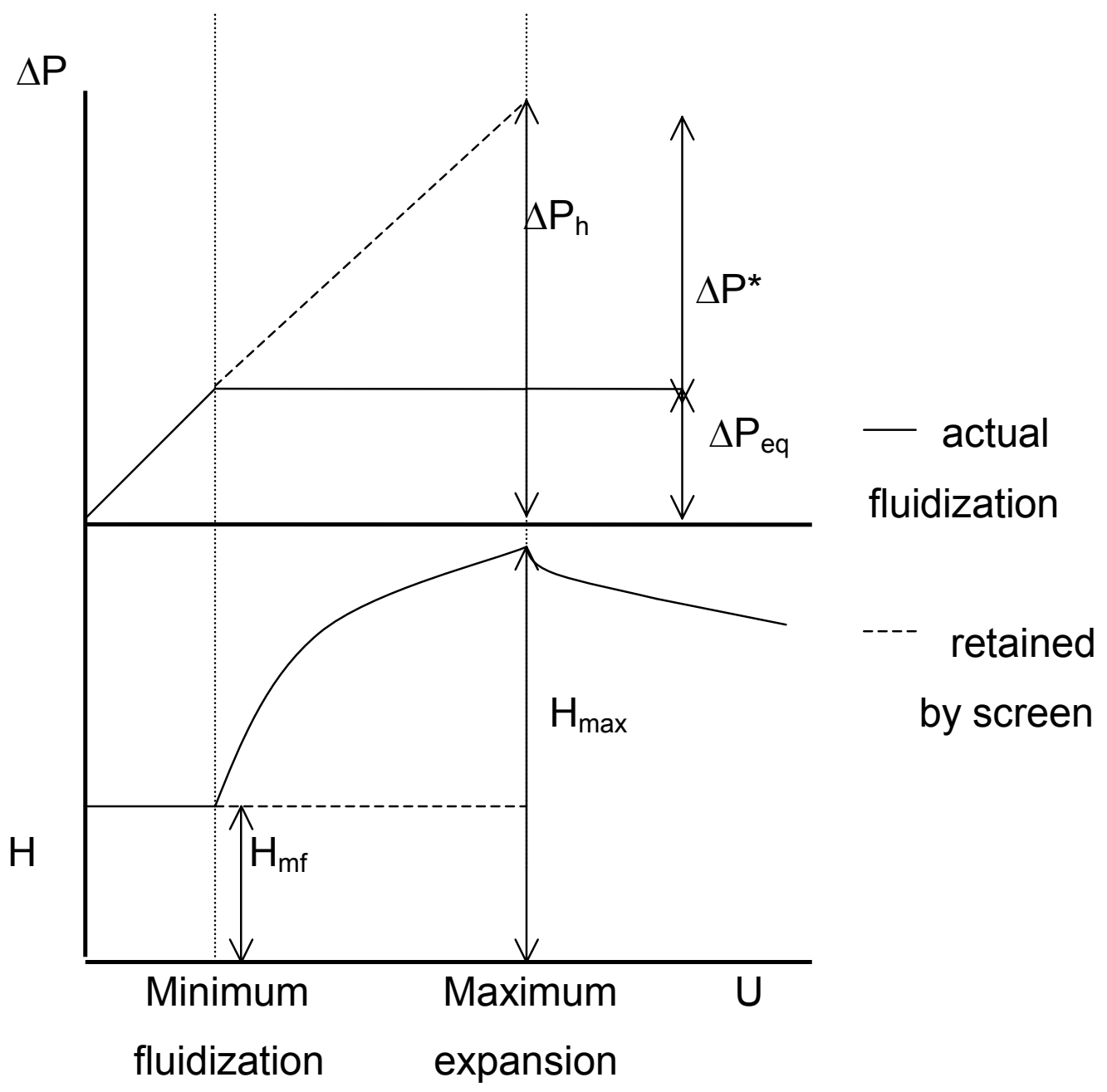

Figure I.3.1. Typical plot of fine powder aeration data 
At low gas velocity $(\operatorname{Re}<1), \Delta P_{h}$ will exhibit the linearity of the viscous term of Ergun's equation (Ergun and Orning, 1949, McCabe et al., 2001):

$$
\Delta P_{h}=150 H \frac{(1-\varepsilon)^{2}}{\varepsilon^{3}} \frac{\mu U}{\left(\phi_{s} d_{p}\right)^{2}}
$$

For the case of fine powder aeration, the values of Re are typically much less than 1. As an example, Re for the aeration of Starch 1 with nitrogen at ambient temperature was 0.03 .

In the situation where the powder is retained under a screen, the pressure drop will be $\Delta P_{h}$, which is a linear function of gas velocity according to Eq. (I.3.1). This case is represented by the dashed line in Figure I.3.1. The pressure drop will keep increasing even in the range of $U_{m f}<U<U_{m b}$ as opposed to the actual aeration condition shown by the bold line in Figure I.3.1.

If suddenly the screen is removed while the gas velocity is at some point between $U_{m f}$ and $U_{m b}$, the bed will immediately expand following the bold line on the bed height curve in Figure I.3.1 while the pressure drop will suddenly drop to the constant value $\left(\Delta \mathrm{P}_{\text {eq }}\right)$ indicated by the bold line on the pressure drop curve in Figure 1.3.1. This constant pressure drop is known as the pressure drop from the drag force used to overcome the weight of the particle. This pressure drop represents the energy dissipation in the aerated system (Foscolo et al., 1983). When the powder is still retained under the 
screen, the energy from the incoming gas is represented by $\Delta P_{h}$ but after screen removal, at the same gas velocity, there only remains $\Delta P_{\text {eq }}$ observed, which is much lower than $\Delta \mathrm{P}_{\mathrm{h}}$. Hence, the next logical question is then where the rest of the energy goes.

The difference between $\Delta \mathrm{P}_{\mathrm{h}}$ and $\Delta \mathrm{P}_{\mathrm{eq}}$ is a representation of a portion of the energy from the incoming gas consumed by the bed for expansion in the range of $U_{m f}<U<U_{m b}$. This portion is called the 'excess pressure drop'. By definition, excess pressure drop is the difference between the pressure drop across a bed at certain gas velocity if the porosity of the bed is maintained constant at $\varepsilon_{\mathrm{mf}}$ and the pressure drop of an expanded bed with variable porosity, $\varepsilon(U)$, at the same gas velocity. It is mathematically represented as:

$$
\Delta \mathrm{P}^{*}=\Delta \mathrm{P}_{\mathrm{h}}-\Delta \mathrm{P}_{\text {eq }}
$$

As long as the aerated powder still behaves as HAE emulsion phase, the interparticle forces will maintain a homogeneous structure of the emulsion phase and prevent it from being broken by the force from the incoming gas represented by $\Delta \mathrm{P}^{*}$. When the $\Delta \mathrm{P}^{*}$ becomes too strong for the interparticle forces, the homogeneous structure will be destroyed. This point is analogous to the minimum bubbling point in conventional fluidization theory.

\section{Generalized variables}

Experiment has shown that the bed aspect ratio (B.A.R) which is defined as: 


$$
\text { B.A.R }=\frac{H_{m f}}{D}
$$

affects the aeration data in the sense that different bed aspect ratio gives different set of bed height and pressure drop data. This will create a problem in determining the elastic deformation coefficient because this coefficient should only depend upon the material and not be a function of the quantity of the material. For this reason, it is necessary to define new variables that can eliminate the effect of bed aspect ratio. These new variables are to be named 'generalized variables'.

In order to make this generalization, the degree of bed expansion is expressed in term of bed expansion ratio specifically named 'powder strain' which is mathematically defined as:

$$
\mathrm{S}=\frac{\mathrm{H}-\mathrm{H}_{\mathrm{mf}}}{\mathrm{H}_{\mathrm{mf}}}
$$

To generalize the excess pressure drop data, another variable will be introduced. In the concept of HAE emulsion phase, the particles in the aerated powder bed are assumed to arrange themselves in $\mathrm{N}$ numbers of 'horizontal powder layer units' defined in previously published paper (Kono et al., 1994). Figure I.3.2 shows the illustration of this assumption.

For powders with uniform particle size $\left(d_{p}\right)$, numbers of powder layer units for a certain amount of a particular powder material is expressed as: 


$$
\mathrm{N}=\frac{\mathrm{H}_{\mathrm{mf}}}{\mathrm{d}_{\mathrm{p}}}
$$

As the expansion proceeds with increasing gas velocity, the number of powder layer units is assumed to be constant, only the height of each layer will be larger at higher gas velocity.

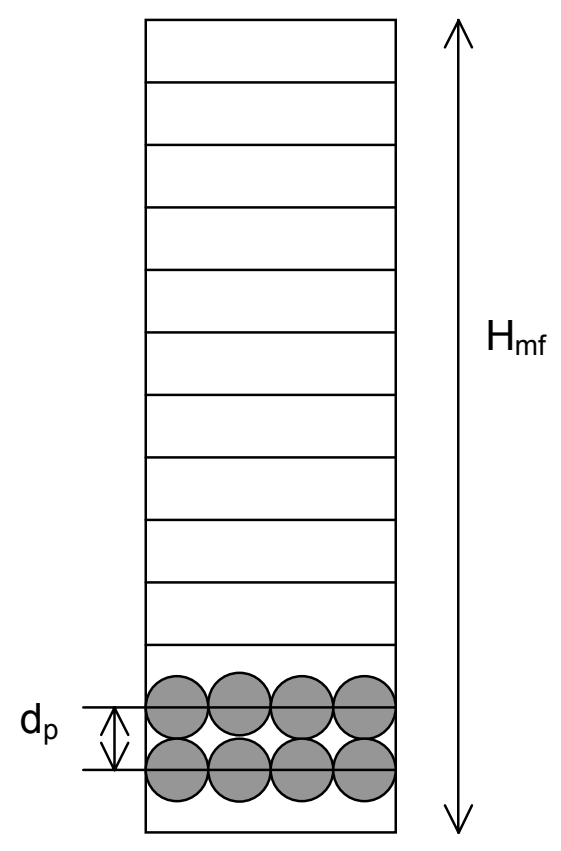

Figure I.3.2. The concept of powder layer unit

The excess pressure drop defined in Eq. (I.3.2) refers to the whole bed of the HAE emulsion phase. Since this HAE emulsion phase consists of $\mathrm{N}$ horizontal 
homogeneous powder layer units, the excess pressure drop across each layer will be:

$$
\Delta \mathrm{P} * *=\frac{\Delta \mathrm{P}^{*}}{\mathrm{~N}}
$$

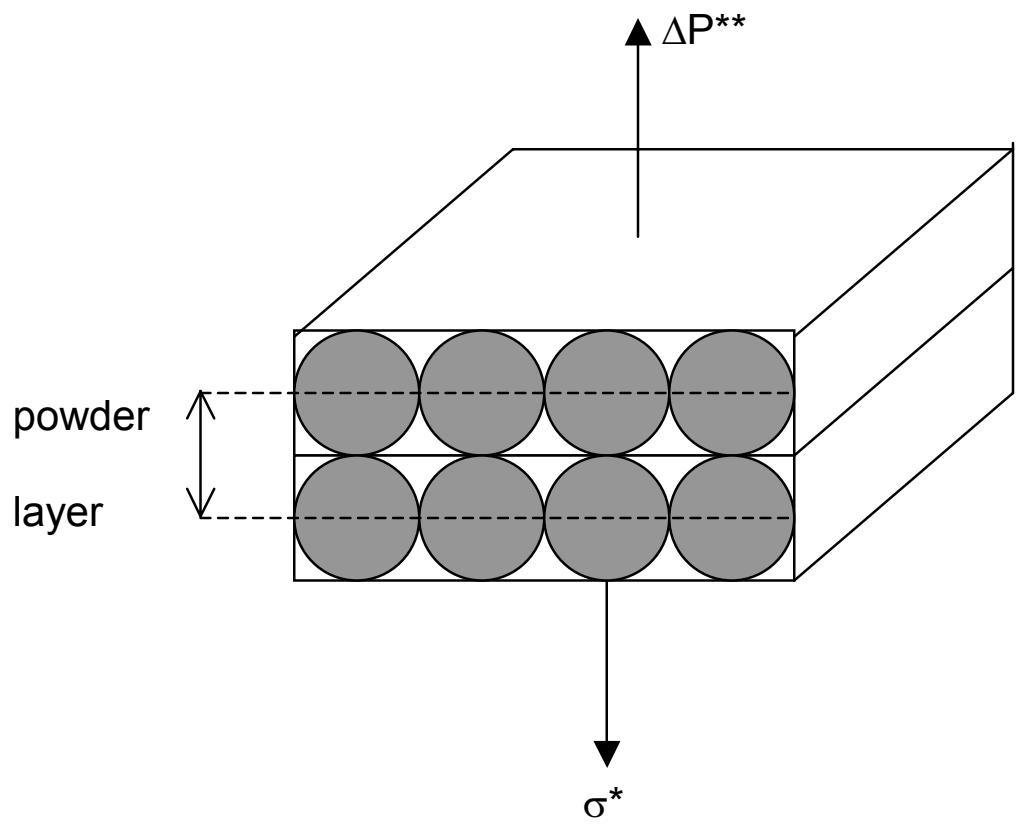

Figure I.3.3. Force balance on each powder layer unit

This $\Delta \mathrm{P}^{* *}$ corresponds to the force from incoming gas with certain gas velocity $U$ per unit area of the aeration column, which is counterbalanced by the interparticle force within each powder layer in the HAE emulsion phase 
(Kono et al., 1994), as illustrated in Figure I.3.3. Therefore, at equilibrium bed height for certain $U$, HAE emulsion phase tensile stress $\left(\sigma^{*}\right)$ is defined as:

$$
\sigma^{*}=\Delta P^{* *}
$$

\section{Elastic deformation coefficient}

Elastic deformation coefficient $(\mathrm{Y})$ is defined as the slope at any arbitrary points on the plot of tensile stress against strain:

$$
Y=\frac{d \sigma^{*}}{d S}
$$

For a small change of strain $(\Delta S)$, the expansion is assumed to be linear so that the elastic deformation coefficient can be determined as:

$$
Y=\frac{\Delta \sigma^{*}}{\Delta S}
$$

From aeration experiments, gas velocity $(U)$, excess pressure drop $\left(\Delta \mathrm{P}^{*}\right)$, numbers of powder layer units $(\mathrm{N})$, powder strain $(\mathrm{S})$, and bed height at various gas velocity $\left(\mathrm{H}_{\mathrm{mf}}\right.$ and $\left.\mathrm{H}\right)$ are readily obtained. The data are used to determine the HAE emulsion phase tensile stress $\left(\sigma^{*}\right)$ based on Eq. (I.3.7) at several small increments of $\Delta S$ in the range of $S_{m f}<S<S_{\max }$. At each increment, elastic deformation coefficient $(Y)$ is then determined using Eq. (I.3.8b). 
The values of $Y$ imply the flow characteristics of the HAE emulsion phase. An abrupt change of $Y$ value indicates that a significant structural change takes place in the initially homogeneous internal structure of HAE emulsion phase. Therefore, by measuring $Y$ at small increments of $\Delta S$ in the range of $S_{m f}<S<S_{\max }$, one can locate the point of the first major fractures of HAE emulsion phase, i.e. the physical meaning of the intrinsic minimum bubbling point. 


\section{CHAPTER I.4. EXPERIMENTAL PROCEDURES}

\section{Material}

Table I.4.1. The amount of starch used in the experiments

\begin{tabular}{|c|c|c|}
\hline Starch & $\mathrm{H}_{\mathrm{mf}} / \mathrm{D}(-)$ & $\mathrm{M}(\mathrm{g})$ \\
\hline 1 & 1 & 630.8 \\
& 1.5 & 946.2 \\
& 2 & 1261.6 \\
& 2.5 & 1577 \\
& 3 & 1892.4 \\
\hline 2 & 1.2 & 730 \\
\hline 3 & 0.7 & 425.8 \\
& 1.2 & 730 \\
\hline
\end{tabular}

A starch (solid density $=1.5 \mathrm{~g} / \mathrm{cm}^{3}$ ) with specially coated surface was chosen as a sample powder. The powder was received in three different sizes, which were Starch 1 (average diameter $=15 \mu \mathrm{m})$, Starch 2 (average diameter $=20$ $\mu \mathrm{m}$ ), and Starch 3 (average diameter $=40 \mu \mathrm{m}$ ). The particle shape is spherical for all these starches. Due to its special surface properties, this sample powder could very well be aerated homogeneously in a relatively wide 
range of superficial gas velocity. The amount of starch aerated in each experiment was listed in Table I.4.1.

Nitrogen gas was used as the aerating gas in all experiment. The benefits of using nitrogen from its pressurized tank were its moisture-free nature and the fact that this gas did not chemically react with the powder.

\section{Experimental set up}

\section{a) Powder bed retained under a fixed screen}

In order to verify the linearity of the plot of excess pressure drop against gas velocity, an experiment was conducted using Starch 3 on a special aeration column designed so that a porous metal could be placed on top of the powder bed. The equipment was schematically drawn in Figure I.4.1. 


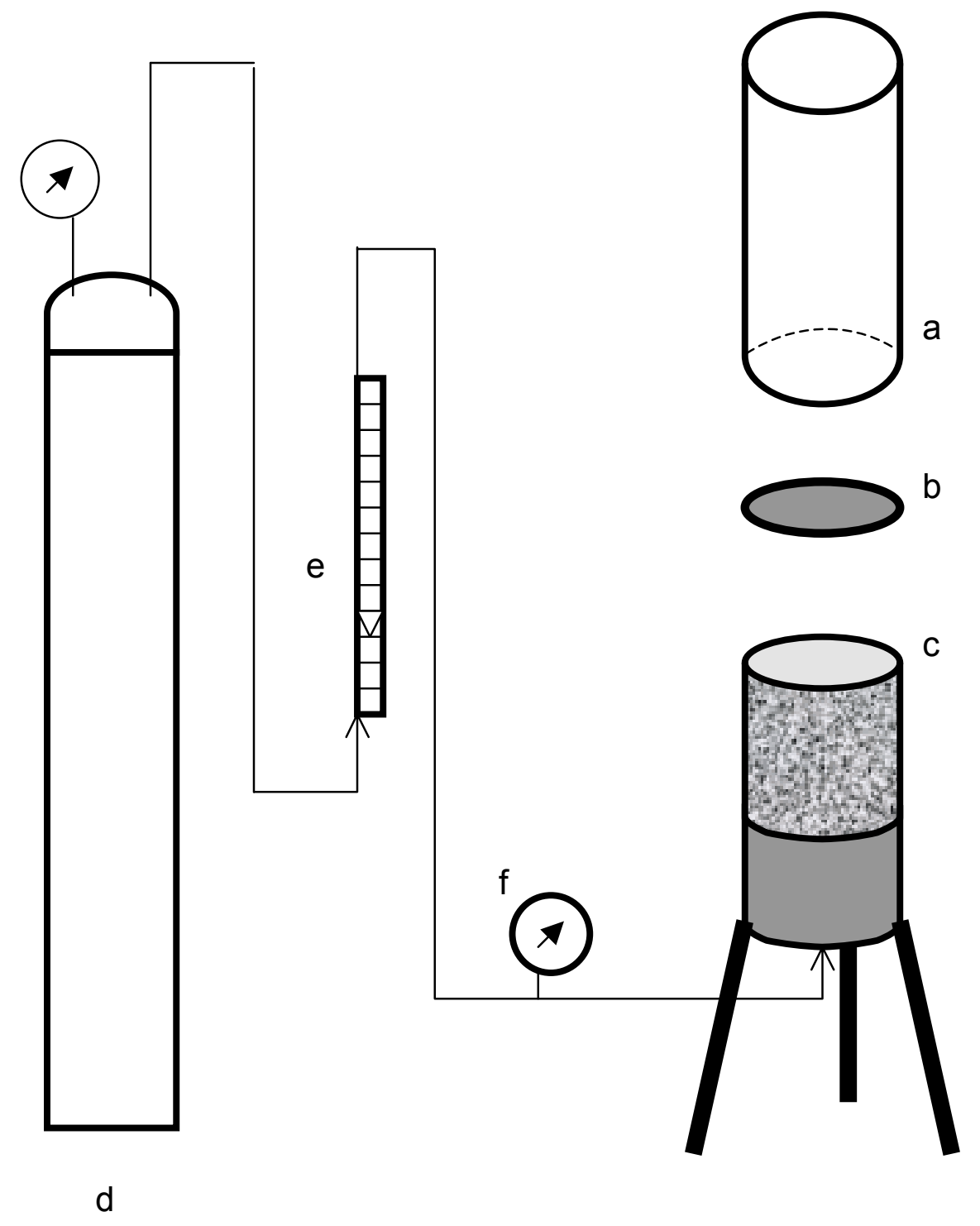

Figure I.4.1. Equipment for excess pressure drop measurement 
The aeration column (10 cm ID) consisted of three separable parts (part $a, b$, and $\mathrm{c}$ in Figure I.4.1), which were:

a. The top cylinder

b. Porous metal plate

c. The bottom cylinder which was mounted on a steel base equipped with porous metal plate as gas distributor

The bottom cylinder (part c), which was shorter than the top cylinder, was filled by the starch until the surface of the powder bed was flat at the upper end of the cylinder. The filling process was done very carefully by passing the starch through a very fine sieve in order to break any possible agglomeration and to create a packed bed structure as close as possible to the assumption of ideal packing in HAE emulsion phase.

A porous metal plate (Figure I.4.1b) was then put on top of this powder bed. The top cylinder (Figure I.4.1a) was placed right above this plate. All of these three parts were held tight together by a strong plastic tape.

Aeration was begun by flowing nitrogen gas from the gas cylinder (Figure I.4.1d) through a flow meter (Figure I.4.1e). The gas entered the bed from the bottom of the column base. A pressure gage (Figure I.4.1f) was placed on the gas line to make pressure drop reading. The gas flow rate was gradually 
increased and at each value of gas flow rate, the pressure drop was recorded.

This experiment was best done by Starch 3 which had the largest particle size among the other starches. Experimental data from this starch was the most reliable to verify the linearity of excess pressure drop with increasing gas velocity. This was because the experiment could be carried out in a wide range of gas velocity without causing excessive powder compression. When this experiment was done using Starch 1 and Starch 2, whose size was half of that of Starch 3, bed compression was observed early at the beginning of the experiment so that it was impossible to assume constant bed porosity.

\section{b) Regular aeration experiment}

The regular aeration experiment was similar to the previous packed bed experimental set up, except for the pressure drop measurement. In the case of packed bed experiment, the pressure drop could be so high that a pressure gage was needed to measure it. In regular aeration experiment for these starches, the pressure drop of its aerated condition was much lower than its packed bed condition and the pressure gage scale was too large to be able to detect this aerated pressure drop. Therefore, for aeration experiment, the pressure gage was replaced by water manometer that could read a pressure drop value more accurately. The experimental set up for the regular aeration is shown in Figure I.4.2. 
The aerating gas was flown from the gas cylinder (a in Figure I.4.2) through a couple of flow meters (b1 and b2 in Figure I.4.2) arranged in parallel. The first flow meter (b1 in Figure 1.4.2) had finer scale and lower gas velocity range than the other (b2 in Figure 1.4.2). Both flow meters were always opened together. The purpose of this arrangement was to facilitate small decrease or increase in gas flow rate. Besides, this arrangement made it possible to observe smooth transition from aerated bed to packed bed condition near $\cup_{\mathrm{mf}}$ point. In this experiment, $U_{m f}$ point was very close to the lowest scale of flow meter b2 so that flow meter b1 was necessary to obtain an accurate reading.

The gas entered the quartz column $(10 \mathrm{~cm}$ ID) to aerate the powder through a chamber ( $\mathrm{f}$ in Figure I.4.2) and a porous metal plate (e in Figure I.4.2) as the gas distributor. At the bottom of the chamber, a branched was placed to make a gas line to the water manometer.

Experiment was started at gas velocity high enough to make a powder bed bubbling for several minutes. This was necessary to make sure that any possible agglomerations were already broken. The gas flow rate was then gradually reduced and at each gas flow rate, the bed height was read on the scale (d in Figure I.4.2) and the pressure drop was recorded from the water manometer (g in Figure 1.4.2). 


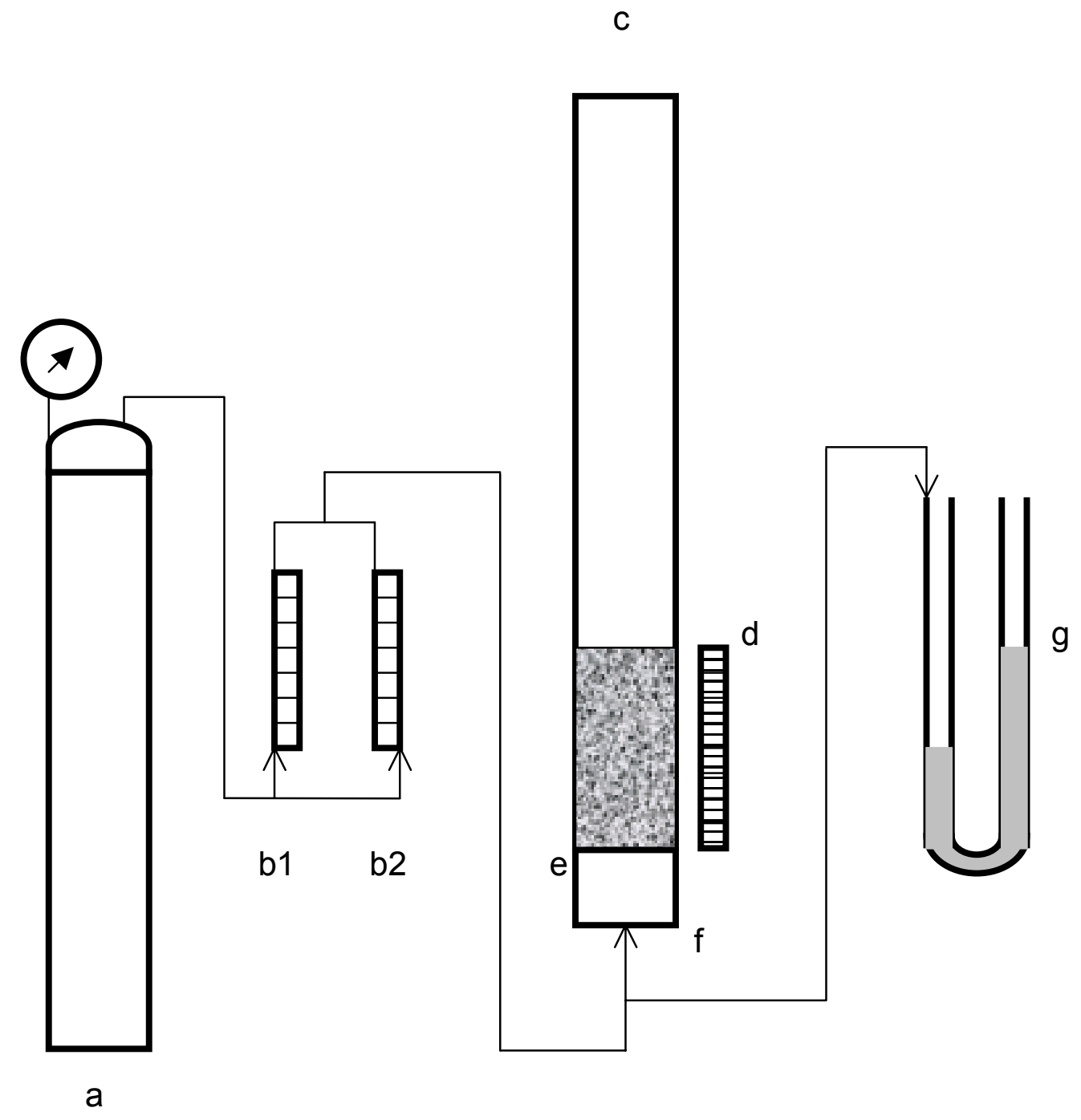

Figure I.4.2. Regular aeration experiment 


\section{CHAPTER I.5. RESULTS}

\section{Verification of 'excess pressure drop' concept}

Figure 1.5.1 shows a comparison between the result of a regular aeration experiment (the experimental set up is represented by Figure I.4.2) and an experiment using screen to maintain constant bed height (illustrated by Figure I.4.1). The data from the experiment with screen show a linear tendency over the whole range of gas velocity applied in the experiment, as expected by the viscous term of Ergun equation (in Eq. I.3.1).

However, it was found that the linear constant calculated using the relation suggested by Ergun equation was lower than the linear constant obtained by regression of the data presented in Figure I.5.1. There might be two possible explanations for this discrepancy. The deviation from Ergun equation was most likely caused by the compaction of the particles in the bed. Ergun equation was derived based on the assumption of constant porosity (Ergun and Orning, 1949, McCabe et al., 2001). With a screen put on top of the bed surface and gas flowing upwardly, the particles were pushed upwardly to some extent. Consequently, the porosity will slightly decrease. For the case of Starch 1 and Starch 2, this compaction was clearly visible because the lower end of the powder bed was actually lifted during the aeration and visibly dropped when the gas flow was suddenly cut. In the case of Starch 3, which 
was used to obtain the data in Figure I.4.1, this compaction was not actually obvious. Nevertheless, judging from the discrepancy from Ergun prediction, such a compaction must have taken place as well.

Another possible cause was the non-uniformity of the particles. Size distribution of the particle and also its possibly imperfect sphericity might cause the powder bed to have lower porosity than that estimated by the assumption of uniform spherical particles. If it was the case, the pressure drop predicted by Ergun equation would be lower than the observed pressure drop.

One of the advantages of the characterization method based on HAE emulsion phase theory presented in this dissertation is that it is not necessary to concern about the microscopic detail such as the porosity of the bed. All of the calculations and verifications can be done based on the macroscopic data only. Therefore, the detail discussion on the microscopic aspect concerning Ergun equation is beyond the scope of this dissertation. 


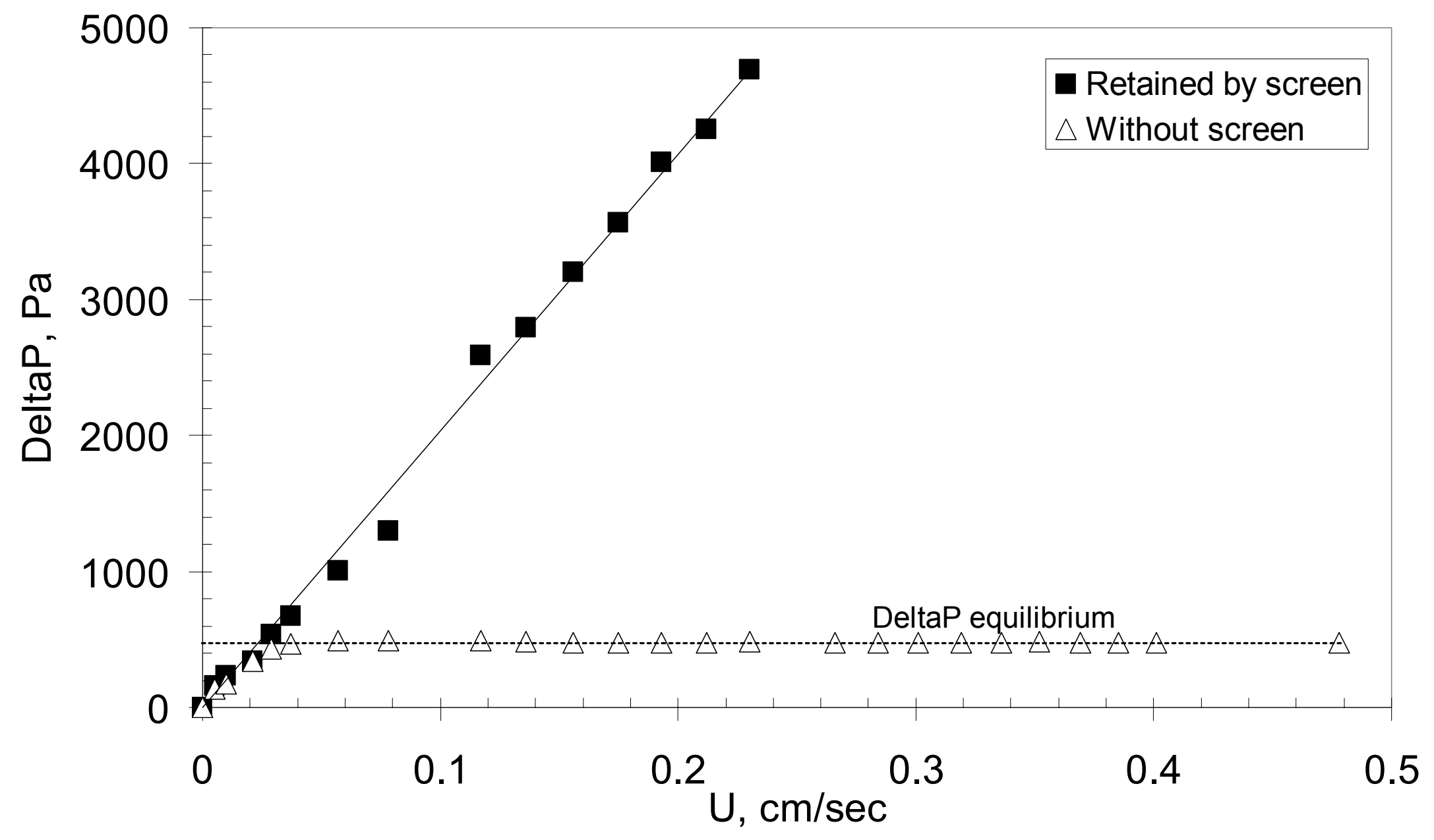

Figure I.5.1. Comparison between the data from actual aeration experiment and the data from experiment using screen to prevent bed expansion 
The finding of this discrepancy gives important information that Ergun equation is not recommended to predict the value of $\Delta \mathrm{P}_{\mathrm{h}}$ in the HAE emulsion phase theory. Nevertheless, the linearity shown by the data in Figure I.5.1 has verified the assumption taken in Chapter I.3 that for the case of fine powders whose Reynolds number is usually less than one, the pressure drop will linearly increase with gas velocity if the bed does not expand. It is preferred to calculate the actual value of $\Delta \mathrm{P}_{\mathrm{h}}$ for a particular aeration system using regression method on the linear part on the pressure drop plot against gas velocity (in the range of $0<U<U_{m f}$ ) rather than estimating based on Ergun equation.

\section{Original aeration data}

In a standard aeration experiment, data of $\Delta \mathrm{P}$ and $\mathrm{H}$ against superficial gas velocity were easily obtained by the method described in Chapter I.4. Figure I.5.2 and I.5.3 are examples of such data. For every data set from aeration experiment, $\Delta \mathrm{P}_{\mathrm{h}}$ values were calculated using correlation obtained by linear regression of data points on the linear part of Figure 1.5.3 in the range of $0<U<U_{m f}$ and accordingly, $\Delta \mathrm{P}^{*}$ was calculated based on its definition expressed in Eq. (I.3.2). The results are displayed in Figure I.5.4. An example of this calculation procedure is provided in Appendix A. 


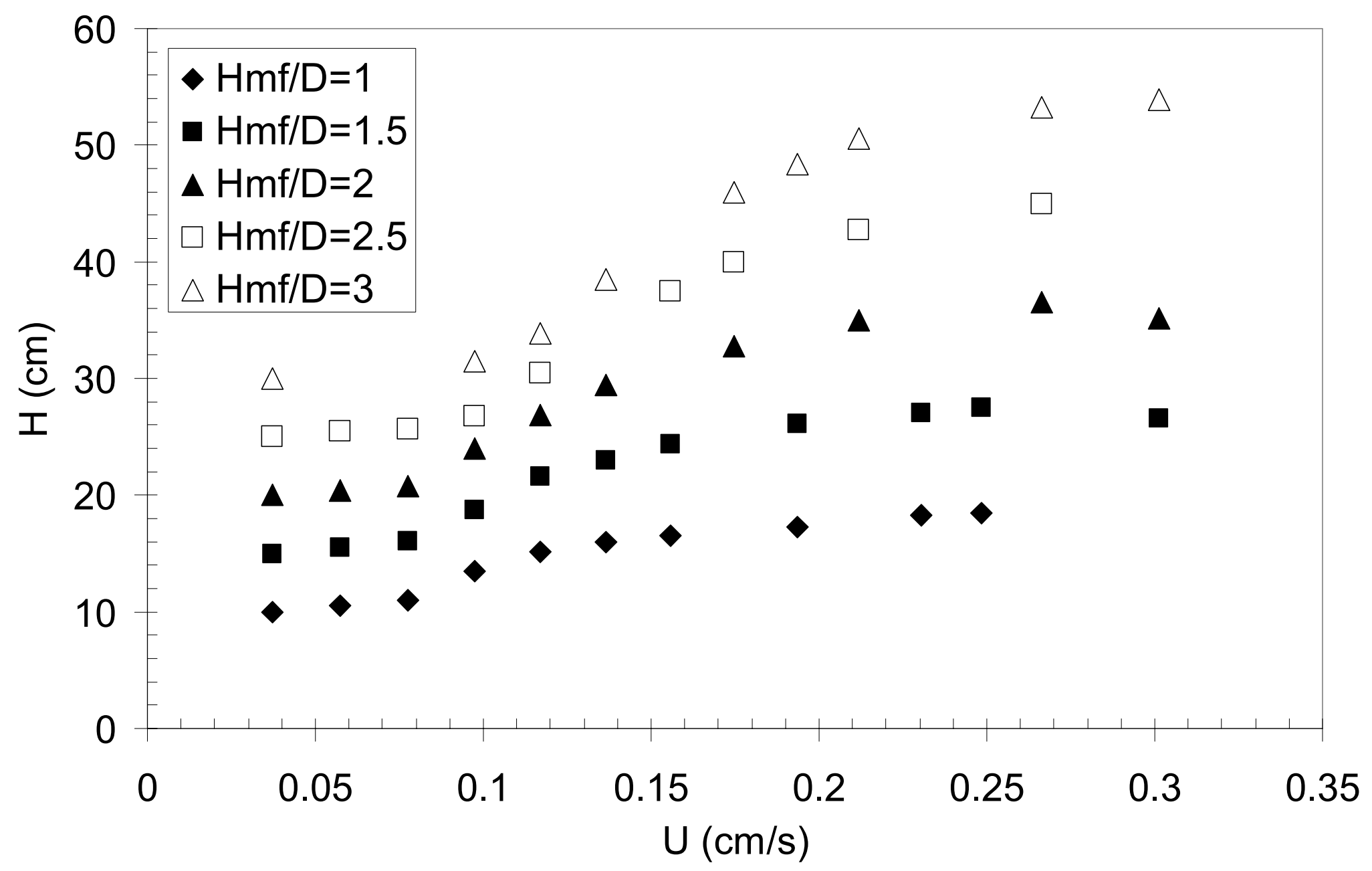

Figure I.5.2. Bed height against gas velocity at various bed aspect ratios (Starch 1, ambient condition) 


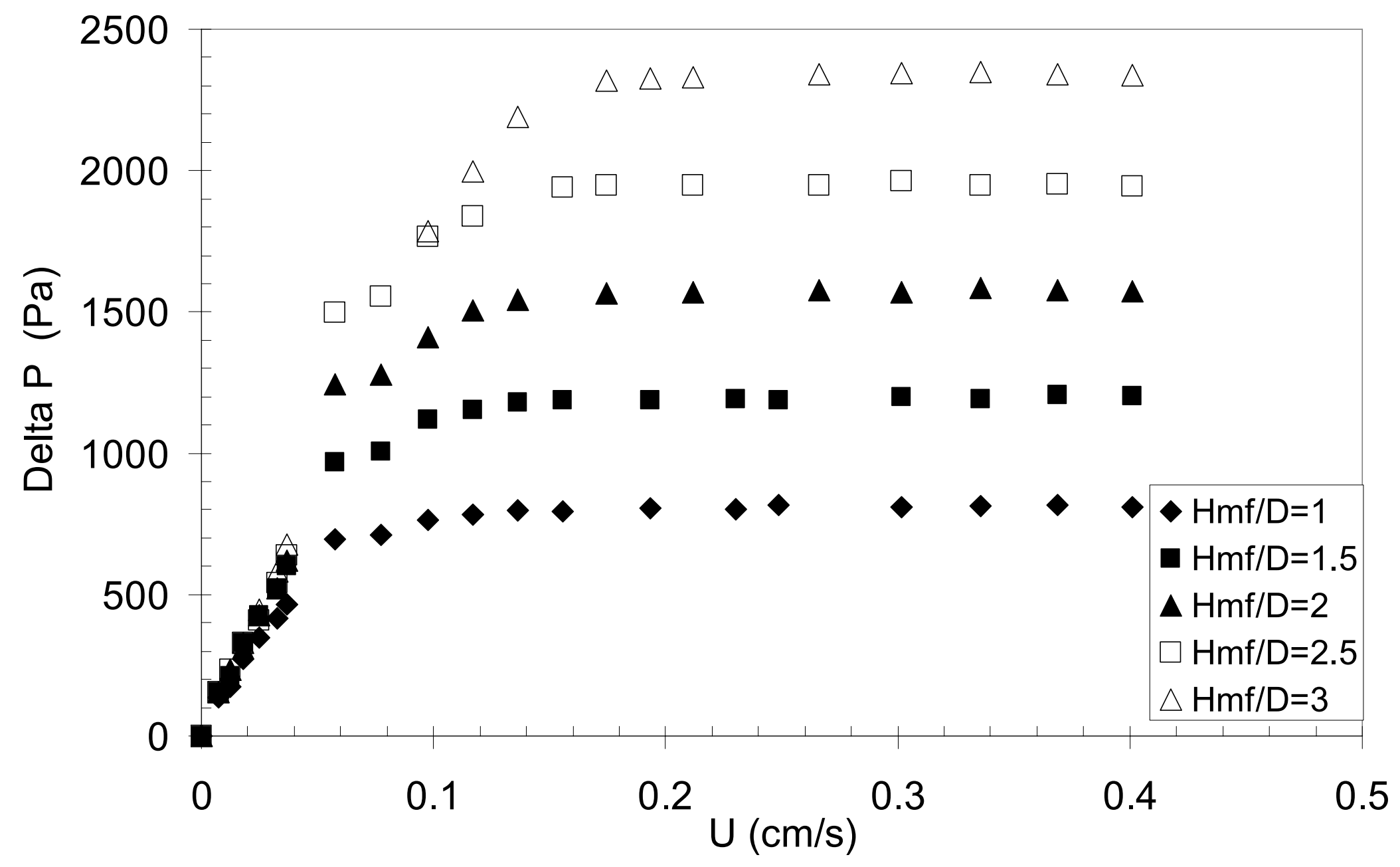

Figure I.5.3. Pressure drop against gas velocity at various bed aspect ratios (Starch 1 , ambient condition) 


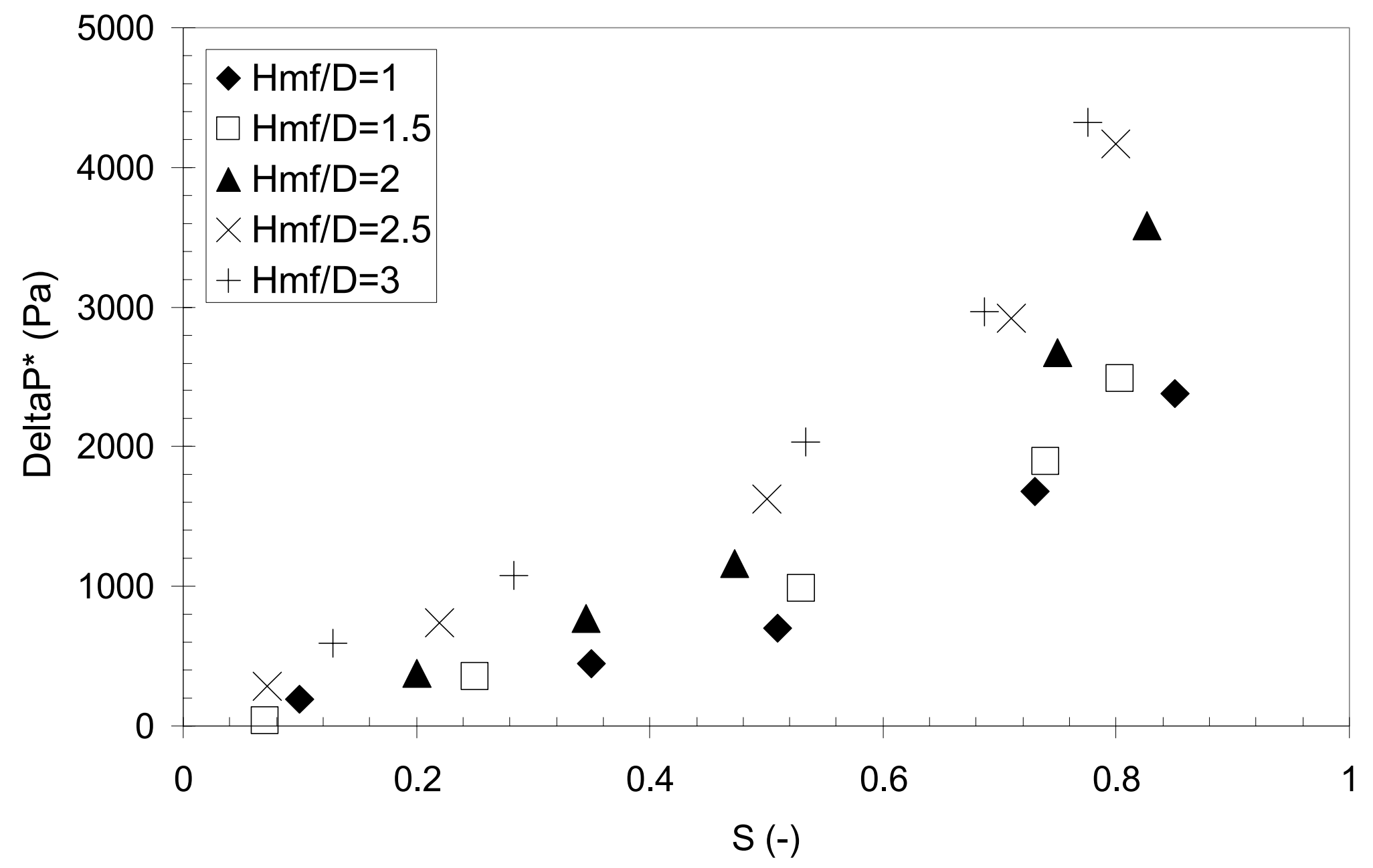

Figure I.5.4. Excess pressure drop against powder strain at various gas aspect ratios (Starch 1, ambient condition) 
Figure I.5.2, 3, and 4 shows that different bed aspect ratios give different curves. On the other hand, rheological properties of any materials must not depend on the quantity of the material. Therefore, generalized variables need to be introduced to eliminate the factor of bed aspect ratio in determining $\mathrm{Y}$.

The example of the transformation of these original aeration data into the generalized variables, which are powder strain and excess pressure drop per powder layer unit, are given in Appendix A. The results of such calculation are presented in the figures in the next section of this chapter.

\section{Transformation to generalized variables}

As briefly mentioned in previous section, powder strain (S) and excess pressure drop per unit layer $\left(\Delta \mathrm{P}^{* *}\right)$ will serve as generalized variables to determine the rheological properties of an HAE emulsion phase. Figure I.5.5 is the powder strain calculated using Eq. (I.3.4) corresponding to original data in Figure I.5.3. An example of this calculation is available in Appendix A. It is shown in Figure I.5.5 that now the data are clustered together on a single curve. The same case is observed for the excess pressure drop per powder layer unit. While the plots of $\Delta \mathrm{P}^{*}$ are widely separated between each bed aspect ratio (Figure I.5.4), its corresponding $\Delta \mathrm{P}^{* *}$ values are close to each other (Figure I.5.6). 


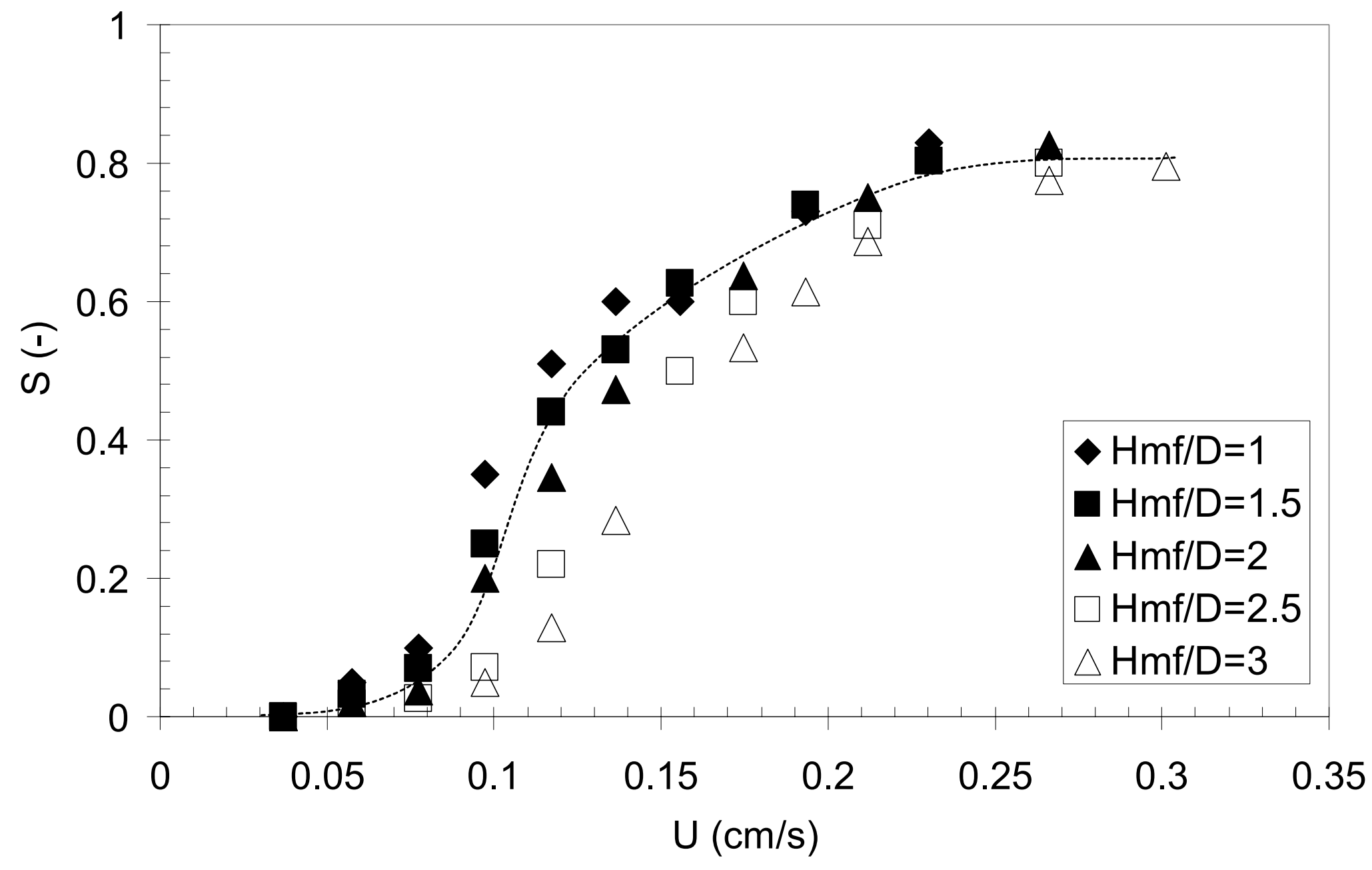

Figure I.5.5. Powder strain against gas velocity at various bed aspect ratios (Starch 1 , ambient condition) 


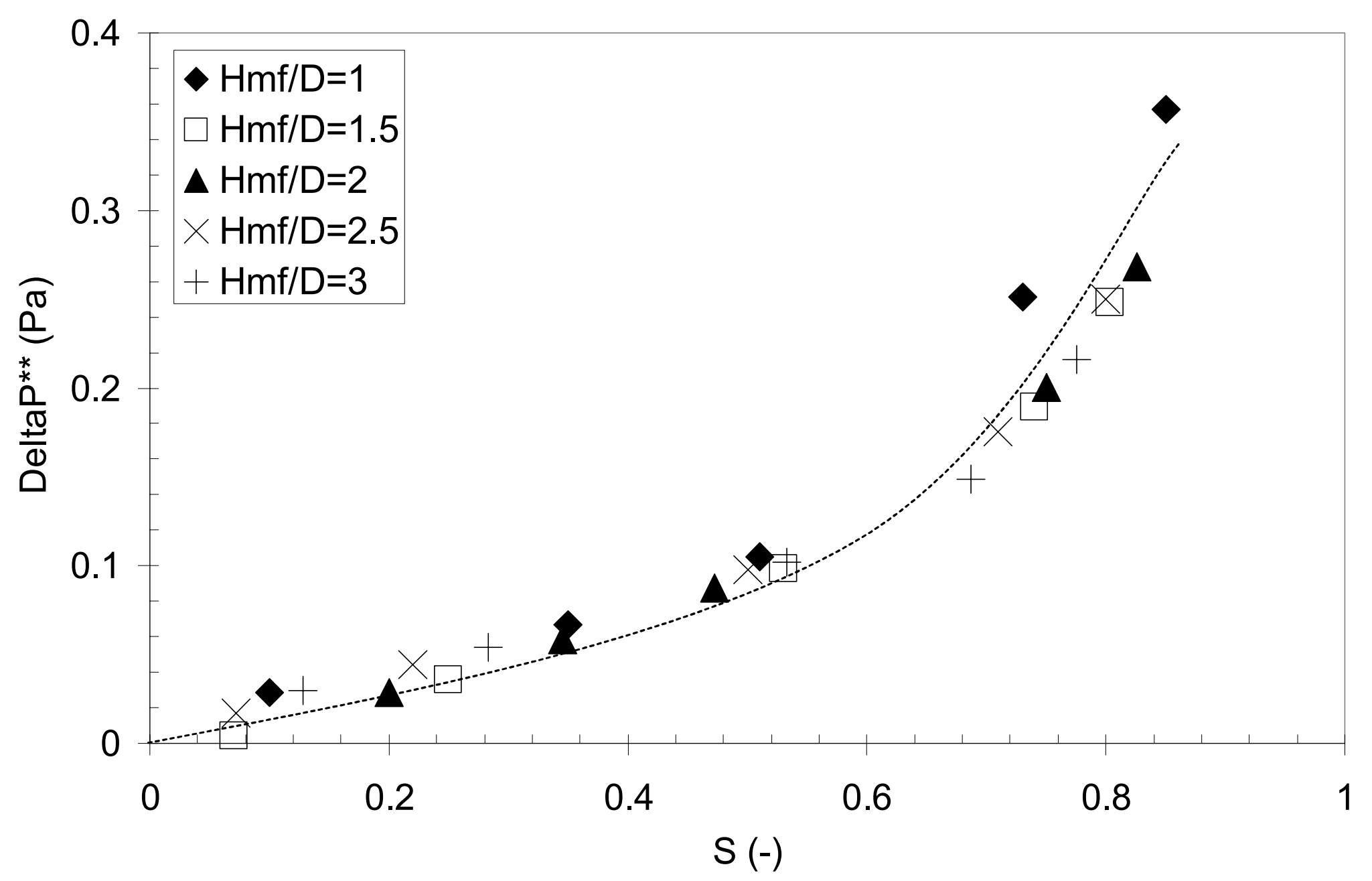

Figure I.5.6. Powder tensile stress against powder strain (Starch 1, ambient condition) 
Figure I.5.6 shows that $\Delta \mathrm{P}^{* *}$, which is powder tensile stress, is initially proportional to the powder strain but when the powder strain becomes higher, this linearity vanishes. The behavior of this curve is best characterized by a parameter called 'elastic deformation coefficient', which is mathematically analogous to the elasticity modulus in the stress-strain diagram.

Despite the similar mathematical definition, it is worth mentioning that the term elastic deformation coefficient defined for the case of HAE emulsion phase has a different physical meaning from the term elasticity modulus widely used for the case of actual solid because of the difference in the mechanism of the deformation. The specific feature of HAE emulsion deformation is that it is only assumed to be a quasi-solid material while in fact it is composed by discrete particles. Therefore, the interpretation of the powder stress-strain correlation in Figure I.5.6 will also be different from that for the actual solid materials.

\section{Elastic deformation coefficient $(\mathrm{Y})$}

The measurements of $Y$ were done in several small changes of strain in the range of $S_{m f}<S<S_{\max }$. The procedure for this incremental $Y$ calculation is documented in Appendix B. The values of $Y$ for Starch 1 at various bed aspect ratios were plotted against powder strain as shown in Figure 1.5.7. An ANOVA test conducted on the data shown in Figure I.5.7 confirmed that bed aspect ratio did not make any significant differences on the $Y$ data. The ANOVA test and also the box plot representation of Figure I.5.7 are presented in Appendix D. 


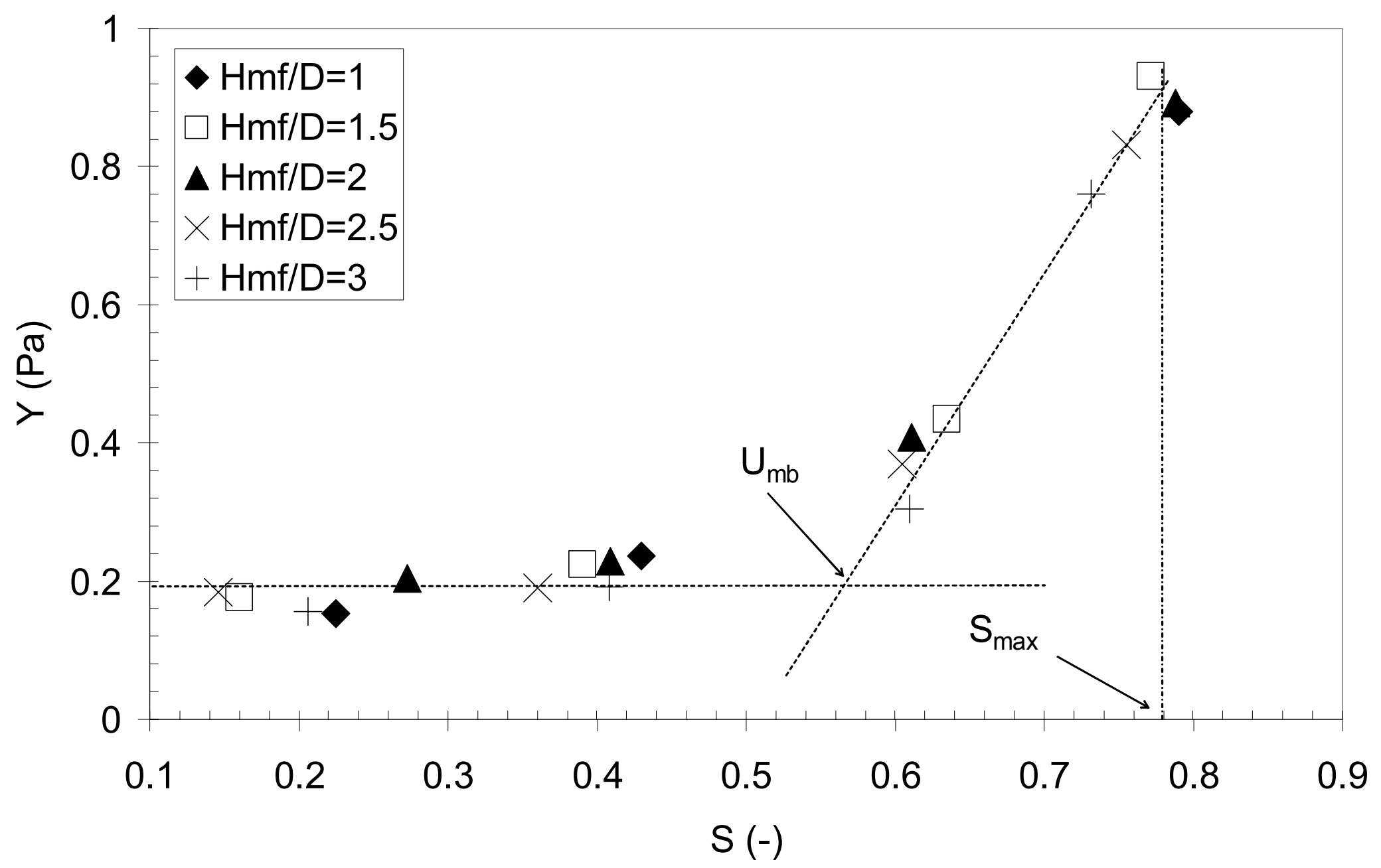

Figure I.5.7. Elastic deformation coefficient for Starch 1 at ambient temperature 
Figure I.5.7 shows that for the starches tested in this experiment, the value of elastic deformation coefficient is constant only up to a certain value of powder strain $(S=0.58)$ and then the value abruptly increase until it finally reaches the maximum strain $\left(S_{\max }=0.78\right)$. The increasing values of elastic deformation coefficient imply that more stress is needed to achieve the same $\Delta \mathrm{S}$. This is caused by the immediate formation of several bubbles in the bed when gas velocity reached a certain value. To explain this phenomenon, an analysis based on the concept of 'powder layer unit' originally defined by Kono et al. (2002) is given as the following.

Figure I.5.8 gives an illustration of powder layer unit expansion. At $U=U_{m f}$, all particles are still in contact with each other and the height of each powder layer unit $\left(h_{1}\right)$ is assumed to be equal to the particle diameter (Figure I.5.8a). While expansion is taking place in the range of $U_{m f}<U<U_{m b}$, the height of each powder layer unit $\left(h_{2}\right)$ increases but it is still small enough to maintain a close distance between particles and the particles are still dynamically in contact with each other so that their interparticle forces are still significant to resist the stretching force from the incoming gas (Figure I.5.8b). The structure of HAE emulsion phase is then still very homogeneous and all of the incoming forces from the gas flow are consumed for bed expansion. This situation is represented by a constant value of $Y$. 
When the expansion comes to its bubbling point, the incoming gas starts to form 'fractures' in the initially homogeneous structure of the HAE emulsion phase (Figure 1.5.8c). These fractures are responsible for the increasing value of elastic deformation coefficient because with the fractures that form some 'voids' in the HAE emulsion phase, only a partial amount of the total gas supplied can be actually used for expanding the bed. A portion of the gas that appears as these voids is not useful for expansion (as has been explained in section 1 of Chapter I.1).

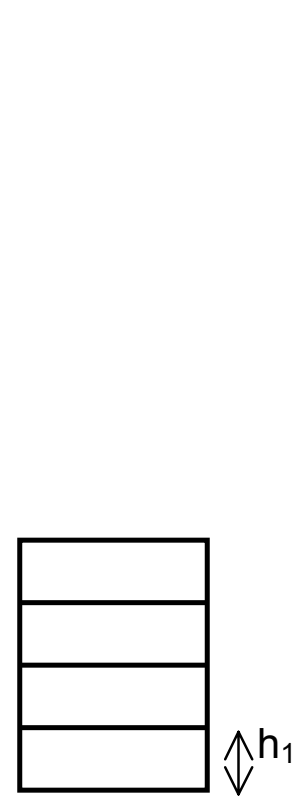

(a)

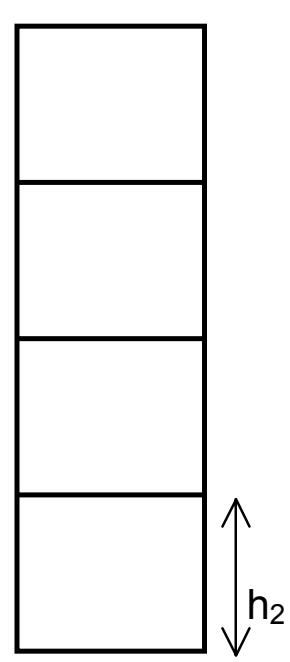

(b)

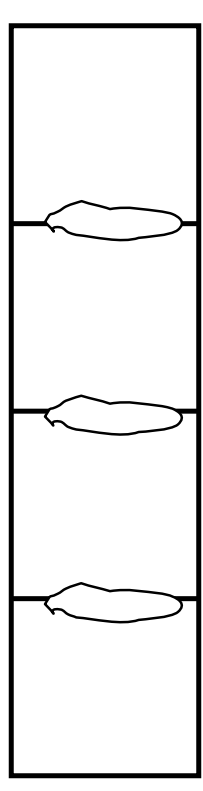

(c)

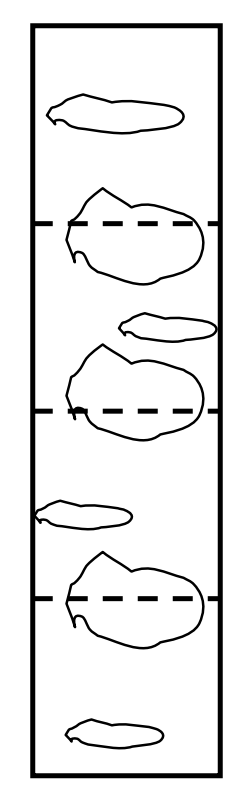

(d)

$\mathrm{U}=0$

$\mathrm{U}_{\mathrm{mf}}<\mathrm{U}<\mathrm{U}_{\mathrm{mb}}$

$\mathrm{U}=\mathrm{U}_{\mathrm{mb}}$

$\mathrm{U}>>\mathrm{U}_{\mathrm{mb}}$

Figure I.5.8. Illustration of the physical meaning of the change in $Y$ value 
Due to the void formation at the condition in Figure $1.5 .8 \mathrm{c}$, the same increase of gas velocity $(\Delta U)$ does not cause an increase on bed height as high as that of the condition in Figure 1.5.8b anymore. At higher gas velocity, these voids become bigger and more new voids are also formed so that less portion of the incoming gas is actually used for bed expansion (Figure 1.5.8d). Therefore, much more incoming gas is needed to make the same degree of expansion so that the elastic deformation coefficient is observed to be very high as $U$ is increasing beyond $U_{m b}$.

The point at which a sudden increase of $Y$ is observed indicates a significant change in the internal structure of the HAE emulsion phase and hence the gas velocity corresponding to this point is defined as the 'new' $U_{m b}$, which is the upper limit of the HAE emulsion phase. It is worth mentioning that this newly defined $U_{m b}$ is different from the conventional meaning of $U_{m b}$ in the sense that visual observation of bubble appearance is not required to determine this newly defined $U_{\mathrm{mb}}$.

Figure I.5.9 presents a comparison among Starch 1, 2, and 3 with respect to their $U_{m b}$ points determined based on their $Y$ data. The numerical values of the $U_{m b}$ are tabulated in Table I.5.1. Although the $U_{m b}$ for Starch 1 are almost identical with those of Starch 2, whose average diameter is only $30 \%$ larger than that of Starch 1, the general tendency observed in Figure I.5.9 is that larger particles will have lower powder strain which is corresponding to the minimum bubbling 
condition. This fact implies that the role of interparticle forces, which is important to maintain the homogeneity of the HAE emulsion phase, is much stronger on the HAE emulsion phase of smaller starch than that on larger starch. The interparticle forces are needed to prevent the formation of voids inside the homogeneous structure of HAE emulsion phase.

Table I.5.1. $\mathrm{U}_{\mathrm{mb}}$ values for Starch 1,2, and 3 aerated at ambient temperature

\begin{tabular}{|c|c|c|c|c|c|c|}
\hline Starch & $\begin{array}{c}\text { Average } \\
\mathrm{d}_{\mathrm{p}}(\mu \mathrm{m})\end{array}$ & $\begin{array}{c}\mathrm{U}_{\mathrm{mb}} \\
(\mathrm{cm} / \mathrm{s})\end{array}$ & $\begin{array}{c}\mathrm{U}_{\max } \\
(\mathrm{cm} / \mathrm{s})\end{array}$ & $\begin{array}{c}\mathrm{S}_{\mathrm{mb}} \\
(-)\end{array}$ & $\begin{array}{c}\mathrm{S}_{\max } \\
(-)\end{array}$ & difference $\left.{ }^{*}\right)$ \\
\hline 1 & 15 & 0.16 & 0.36 & 0.58 & 0.78 & 25.6 \\
\hline 2 & 20 & 0.14 & 0.20 & 0.54 & 0.74 & 27.0 \\
\hline 3 & 40 & 0.19 & 0.32 & 0.39 & 0.46 & 15.2 \\
*) $\% \mathrm{~S}=\frac{\left(S_{\max }-S_{\operatorname{mb}}\right)}{S_{\max }}$
\end{tabular}

Table I.5.1. shows that the intrinsic minimum bubbling condition $\left(\mathrm{S}_{\mathrm{mb}}\right)$ determined by this $\mathrm{Y}$ method is 15.2-25.6 \% lower than the bubble points determined conventionally at the maximum bed expansion $\left(\mathrm{S}_{\max }\right)$. The corresponding intrinsic $U_{m b}$ point is much lower than the gas velocity corresponding to the maximum expansion. 


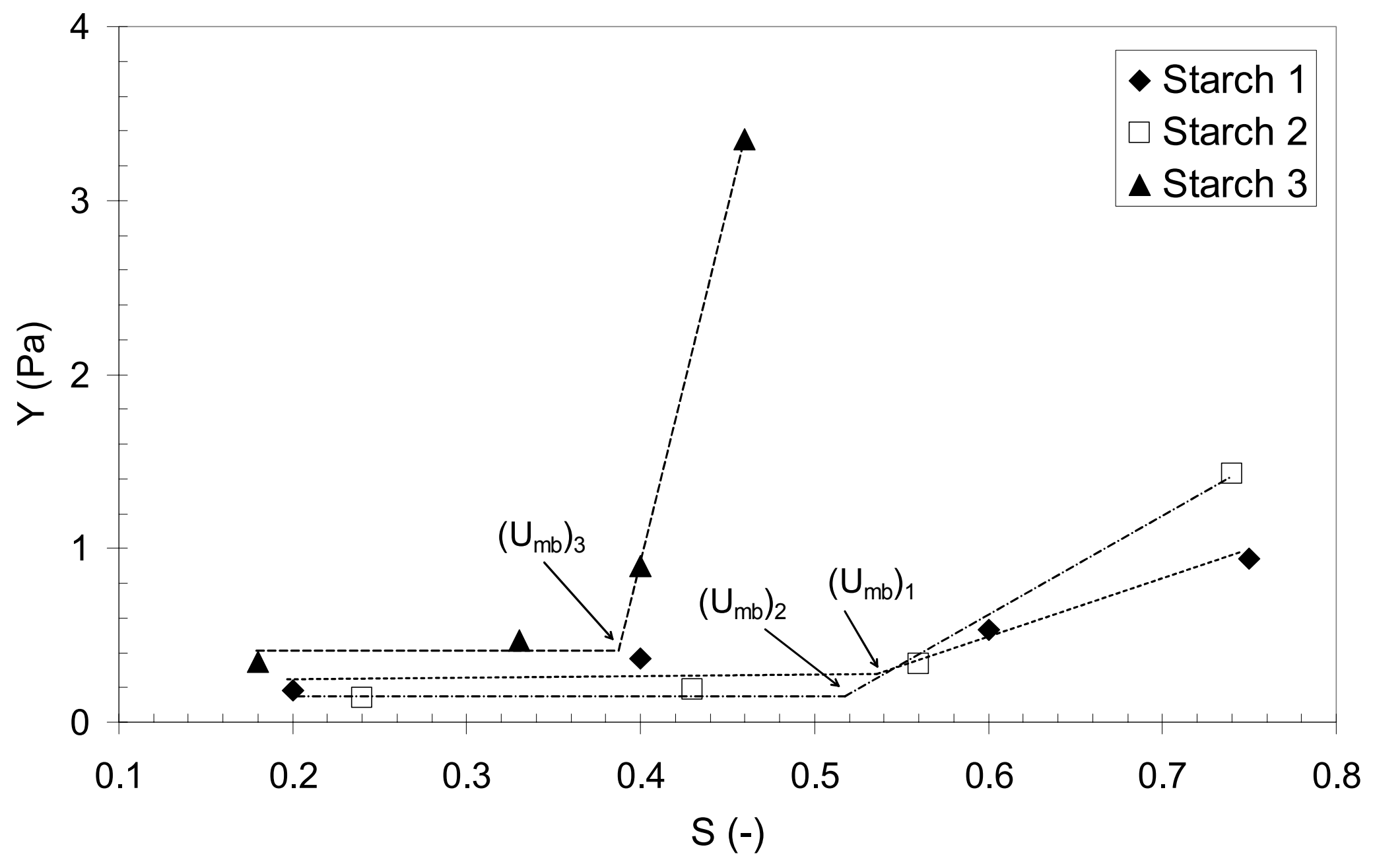

Figure I.5.9. Comparison of $Y$ values among starch 1,2, and 3 
This $Y$ value method gives an accurate determination of the actual $U_{m b}$. In order to achieve and maintain the desirable yield, one can choose the conditions needed to operate the aeration process in the HAE emulsion phase region and make sure that there are only negligible amount of bubbles. This control is very important especially in the aeration system involving chemical reactions because even very small improvement in conversion, as little as $0.5 \%$, could increase profits by millions of dollars worldwide (Geldart, 1989).

Another important application of this $Y$ value method is to quantitatively compare several systems of powder aeration, which can be those of different particle size, different physical properties, and/or different process condition. For example, it has been well known that addition of fine particles to a bed of coarser particles can improve the aeration quality. It is exhibited in Figure I.5.10 that addition of Starch 1 to Starch 3 can drastically shift its aeration behavior towards a much more expandable one. Based on the observation of its $Y$ values, a mixture of $50 \%(w / w)$ of Starch 3 and $50 \%(w / w)$ of Starch 1 behaves very similarly to the HAE emulsion phase of pure Starch 1 presented in Figure 1.5.7. Although the constant $Y$ value in the HAE emulsion phase region is still closer to that of Starch 3, the minimum bubbling point of the mixture is now the same as that of Starch 1 and the maximum $Y$ value is also much lower than that of the pure Starch 3. 


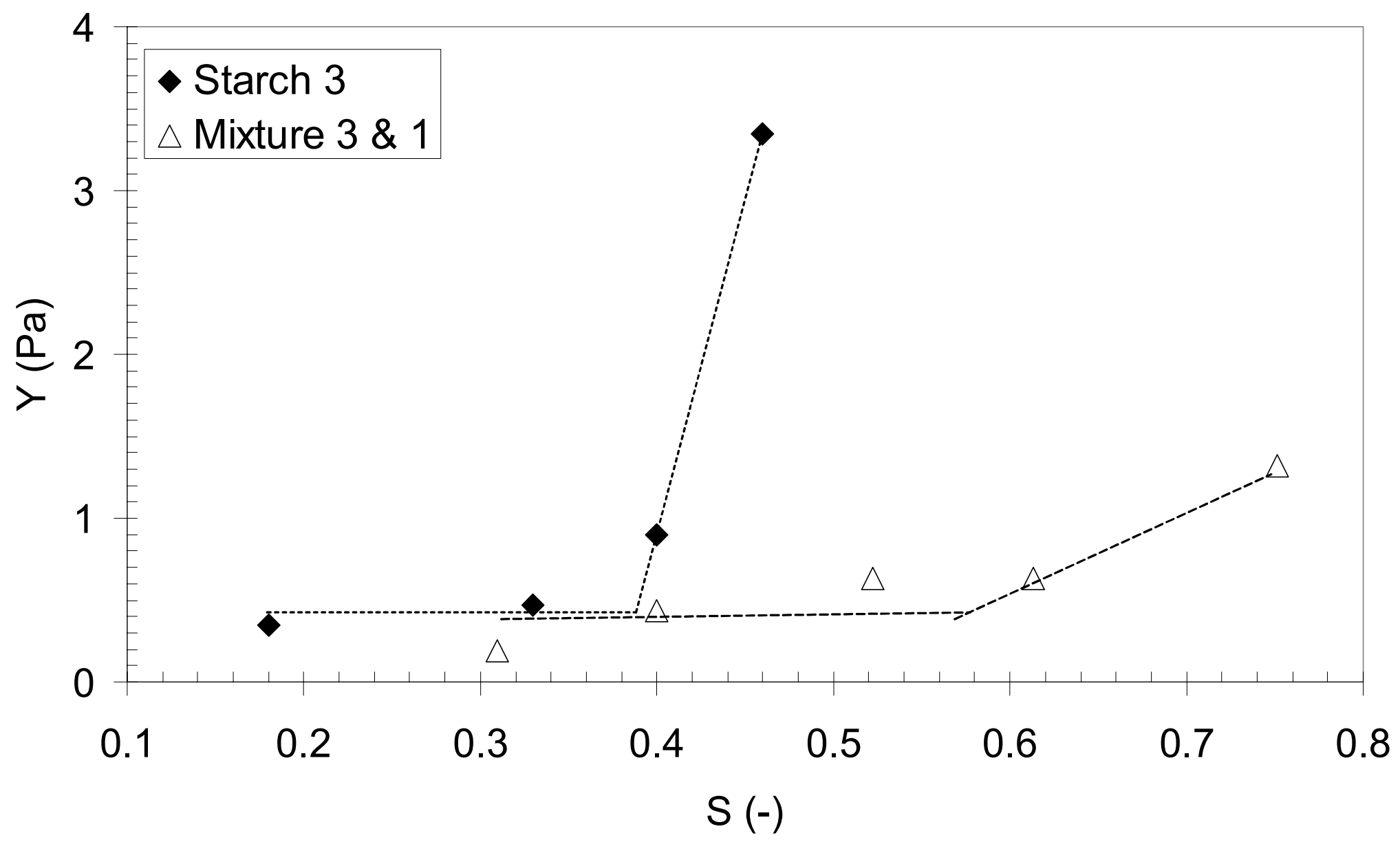

Figure I.5.10. Effect of mixing of starches with different sizes on the aeration behavior 
By using sets of data as those exemplified in Figures I.5.9 and I.5.10, it will be easier to characterize fine powder of any materials and sizes aerated with any gas. Those data are also helpful to quantitatively compare the aeration qualities among several different aeration system in order to make decision of the best condition for a particular process which expects homogeneous fine powder aeration. 


\section{CHAPTER I.6. CONCLUSION AND SIGNIFICANCE}

The analysis conducted on fine powder aeration behavior in this dissertation was based on the theory of HAE emulsion phase, which viewed a system of aerated fine powders as a quasi-solid single phase. This emulsion phase was homogeneously expandable until a point where the formation of fractures ended its homogeneity. From extensive experiments using a type of starch with specially coated surface, the following conclusions were drawn.

1. Original aeration data from a fine powder aeration experiment, which were pressure drop and bed height as a function of gas velocity, need to be transformed to new variables specifically defined for fine powder, which were powder strain and powder tensile stress, to define generalized variables that could eliminate the effect of bed aspect ratio. The plots of powder tensile stress against powder strain indicated a consistent tendency for all aeration systems studied for this dissertation. Based on this fact, a parameter called elastic deformation coefficient, which was mathematically analogous to the elasticity modulus, was defined as the characterization parameter for fine powder aeration behaviors.

2. Elastic deformation coefficient determined by the method presented here had been proven to be an important parameter to define the intrinsic minimum bubbling point of an HAE emulsion phase, so that the point of the first bubble 
formation that caused the fracture of the HAE emulsion phase could be accurately determined. This method does not require visual observation of the first appearance of the bubble.

3. This $Y$ method provided a quantitative tool to compare the aeration quality of several different systems of fine powders. With a numerical value to denote 'how good is good and how bad is bad' in the case of fine powder aeration, it would be easier to carry out an optimization of an existing unit or to design a completely new process involving fine powder aeration.

4. Besides its high reproducibility and precision, this method was of great practical importance because it was simple and did not need any instrument to be inserted inside the powder bed. The measurement was conducted by merely collecting the regular aeration data (gas velocity, pressure drop, and bed height) which would be easily measured by external devices so that the internal structure of the aerated powder could be maintained undisturbed and the data obtained would really reflect the actual internal condition of an aerated fine powder system. 


\section{PART II}

CHARACTERIZATION OF FINE POWDER

AERATIONS AT ELEVATED TEMPERATURE 


\section{CHAPTER II.1. INTRODUCTION}

\section{Background}

The most important aspect of the theory presented in Part I of this dissertation is its applicability at elevated temperature. Majority of the processes involving powder aeration in industry are conducted at elevated temperature but most researches on powder aeration have been done at ambient temperature. It has been known that many aeration behaviors which are essential for further characterization of the aerated bed, such as minimum fluidization velocity and minimum bubbling velocity, significantly depend on temperature without a convincing explanation available yet. That is why the $Y$ method, which has been shown to provide a good characterization parameter at ambient temperature, needs to be tested at elevated temperature.

In order to systematically study a phenomenon, it is necessary to decide which variables to be measured that can give the best insight of the phenomenon. Therefore, the key step in studying temperature effect on fine powder aeration is firstly to define characterization parameters, which have to be consistent in both ambient and elevated temperature conditions.

There have been many researches conducted to use the ambient data to predict the corresponding behaviors at elevated temperature but the outcomes are not yet satisfactory. There will be several major papers 
regarding this issue to be briefly reviewed in the next chapter (e.g. Kai and Furusaki, 1985, Wu and Baeyens, 1991, Raso et al., 1992, Yates, 1996, Lettieri et al., 2001). Some more papers will also be mentioned to underscore the fact that despite those many attempts in the past, there is still room for improvement. It is due to the lack of generality in the previously proposed methods to characterize fine powder aeration at elevated temperature.

Most of the studies in the past ascribed the effect of temperature to the changes in gas density and, more importantly, viscosity. Thence, by using the same hydrodynamic models with slight modifications on gas properties as temperature increased, aeration behavior at elevated temperature was predicted based on correlation originally developed at ambient temperature.

\section{Problem}

For a long time, the influence of the operative temperature on fluid-dynamic characteristics of the aerated systems has been done by simply extrapolating results and relationship from those developed at ambient temperature. Unfortunately, this method was not always reliable. This approach overlooks possible modifications caused by temperature in the internal structure of the aerated bed. This structural change can cause drastic changes in the flow behavior of the aerated powders, which most of the time is unpredicted by pure hydrodynamic approach. It may lead to serious errors in evaluating the 
transport phenomena, which in turn causes miscalculation in designing the process.

The past publications on this field showed that the effect of temperature on fine powder bed behavior could not be explained on a hydrodynamic basis alone, as widely accepted at the present. Taking into consideration only the variations of gas density and viscosity with temperature, as has been done in most of the studies in this field, has not proved sufficient to provide design criteria that can predict the behaviors of the bed as accurately as those observed at ambient temperature.

Another approach attributed the changes in aerated powder behavior at elevated temperature to the changes of the interparticle forces at higher temperature, especially in the case of fine powder aeration. This new standpoint is expected to complement the discussion based on pure hydrodynamic approach and still need more explorations.

\section{Objective}

In Part I, it has been shown that elastic deformation coefficient $(Y)$ and $U_{m b}$ can very well define the flow characteristics of an HAE emulsion phase. Part II is devoted to application of $Y$ method at elevated temperature. It will be shown that the $\mathrm{Y}$ method gives consistent results at elevated temperature as well. Furthermore, the $Y$ value will be used to quantify the changes in the 
aeratibility of fine powders when the aeration temperature is increased and the correlation between $\mathrm{Y}$ values and temperature will be also evaluated.

Part I has already set the necessary foundation for the method, which was verified by using starches at ambient temperature. Part II deals with the more practical application at elevated temperature and studies how temperature will affect the $Y$ values and the corresponding $U_{m b}$. Starches would be burnt during the experiment at elevated temperature so that it was impossible to use it for that purpose. Hence, spent FCC catalyst was chosen to be the sample powder at elevated temperature.

The data to be analyzed in Part II are the untreated and unpublished data of the previous student, J.J. Su, who did the experiment in 1995. However, those are merely raw aeration data consisted of superficial gas velocity and the corresponding pressure drop and bed height at various temperatures ranged from $26^{\circ} \mathrm{C}$ to $600^{\circ} \mathrm{C}$. All analysis presented in this dissertation is completely original and different from the analysis presented by Su (1995).

This part is a continuation from the previous part (Part I) which has given both theoretical development and experimental evidence to propose a new physical meaning of intrinsic $U_{m b}$, which is different from its conventional definition. Therefore, it is important to note that hereinafter all discussions 
involving the term ' $U_{m b}$ ' are always refer to the new definition of intrinsic $U_{m b}$ presented in Part I of this dissertation unless it is indicated otherwise.

\section{Significance}

The urgency in the study of temperature effect on fine powder aeration is of increasing importance because:

1. Most usage of these fine particles is as catalyst in reacting systems, which are most likely carried out at elevated temperature.

2. People are still struggling to find the best correlation to apply pure hydrodynamic approach on coarse particles at elevated temperature. Their correlations, which are developed at ambient temperature, do not provide accurate characterization parameters for the same powders at higher temperature. For the more complex case of fine powder, pure hydrodynamic approach often fails even at ambient temperature so that more discrepancies will be encountered at elevated temperature. The study of fine powder aeration at elevated temperature is still in need of a better characterization method. 


\section{CHAPTER II.2. LITERATURE REVIEW}

\section{The pure hydrodynamic approach}

There have been many attempts to correlate the ambient data to predict the corresponding behaviors at elevated temperature. Most of the studies in this field were conducted on particles whose average diameters are larger than $100 \mu \mathrm{m}$ so that the effect of interparticle forces was always overlooked. It is true that interparticle forces are negligible in aerated coarse particle at ambient temperature, but there have been some researches showing that interparticle forces can be much stronger at elevated temperature, even for the particles which are traditionally recognized as 'coarse particles' (e.g. Kai and Furusaki, 1985, Yamazaki et al., 1986, Kamiya et al., 2002).

Therefore, neglecting interparticle forces at elevated temperature may result in serious error, not only for fine powder systems but also for coarse particle systems. For example, Wu and Baeyens (1991) studied the effect of temperature changes in the prediction of $U_{m f}$ based on Ergun equation. They stated that when the temperature of the powder bed changed, the only obvious changes were in the properties of the aerating gas. These in turn affected $U_{\mathrm{mf}}$. With increasing temperature, the density of the gas decreased and the viscosity of the gas increased. They did not look into the possibility of the effect of temperature on interparticle forces because their sample powders ranged between 134 to $1970 \mu \mathrm{m}$ so that they assumed that the 
interparticle forces would be always insignificant. However, they observed an unexplained behavior of the powders starting at $100^{\circ} \mathrm{C}$. Their predictions deviated significantly from the experimental data and they had to introduce some new adjustable parameters to make the model well fit the data. Nevertheless, there was no theoretical background provided in their paper to explain these empirical adjustments. A similar treatment was also conducted by Mii et al. (1973), Nakamura et al. (1985), Fan et al. (1986), Saxena et al. (1990), Fletcher et al. (1992), and Rapagna et al. (1994).

In spite of the extensive work conducted to study powder behavior at elevated temperature, the present understanding of the characteristics of a bed of solids aerated at elevated temperature is still far from satisfactory and design criteria devised so far are still more or less empirical. This makes it difficult to perform scale up/down operations or to modify the existing unit to gain more yield on processes involving aerated powders.

\section{Effect of temperature on interparticle forces in aerated powder beds}

Raso et al. (1992) pointed out that accounting only for the variations of the physical properties of the aerating gas (density and viscosity) with temperature has not proved sufficient to provide a characterization of the fine powders as accurate as those obtainable at ambient condition. Raso et al. based their analysis on the effect of temperature on the bed voids near $U_{\mathrm{mf}}$ point and they reported that their experimental data could not be explained on 
a pure hydrodynamic basis. They observed that the increase in bed porosity also occurred even in the packed bed arrangement of the powders before the bed start expanding. This was shown to be a consequence of the enhancement of the interparticle forces acting in the particulate phase at medium and high temperature. The same tendency was also reported previously by Botterill et al. (1982) on the bed of coarse particles (each group of particles had a narrow size distribution in the range of $370-2320 \mu \mathrm{m}$ ); although they could not offer any explanations regarding the cause of that phenomenon.

Experimental evidence obtained in the study based on Rumpf's powder structure theory showed that there was viscoelastic deformation observed at elevated temperature which was still below the sintering point of the powder particles. Viscous flattening of solid particles gave more space for a larger interparticle contact area so that it enhanced the effectiveness of Van der Waals forces. Because of this phenomenon, it is possible to observe more loosen yet stable structure of the powders at elevated temperature due to the fact that the stronger interparticle forces would stabilize the bed (Raso et al., 1992).

The significant effect of temperature on interparticle forces was also reported by several other authors in this area. Nevertheless, they offered various detail explanations which were different from each other. For example, Kai and 
Furusaki (1985) believed that dry fine powders were greatly influenced by electrostatic forces among them at ambient temperature so that the fluidity was very poor. This electrostatic effect vanished at higher temperature so that the aerated powder gained more fluidity. Similar explanation was also presented by Yamazaki et al. (1986). Lettieri et al. (2000) showed the effect of temperature on the aeration behavior of FCC catalyst by observing the bed collapse rate and calculated the relative magnitude of the hydrodynamic forces and the interparticle forces as temperature increased. They stated that the characteristics of the surface of this catalyst changed as a function of temperature. Their results emphasized that a pure hydrodynamic equation could only predict the aeration behavior where the interparticle forces did not show a dominant role over the hydrodynamic forces. This fact was also underscored in the review paper authored by Yates (1996). Therefore, the new standpoint known as 'rheological approach' which accounted for interparticle forces complemented the discussion based on pure hydrodynamic approach.

Another research group was more concerned about measuring the manifestation of the interparticle forces, which is powder bed tensile strength, at elevated temperature (Kamiya et al., 2002). Up to date, there are no measuring devices available for such a measurement purpose because most of the conventional measuring devices were made of metal and had to be in contact with the very hot powders. Thermal expansion coefficient of the metal 
was much larger than that of the powder. Therefore the accurate measurement of the powder bed tensile strength was almost impossible to be done using conventional devices. On the other hand, the data of powder bed tensile strength is important in the rheological study of fine powder aeration.

\section{Minimum bubbling point at elevated temperature}

Compared to the work devoted to studying the effect of temperature on $U_{\mathrm{mf}}$, there has been very little work devoted to $U_{m b}$ at elevated temperatures. With respect to bubble behavior, most of the work was done on coarse particles because earlier application of aerated powder was more concerned with this class of aeration. As an example, Sitthiphong et al. (1981) studied the eruption diameter of bubbles in beds of large particles (average diameter of 3 $\mathrm{mm}$ ) and found a significant increase with temperature under equivalent conditions. However, this finding is contradictive to what has been observed in small particle systems (Yates, 1996).

When fine powders became more frequently met in industrial processes, more attention has been drawn to the determination of $U_{m b}$ point, rather than the behavior of the bubbles, because in fine powder aeration, people usually want to maintain a bubble-free aeration. Therefore, in order to avoid operating the units in the bubbling region, the main concern in fine powder operation is to determine when the bubbles are actually formed. Moreover, there is still a challenge in the study of fine powder aeration to define characterization 
parameters for aerated powders, which are consistent at ambient and elevated temperature, in order to better understand their behaviors.

From hydrodynamic standpoint, one among several conventional ways to address fine powder aeration quality was by visual observation of the first bubble formation in the bed. An improved method which still relied upon visual observation was to watch for the first clearly recognizable bubble eruptions at the bed surface. This might provide more clear observation, rather than trying to see bubble formation inside a three-dimensional aeration column. Geldart and Kapoor (1976) defined these 'recognizable bubble eruptions' as those whose sizes were about $2-3 \mathrm{~mm}$ in the aerated bed of particles of $118 \mu \mathrm{m}$ average diameter. Based on that method, they concluded that $U_{m b}$ was least likely affected by temperature. However, they found that bubble size at 200 and $300^{\circ} \mathrm{C}$ was $75-85 \%$ of the size observed at ambient temperature.

Up to recently, visual observation methods are still used to determine the aeration quality. Lettieri et al. (2001) verified 'good bed mixing' and measured $\mathrm{U}_{\mathrm{mb}}$ by visual observation of the bed surface using $\mathrm{X}$-rays technique. The condition of internal flow patterns of the fluid and solids inside the column was qualitatively recorded as the indication of particulate/bubbling aeration and $U_{m b}$ was determined by noting the velocity at which the first bubbles began to appear as aerating gas velocity was increased. Furthermore they reported 
their data as the ratio between the measured pressure drop across the bed $\left(\Delta \mathrm{P}_{\mathrm{m}}\right)$ and theoretical equilibrium pressure $\operatorname{drop}\left(\Delta \mathrm{P}_{\mathrm{c}}=\mathrm{Mg} / \mathrm{A}\right)$ against gas velocity. They concluded that increasing temperature improved the aeratibility of the FCC catalyst.

Another method was based on uniformity index based on pressure fluctuation and bubble frequency (Kai and Furusaki, 1985). The pressure fluctuations were detected by means of a piezoelectric pressure transducer. The point at which the pressure fluctuations become noticeable was defined as the $U_{m b}$ point. Although this method still involved a subjective judgment about the measure of 'noticeable fluctuations', it had provided more systematic discussion about temperature effect on $\cup_{m b}$ point. Kai and Furusaki (1985) worked on fine particles (average diameter of $70 \mu \mathrm{m}$ ) and they reported that high temperature resulted in smaller amplitudes in the pressure fluctuations and also lower bubble frequency. This was an indication of better aeration quality. Bubble size was also significantly decreased with increasing temperature and it also indicated improvement in the quality of aeration with increasing temperature. Furthermore they attributed the improvement at elevated temperature to the vanishing effect of electrostatic forces that caused severe agglomeration at ambient temperature. This explanation was contradictive to the findings by other authors that reported increasing interparticle forces at higher temperature (e.g. reviewed by Raso et al., 1992). 
A similar treatment based on pressure fluctuations was conducted by Rapagna et al. (1994). However, they did not account for interparticle forces. Their analysis was based on the pure hydrodynamic approach proposed by Foscolo and Gibilaro (1984). They concluded that the onset of bubbling, as measured by the minimum bubble voidage, was progressively delayed with increasing temperature.

\section{Effect of temperature on HAE emulsion phase}

Based on the theory of HAE emulsion phase described in Part I, previous researches suggested that the values of rheological parameters (elastic deformation coefficient and powder tensile strength) were much more useful at elevated temperature than the classical particle characterization data such as particle size, its shape factor, and the physical properties of the aerating gas (Kono et al., 1995).

Kono et al. (1995) reported that the value of elastic deformation coefficient and powder tensile strength became smaller at elevated temperature. However, when the aeration condition was in the region of HAE emulsion phase, those two rheological parameters followed the same characteristic equation developed at ambient temperature. Smaller values of elastic deformation coefficient were indication of better aeration quality. They also presented a proof of qualitative relationship between the values of those 
rheological parameters and the visual bubble images obtained in twodimensional aerated bed.

The previous publications on HAE emulsion phase behavior (Kono et al., $1994,1995,2002)$ reported the $Y$ value as the average value between $U_{m f}$ and the conventional $U_{\mathrm{mb}}$. This average $\mathrm{Y}$ value was determined by assuming a linear expansion in the whole range of $U_{m f}<U<U_{m b}$. An incremental determination of $\mathrm{Y}$ values, which is presented in Part I, will provide a better insight about the actual phenomena and also may reveal some facts that were overlooked by the previously published average-Y method. 


\section{CHAPTER II.3. BASIC CONSIDERATION}

At elevated temperature, the effect of interparticle forces will become more evident and the measured $Y$ value will give a quantitative description of this effect. The theory of HAE emulsion phase is a general theory so that although it is originally developed and verified at ambient temperature, it will not need any modifications to be applied at elevated temperature. Therefore the same theory as presented in Chapter I. 3 will be also applicable to the case of fine powder aeration at elevated temperature.

However, there are some important considerations in order to apply the $Y$ determination method and to get accurate results on the aerated particles at elevated temperature:

1. The minimum bed height measurement has to be taken at the same temperature as the temperature during aeration experiment. Previous studies showed that the settled fine powder at elevated temperature can expand to some extent, even without gas flowing (Botterill et al., 1982, Raso et al., 1992). Therefore, the height of a settled fine powder bed at elevated temperature can be considerably higher than that at ambient temperature. The $\mathrm{Y}$ method needs accurate values of powder strains, which very much depends on the measurement of minimum bed height $\left(\mathrm{H}_{\mathrm{mf}}\right)$. 
2. The $U_{m b}$ determination method, which defines the intrinsic $U_{m b}$ as the point where the $Y$ value suddenly increase, can only give a valid result if there is no permanent structural change on the particles caused by sintering. The HAE emulsion theory is applicable at elevated temperature situation where the particles still maintain their individuality although high temperature may cause some deformation. Once sintering happen, the particles will agglomerate with a very strong chemical bonding. From HAE emulsion phase point of view, agglomeration is considered the same as bubble formation, i.e. a phenomenon that destroys the homogeneous structure of powder layers in the HAE emulsion phase quasi-solid body. So if sintering is the case, the aeration system cannot be categorized as HAE emulsion phase anymore and hence, the theory presented in Part I is no longer applicable. Nonetheless, the $\mathrm{Y}$ method can also be a help as the indicator of whether sintering happens or not in a particular fine powder aeration system. HAE emulsion phase theory expects lower $Y$ value at higher temperature. When higher $Y$ value is observed at higher temperature, it is an indication that sintering has already taken place. 


\section{CHAPTER II.4. EXPERIMENTAL PROCEDURE}

\section{Material}

The material chosen as sample powder for experiment at elevated temperature was spent FCC catalyst, whose average particle diameter was $67.5 \mu \mathrm{m}$ and had the solid density of $1.85 \mathrm{~g} / \mathrm{cm}^{3}$. All experiments were conducted with $956.3 \mathrm{~g} \mathrm{FCC}$ catalyst in the aeration column. Dry air was used as the aerating gas.

\section{Experimental set up}

The experimental procedure was the same as that done at ambient temperature. Nevertheless, some modifications were made on the equipment to facilitate the aeration condition at very high temperature.

The quartz column (ID = $10 \mathrm{~cm}$ ) was equipped with electrical heater to increase and maintain the temperature of both the powder bed and the aerating gas. The pressure drop could not be measured by water manometer due to the high temperature of the system. Therefore, for pressure measurement, a Validyne Model P305D pressure sensor was utilized together with a PC for data processing. The bed height as a function of gas velocity was recorded by a video camera recorder to help making the measurement from a safe distance from the very hot unit. The schematic picture of the experimental set up is shown in Figure II.4.1. 

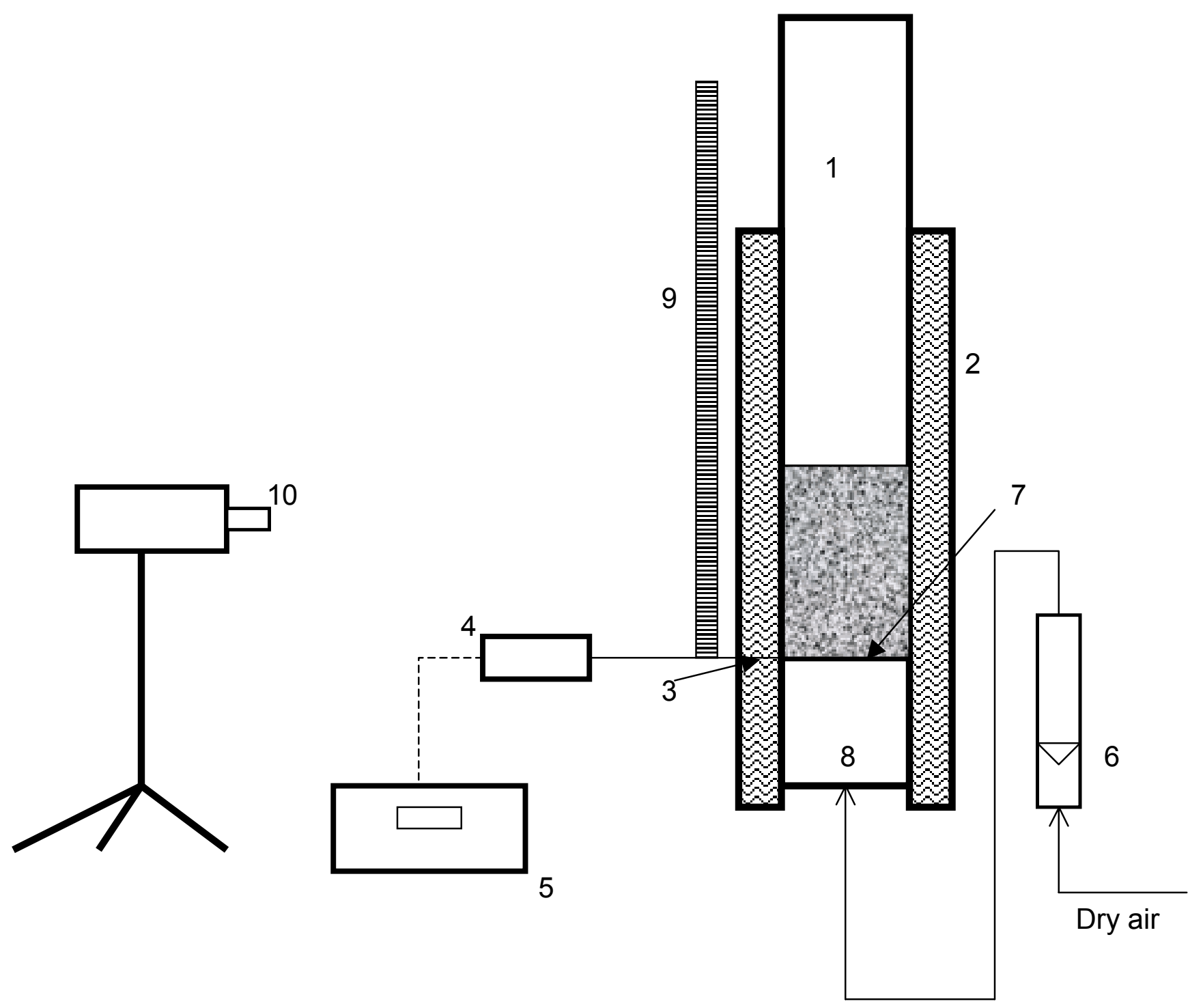

Figure II.4.1. Experimental set up for experiment at elevated temperature (Su, 1995).

(1) 3-D quartz column, (2) electric heater, (3) pressure probe, (4) pressure sensor, (5) digital multimeter, (6) flowmeter, (7) gas distributor, (8) plenum chamber, (9) scale, (10) video camcorder 


\section{CHAPTER II.5. RESULTS}

\section{Original aeration data}

Figure II.5.1 shows that higher temperature leads to higher maximum bed heights for the same powder. This fact has been well-known in aeration practices. Later in this section, a new finding from elastic deformation point of view will be presented.

In the past, the point of minimum bubbling was defined as either the point where the first bubble was visually observed or the point of maximum bed height as shown in Figure II.5.1. It is obvious in Figure II.5.1 that for the spent FCC used in this experiment, the conventional $U_{m b}$ at elevated temperature is about the same as that at ambient temperature. However, degree of expansion at elevated temperature is larger than that at ambient temperature on the same gas velocity. This phenomenon was not observed in the case of starches in Part I. For starches, larger homogeneous expansion was corresponding to higher $\mathrm{U}_{\mathrm{mb}}$. From the fact observed in FCC catalyst aeration, obviously it was not always the case.

Another set of original data is the pressure drop data plotted against gas velocity in Figure II.5.2. All of the experiments were conducted with exactly the same amount of FCC catalyst. Therefore, the pressure drop curves for 26, 400 , and $600{ }^{\circ} \mathrm{C}$ are all identical. Theoretically, the equilibrium pressure drop 
in an aeration process will only depend on the weight of the aerated particles and mathematically define as:

$$
\Delta P_{\text {eq }}=\frac{M g}{A}
$$

Figure II.5.2. implies that the same amount of energy was supplied from the aerating gas to support the particle weight. However, this same amount of energy turned out to cause different extent of expansion of the FCC catalyst bed at 26,400 , and $600{ }^{\circ} \mathrm{C}$ (the corresponding bed height curves is shown in Figure II.5.1). This fact shows that only by increasing temperature of aeration, the powder bed will react differently. At higher temperature, the bed becomes more expandable.

Figure II.5.3. makes it clearer that in the system of aerated FCC catalyst, the same amount of energy from the aerating gas causes more expansion at higher temperature. This can only happen if there are changes on the surface characteristics of the particles due to the elevated temperature, which in turn significantly affects the nature of the interaction among particles or between particles and the aerating gas. Because of these surface phenomena, fractures formation in the HAE emulsion phase can be prevented up to much larger strain at elevated temperature. 


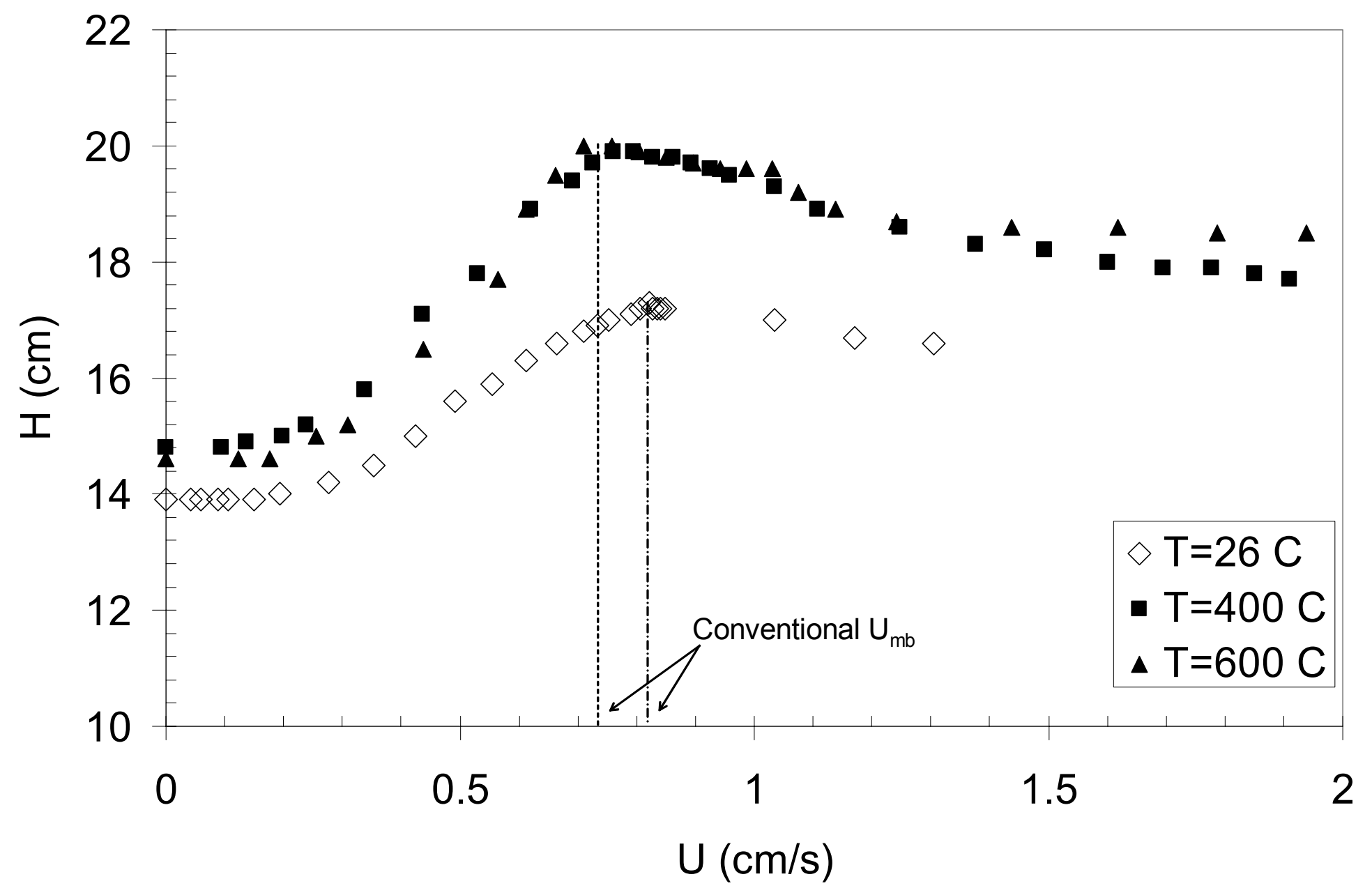

Figure II.5.1. Bed height against gas velocity (FCC catalyst aerated by dry air) 


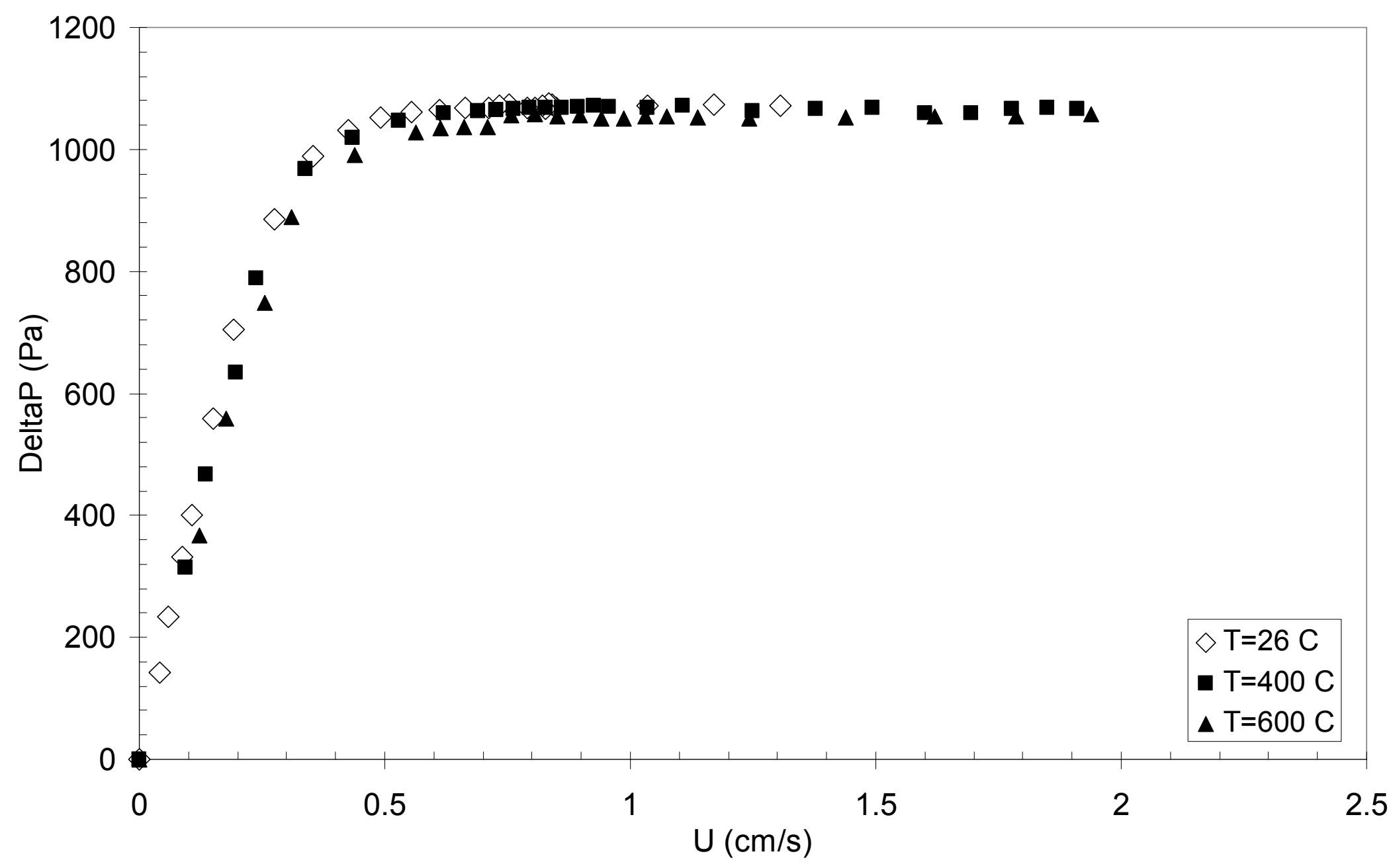

Figure II.5.2. Pressure drop against gas velocity (FCC catalyst aerated by dry air) 


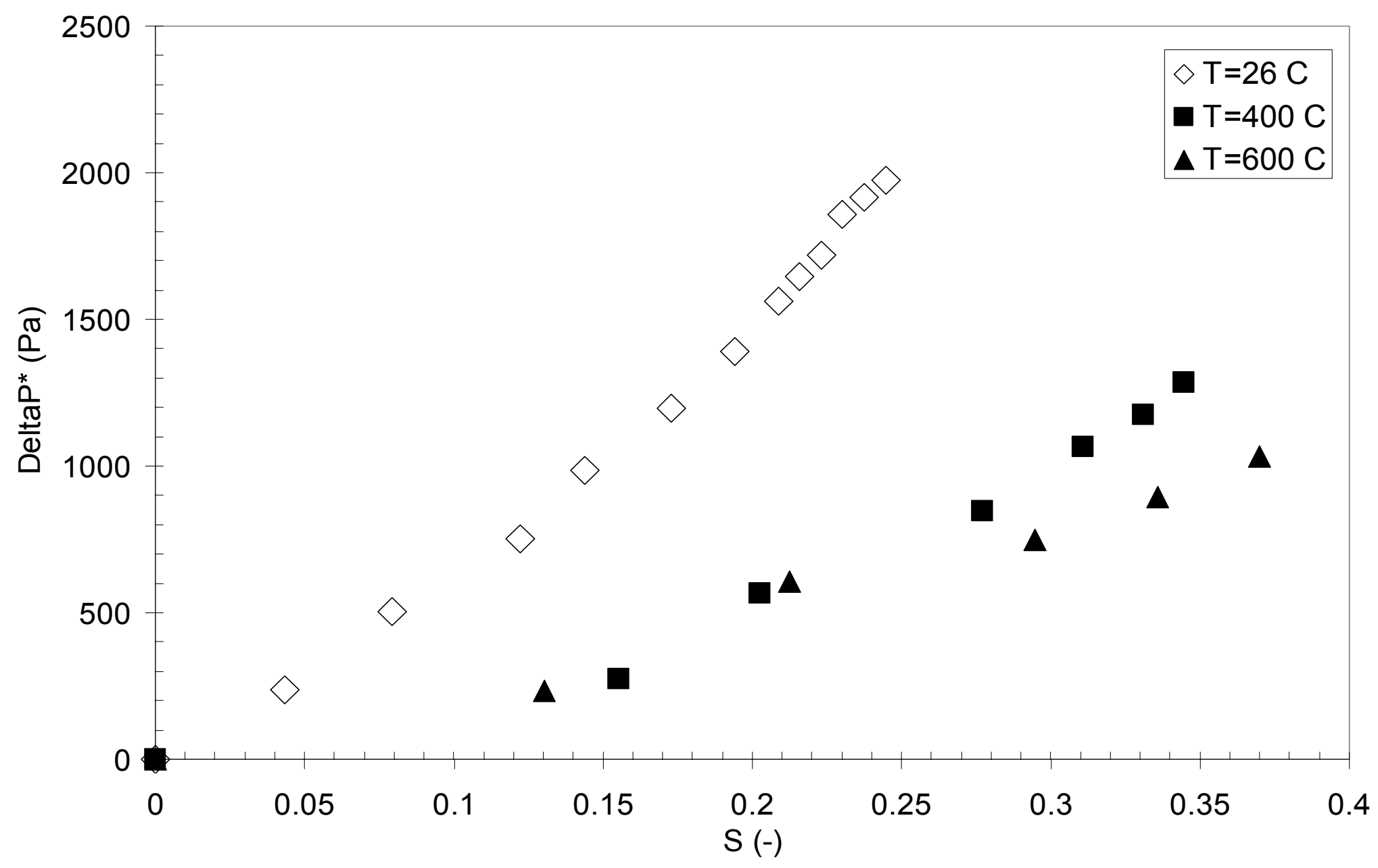

Figure II.5.3. Excess pressure drop against powder strain (FCC catalyst aerated by dry air) 


\section{Transformation to generalized variables}

If the data in Figure II.5.1 was converted into powder strain defined by Eq. I.3.4, Figure II.5.4 displays the fact that the strain curves for spent FCC catalyst at ambient temperature are very similar to those for starches presented in Part I of this dissertation. Nevertheless, it is obvious in Figure II.5.4 that the curve is steeper at higher temperature. For spent FCC catalyst used in this experiment, the curve eventually becomes perfectly linear at 600 ${ }^{\circ} \mathrm{C}$. In the first published paper about elastic deformation coefficient (Kono et al., 1994), it was assumed that an ideal HAE emulsion phase was defined by the linearity of the plot of strain against superficial gas velocity. Figure II.5.4 showed that at high temperature, this linearity can also actually be reached for particles which does not aerate very well at ambient temperature. This ideal situation was also observed in the experiment at ambient temperature using starch with modified surface, which was presented in Part I. Therefore, it is worth mentioning that there are two possible ways to obtain ideal HAE emulsion phase aeration:

a. Particle surface may be modified to engineer the interparticle forces among aerated particles and hence to manage more desirable homogeneous aeration (it is exemplified by the starches in Part I).

b. High temperature can also somehow alter the surface condition of the particles and hence enhance the ability of the bed to expand homogeneously (as shown by FCC catalyst in Part II). 


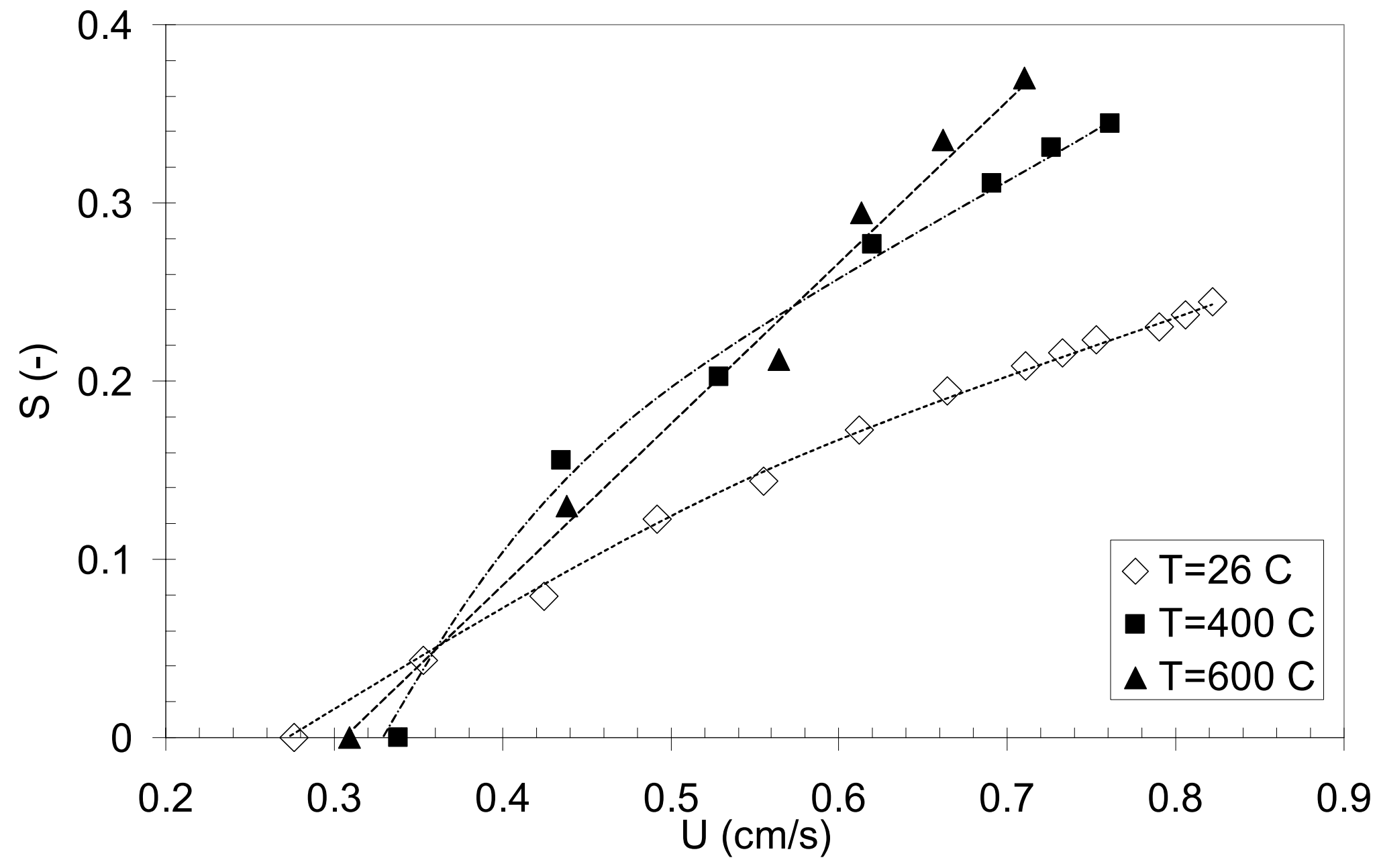

Figure II.5.4. Powder strain against gas velocity (FCC catalyst aerated by dry air) 


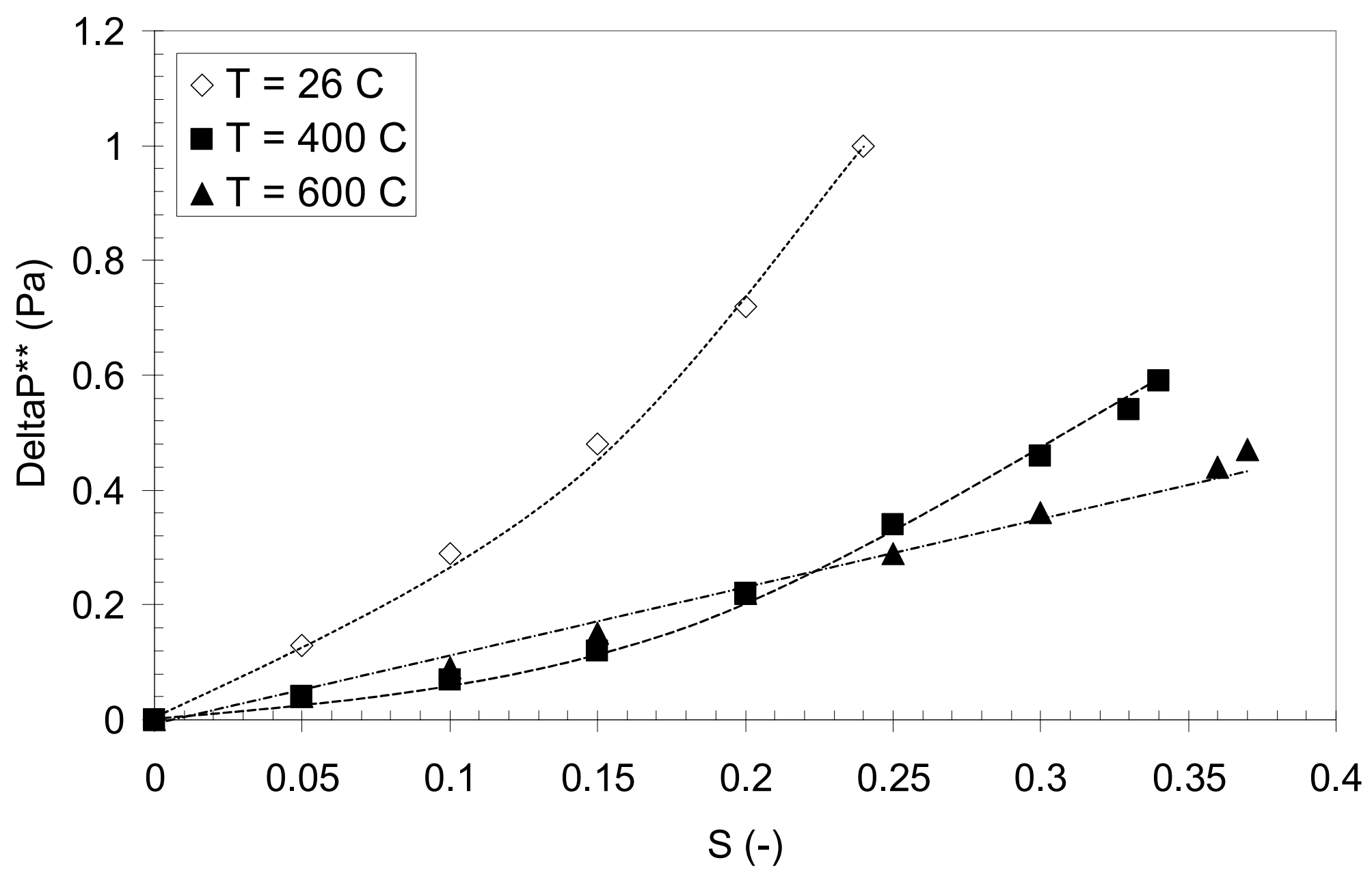

Figure II.5.5. Powder tensile stress against powder strain (FCC catalyst aerated by dry air) 


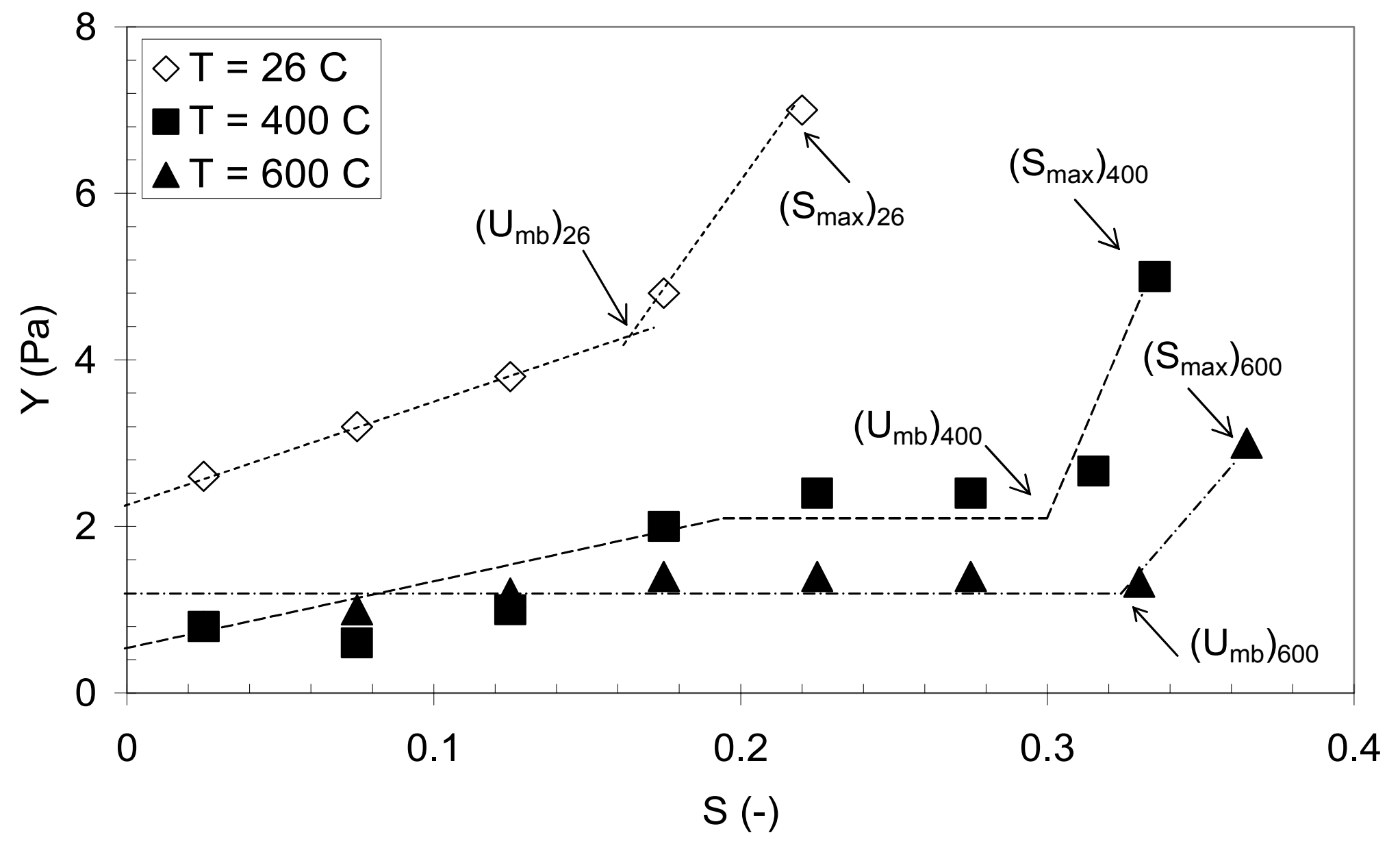

Figure II.5.6. Elastic deformation coefficient against powder strain (FCC catalyst aerated by dry air) 
Figure II.5.5. , which is a plot of powder tensile stress as a function of powder strain, presents a clear picture of the temperature effect on the ideality of the HAE emulsion phase. At $600{ }^{\circ} \mathrm{C}$, this plot becomes perfectly linear. More quantitative description about this temperature effect will be presented on the next section about elastic deformation coefficient.

\section{Elastic deformation coefficient}

Figure II.5.6 shows that at ambient temperature, the curve behaves rather differently from the starch curves presented in Part I. In starch experiment, the $Y$ values were constant until the minimum bubbling point was reached. For FCC catalyst at ambient temperature, the $\mathrm{Y}$ values are already very high at the beginning and the constant region is not observed at all. This high value is caused by the strong cohesiveness among the spent FCC particles that cannot be overcome yet at low gas velocity. As the result of this, most of the gas just flow through channels and does not contribute to bed expansion. High gas flow rate and small strain consequently lead to high value of $Y$. Once the gas velocity is high enough to destroy the channels, the bed now can be aerated homogeneously in the HAE emulsion condition and it behaves like the bed of starch in Part I. This channeling situation did not happen in the experiments using starches in Part I because their modified surface made it possible to prevent the possibility of channeling even at very low gas velocity. Experiments at high temperature are free from channeling at low gas velocity so that the value of $Y$ in Figure II.5.6 is much lower than the ambient case. 
At ambient temperature, as soon as the bed starts expanding at $U_{m f}$, the $Y$ values keep increasing. At the point of $U_{m b}$, however, the sudden jump of $Y$ values is also observed. Therefore, it can be concluded that applying the $Y$ value method to determine the intrinsic $U_{m b}$ point, which has been proven to work well on starches with modified particle surface, is also consistent in the case of FCC catalyst system although some nonideality is encountered at low gas velocity.

The nonexistence of constant $\mathrm{Y}$ region in the plot of FCC catalyst at ambient temperature is interpreted as the highly nonideality of this aerated system. The increasing $Y$ values are indication of either more frequent formation of bubbles or the growth of the existing bubbles.

Some photographs had been taken in the experiment using the FCC catalyst particles aerated in two-dimensional (2-D) column. Figure II.5.7a displays the situation of the aeration at the $\bigcup_{\mathrm{mb}}$ point at ambient temperature. It is obvious that the bubbles are very big and the bed expansion is much lower than those at higher temperature (Figure II.5.7b and c). These big bubbles must have grown from smaller bubbles that already occasionally formed in the range which was generally still expected to be HAE emulsion phase. The increasing values of $\mathrm{Y}$ indicate that FCC catalyst is actually never being an ideal HAE emulsion phase at ambient temperature. Its high $\mathrm{Y}$ values give numerical measure of how bad its aeration quality is. 
When temperature reaches $400{ }^{\circ} \mathrm{C}$ though, the $\mathrm{Y}$ values show an increasing tendency at lower gas velocity but then attain a constant value at higher gas velocity before it suddenly jumps at $U_{m b}$ point. This constant $Y$ value indicates an improvement of the aeration quality by increasing the temperature. At $600^{\circ} \mathrm{C}$, the aeration behavior completely mimics the ideal behavior of the starches in Part I.

The corresponding photographs for experiment at 400 and $600^{\circ} \mathrm{C}$ are Figure II.5.7b and c, respectively. Although at $400^{\circ} \mathrm{C}$ the bubbles at the $U_{m b}$ point are still considered large, they are smaller than the ones in Figure II.5.7a. At $600^{\circ} \mathrm{C}$, the bubbles have been so small that they are barely visible.

The photographs in Figure II.5.8 were taken from experiments in 2-D column specifically intended to take pictures, rather than to take an accurate measurement. In such a narrow slit of this 2-D column, the wall effect was not negligible and significantly contributed to form bigger bubbles. Therefore, in the actual aeration experiment using three-dimensional column at the same conditions (temperature and gas flow rate), the bubbles would be most likely much smaller than those shown Figure II.5.7. 


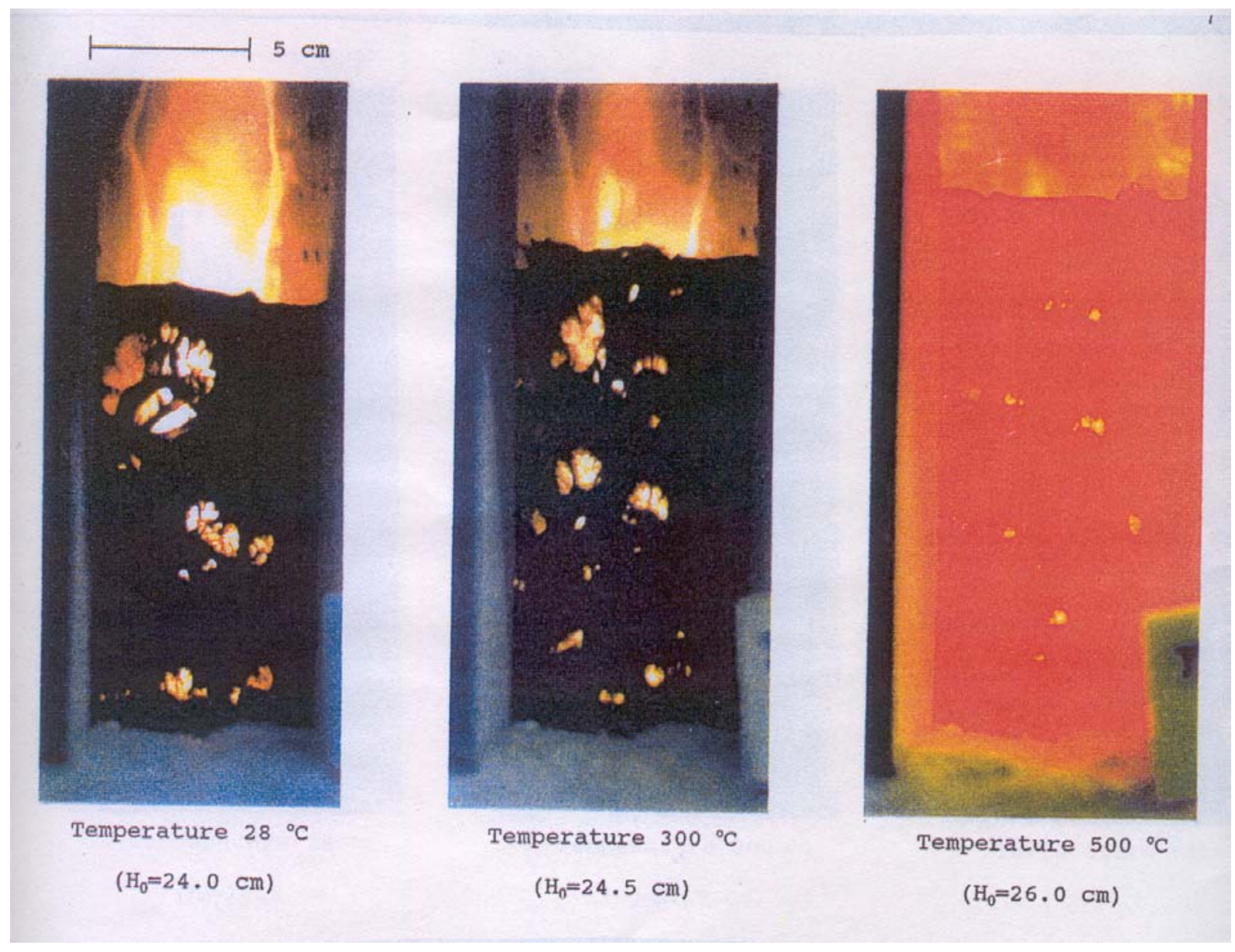

(a)

(b)

(c)

Figure II.5.7. Photographs of FCC catalyst aeration experiments 


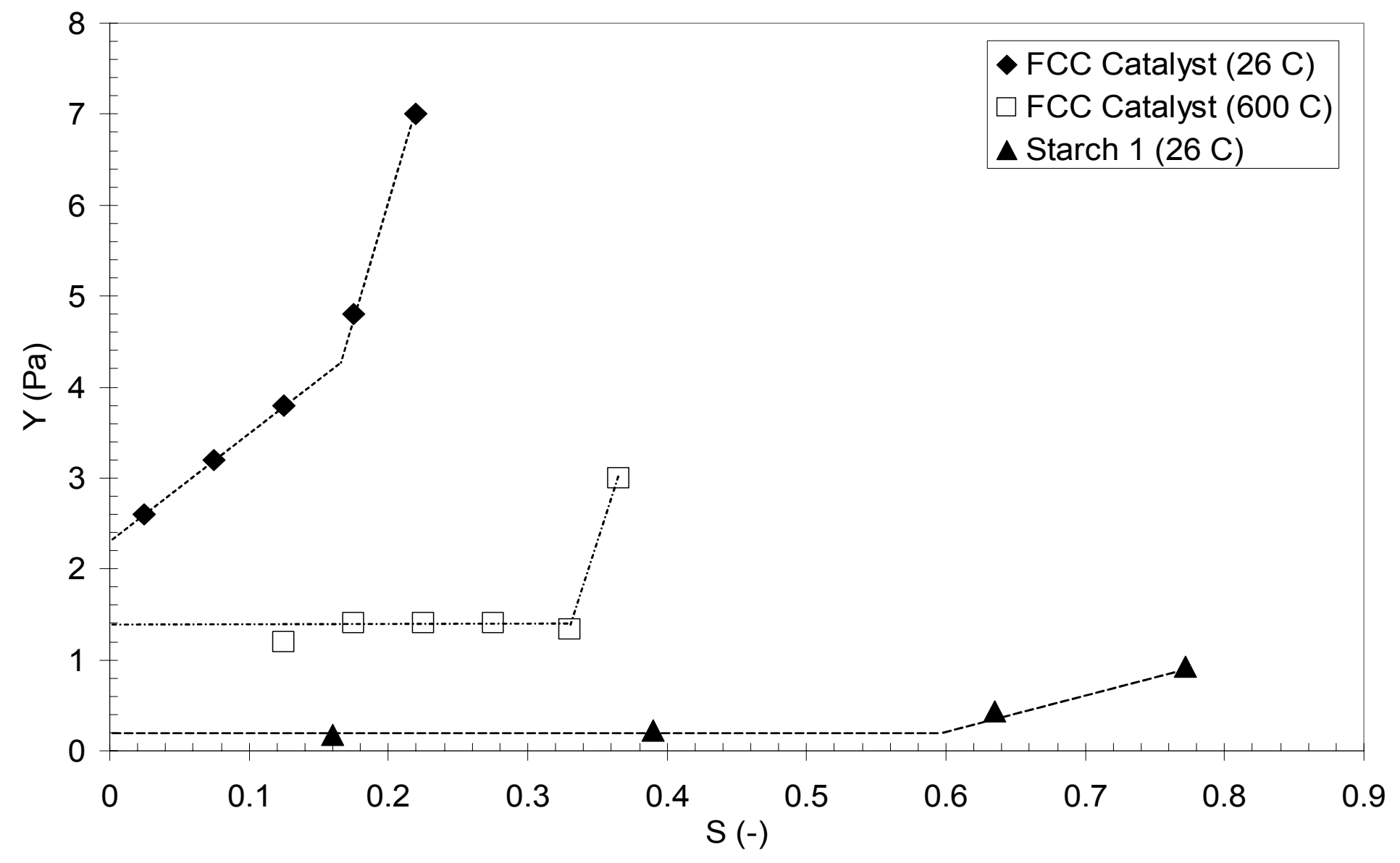

Figure II.5.8. Comparison between FCC catalyst at ambient and elevated temperature and Starch 1 at ambient temperature 
Table II.5.1. $\mathrm{U}_{\mathrm{mb}}$ values for FCC catalyst aerated at 26,400 , and $600{ }^{\circ} \mathrm{C}$

\begin{tabular}{|c|c|c|c|c|c|c|}
\hline $\begin{array}{c}\mathrm{T} \\
\left({ }^{\circ} \mathrm{C}\right)\end{array}$ & $\begin{array}{c}\text { Average } \\
\mathrm{d}_{\mathrm{p}}(\mu \mathrm{m})\end{array}$ & $\begin{array}{c}\mathrm{U}_{\mathrm{mb}} \\
(\mathrm{cm} / \mathrm{s})\end{array}$ & $\begin{array}{c}\mathrm{U}_{\max } \\
(\mathrm{cm} / \mathrm{s})\end{array}$ & $\begin{array}{c}\mathrm{S}_{\mathrm{mb}} \\
(-)\end{array}$ & $\begin{array}{c}\mathrm{S}_{\max } \\
(-)\end{array}$ & $\begin{array}{c}\% \mathrm{~S} \\
\text { difference }\end{array}$ \\
\hline 26 & 67.5 & 0.56 & 0.58 & 0.16 & 0.22 & 27.3 \\
\hline 400 & 67.5 & 0.54 & 0.68 & 0.30 & 0.34 & 11.8 \\
\hline 600 & 67.5 & 0.54 & 0.68 & 0.33 & 0.37 & 10.8 \\
\hline
\end{tabular}

*) $\% S=\frac{\left(S_{\max }-S_{\operatorname{mb}}\right)}{S_{\max }}$

Lower $\mathrm{Y}$ values at higher temperature imply that the quality of aeration is improved by increasing the temperature. Visual observation (Figure II.5.7) confirmed that at elevated temperature, bubble size was smaller and hence the aerated powder bed became more stable. The sudden change of $Y$ observed in this experiment may be relating to the phenomenon of pressure fluctuation reported earlier by Kai and Furusaki (1985). However, by this new $Y$ method, one can define the initiation of the fractures of HAE emulsion phase more quantitatively.

Table II.5.1 shows that for the particles of the same average size, the values of $U_{m b}$ are the same for the whole range of temperature but the degree of 
homogeneous expansion is higher at elevated temperature. This fact indicates that temperature has an important role to prevent bubble formation but does not very much affect the location of $U_{m b}$ point. From starch experiments at ambient temperature, it has been learned that different particle size leads to different $U_{m b}$ point. These empirical results show that $U_{m b}$ point will depend more on the particle size rather than on the temperature of the aerated system.

Sudden increase of $Y$ value at the intrinsic $U_{m b}$ point was certainly not caused by sintering phenomenon in the bed because at higher temperature, the $Y$ values were lower than that at ambient temperature. If sintering did happen, the $Y$ value would be higher at higher temperature because of the strong chemical bonding formed during sintering process. The change in $Y$ values is most likely due to the changes on particle's surface physical characteristics with the increasing temperature, which do not cause permanent deformation encountered in the case of sintering.

Constant $\mathrm{Y}$ indicates a constant internal structure of the emulsion phase which defines an ideal HAE emulsion phase. Therefore, based on the data shown in Figure II.5.8, one can infer that at certain conditions, aeration can be done with perfect HAE emulsion phase condition. Based on Figure II.5.8, these conditions can be either modification on the particle surface (for the case of starch) or elevated temperature (for the case of FCC catalyst). 
Sets of data presented in Figure II.5.6 and II.5.8 exemplifies a systematic way to conduct a characterization experiment to determine the optimum conditions (temperature and powder strain), under which one can expect a perfect HAE emulsion phase. For example, one can see that for FCC catalyst the ideal situation would be reached at $600^{\circ} \mathrm{C}$. However, if the temperature cannot be raised too high, the aeration may also be carried out at lower temperature $\left(400{ }^{\circ} \mathrm{C}\right)$, although based on Figure II.5.6, it has to be restricted to limit the powder strain between 0.2 and 0.3 in order to maintain a perfect HAE emulsion phase.

Figure II.5.9 displays that the value of $Y$ at $U_{m b}$ point is a linear function of temperature. The linear equation for the case of FCC catalyst aerated by air in the range of $26-600^{\circ} \mathrm{C}$ was found to be,

$$
\mathrm{Y}(\mathrm{Pa})=6.44-0.006 \mathrm{~T}\left({ }^{\circ} \mathrm{K}\right)
$$

with the coefficient of correlation of $97.6 \%$. Equation II.5.1 can be used to predict the $\mathrm{Y}$ value of FCC catalyst given a certain value of temperature. Then from the plot of $Y$ as a function of strain (Figure II.5.6), other aeration conditions such as $S_{m b}$ and $U_{m b}$ can be determined (the procedure is presented in Appendix C).

Although physically there is a big difference between HAE emulsion phase (as a quasi-solid material) and the actual solid material such as metal, a similar behavior is observed in the effect of temperature on the elastic 
deformation coefficient. The linearity of elasticity modulus with respect to temperature is not uncommon in the case of actual solid. Nadal and Le Poac (2003) reported that for some metals tested in their study (Ta, Cu, Au, Al, and $\mathrm{Sn})$, the linear approach of elasticity modulus as a function of temperature could be extrapolated from the ambient temperature over a large temperature range based on the fit with experimental data. 


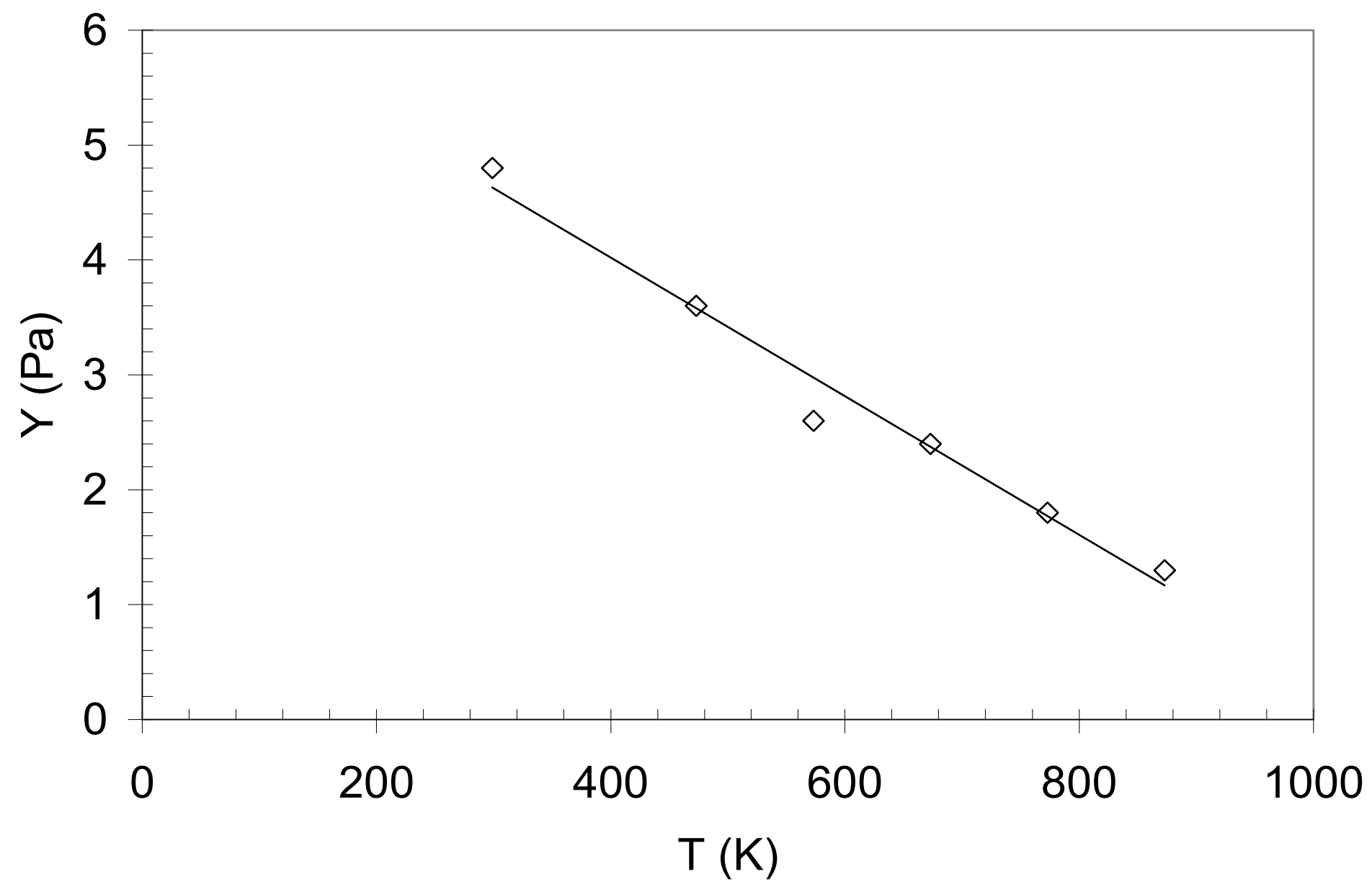

Figure II.5.9. Elastic deformation as a function of temperature (FCC catalyst) 


\section{CHAPTER II.6. CONCLUSION}

By using the data generated previously (Su, 1995), a new analysis about HAE emulsion quality at elevated temperature was conducted based on $\mathrm{Y}$ determination method. From this study, the following points were noted.

1. At ambient temperature, the aeration quality of FCC catalyst was very poor and it was indicated by an initially high $\mathrm{Y}$ which kept increasing through the whole range of strain until the maximum expansion. In contrast to that, at elevated temperature, a region of constant $Y$ was observed in the plot of $Y$ against strain. This fact indicated that at high temperature, in the case of spent FCC catalyst, an ideal HAE emulsion phase could actually be maintained over a wide range of strain until the first fractures occurred.

2. By plotting the values of $Y$ as a function of strain, one could simultaneously determine the conditions, such as the optimum temperature, gas flow rate, and particle size, required to operate the aerated system on the scheme of ideal HAE emulsion phase. In other words, $\mathrm{Y}$ served as a general characterization parameter that could be applied consistently at both ambient (as already described in Part I) and elevated temperature.

3. The $Y$ values decrease linearly with increasing temperature. This behavior is similar to that observed in the case of actual solid material. 


\section{REFERENCES}

Abrahamsen, A.R. and Geldart, D., "Behaviour of gas-fluidized beds of fine powders. Part I : Homogeneous Expansion”, Powder Technol., 26, 35-46 (1980).

Anderson, T.B. and Jackson, R., "The nature of aggregative and particulate fluidization", Chem. Engng. Sci., 19, 509-511 (1964).

Baerns, M., "Effect of interparticle adhesive forces on fluidization of fine particles", Ind. Eng. Chem. Fundam., 5 (4), 508-516, (1966).

Bi, H.T. and Grace, J.R., "Flow regime diagrams for gas-solid fluidization and upward transport”, Int. J. Multiphase Flow, 21(6), 1229-1236 (1995).

Bouillard, J.X. and Gidaspow, D., "On the origin of bubbles and Geldart's classification", Powder Technol., 68, 13-22 (1991).

Botterill, J.S.M., Teoman, Y., and Yuregir, K.R., "The effect of operating temperature on the velocity of minimum fluidization, bed voidage, and general behavior", Powder Technol., 31, 101-110 (1982).

Clift, R., "An Occamist review of fluidized bed modeling", AIChE Symp. Ser., 89, 1-17 (1993).

Davidson, J.F. and Harrison, D., "Fluidised Particles", University Press, Cambridge (1963), p. 19-20.

Donsi, G. and Massimila, L., "Bubble-free expansion of gas fluidized beds of fine particles", AIChE J., 19 (6), 1104-1110 (1973). 
Ergun, S. and Orning, A.A., "Fluid flow through randomly packed columns and fluidized beds", Ind. Eng. Chem., 41 (6), 1179-1184 (1949).

Fan, L.T., Huang, Y.W., and Yutani, N., "Determintaion of the lower bound of Umf, application at elevated temperature", Chem. Engng.Sci., 41 (1), 189-192 (1986).

Fletcher, J.V., Deo, M.D., and Hanson, F.V., "Re-examination of minimum fluidization velocity correlations applied to Group B sands and coked sands", Powder Technol., 69, 147-155 (1992).

Foscolo, P.U. and Gibilaro, L.G., "A fully predictive criterion for the transition between particulate and aggregate fluidization", Chem. Engng. Sci., 39 (12), 1667-1675 (1984).

Foscolo, P.U., Gibilaro, L.G., and Waldram, S.P., "A unified model for particulate expansion of fluidized beds and flow in fixed porous media", Chem. Engng. Sci., 38 (8), 1251-1260 (1983).

Geldart, D., “Types of gas fluidization”, Powder Technol., 7, 285-292 (1973).

Geldart, D., "Challenges in fluidized bed technology", AIChE Symp. Ser., 85 (270), 111-121 (1989).

Geldart, D. and Kapoor, D.S., "Bubble sizes in a fluidized bed at elevated temperatures", Chem. Engng. Sci., 31, 842-843 (1976).

Gibilaro, L.G., Di Felice, R., and Foscolo, P.U., "On the minimum bubbling voidage and the Geldart classification for gas-fluidized beds", Powder Technol., 56, 21-29 (1988). 
Gidaspow, D., "Multiphase flow and fluidization - Continuum and kinetic theory description", Academic Press, Boston (1994).

Jacob, K.V. and Weimer, A.W., "High-pressure particulate expansion and minimum bubbling of fine carbon powders", AIChE Journal, 33(10), 16981706 (1987).

Kai, T and Furusaki, S, "Behavior of fluidized beds of small particles at elevated temperatures", J. Chem. Eng. Japan, 18(2), 113-118 (1985).

Kamiya, H., Kimura, A., Yokoyama, T., Naito, M., and Jimbo, G., "Development of a split-type tensile-strength tester and analysis of mechanism of increase of adhesion behavior of inorganic fine powder bed at high temperature conditions", Powder Technol., 127, 239-245 (2002).

Kono, H.O., Aksoy, E., and Itani, Y., "Measurement and application of the rheological parameters of aerated fine powders - a novel characterization approach to powder flow properties", Powder Technol., 81, 177-187 (1994).

Kono, H.O., Itani, Y., Aksoy, E., Koresawa, E., and Su, J.J., "Characterization of fluidization properties of fine powder FCC catalyst at elevated temperatures - prediction of rheological parameters", AIChE Symp. Ser., 91 (308), 170-179 (1995).

Kono, H.O., Narasimhan, S., Richman, L.M., and Ohtake, T., "Flow properties of homogeneously aerated, expanded emulsion phase of fine 
powders (quasi-solid emulsion phase viscosity)", Powder Technol., 122, 168-176 (2002).

Kwauk, M., Li, J., and Liu, D., "Particulate and aggregative fluidization - 50 years in retrospect", Powder Technol., 111, 3-18 (2000).

Lettieri, P., Newton, D., and Yates, J.G., "High temperature effects on the dense phase properties of gas fluidized beds", Powder Technol., 120, 3440 (2001).

Lim, K.S., Zhu, J.X., and Grace, J.R., "Hydrodynamic of gas-solid fluidization", Int. J. Multiphase Flow, 21(Suppl.), 141-193 (1995).

Loezos, P.N., Costamagna, P., and Sundaresan, S, " The role of contact stresses and wall friction on fluidization", Chem. Engng. Sci., 57, 5123$5141(2002)$.

McCabe, W.L., Smith, J.C., and Harriott, P., "Unit operations of chemical engineering", $6^{\text {th }}$ ed., pp.157-183, McGraw-Hill Book Co., Boston (2001).

Mii, T., Yoshida, K., and Kunii, D., "Temperature-effects on the characteristics of fluidized bed", J. Chem. Eng. Japan, 6 (1), 100-102 (1973).

Molerus, O., "Interpretation of Geldart's type A, B, C, and D powders by taking into account interparticle cohesion forces", Powder Technol., 33, 81-87 (1982).

Mutsers, S.M.P. and Rietema, K., "The effect of interparticle forces on the expansion of a homogeneous gas-fluidized bed", Powder Technol., 18, 239-248 (1977). 
Nadal, M-H, and Le Poac, P., " Continuous model for the shear modulus as a function of pressure and temperature up to the melting point : analysis and ultrasonic validation", J. Appl. Phys., 93 (5), 2472-2480 (2003).

Nakamura, M, Hamada, Y, Toyama, S, Fouda, A.E., and Capes, C.E., "An experimental investigation of minimum fluidization velocity at elevated temperatures and pressures", Can. J. Chem. Eng., 63, 8-13 (1985).

Poletto, M. and Massimilla, L., "Stability analysis of uniformly fluidized beds in terms of the elastic modulus of the dispersed phase", Powder Technol., 72, 89-95 (1992).

Rapagna, S., Foscolo, P.U., and Gibilaro, L.G., "The influence of temperature on the quality of gas fluidization", Int. J. Multiphase Flow, 20(2), 305313 (1994).

Raso, G., D'Amore, M., Formisani, B., and Lignola, P.G., "The influence of temperature on the properties of the particulate phase at incipient fluidization", Powder Technol., 72, 71-76 (1992).

Rietema, K., in Proc. Int. Symp. Fluidization, Eindhoven, A. Drinkenburg (ed.), Netherlands University Press, Amsterdam (1967), p. 154.

Rietema, K., "Powders, what are they ?", Powder Technol., 37, 5-23 (1984).

Rumpf, H., "Grundlagen und Methoden des Granulierens", Chem. Ing. Techn., 30, 144 (1958).

Saxena, S.C., Rao, N.S., and Zhou, S.J., "Fluidization characteristics of gas fluidized beds at elevated temperature", Energy (Oxford), 15 (11), 1001-1014 (1990). 
Sciazko, M and Bandrowski, J., "Effect of pressure on the minimum bubbling velocity of polydisperse materials", Chem. Engng. Sci., 40 (10), 1861-1869 (1985).

Seville, J.P.K., Willett, C.D., and Knight, P.C., "Interparticle forces in fluidization : a review", Powder Technol., 113, 261-268 (2000).

Sitthiphong, N, George, A.H., Bushnell, D., "Bubble eruption diameter in a fluidized bed of large particles at elevated temperature", Chem. Engng. Sci, 36 (7), 1259-1260 (1981).

Su, J.J., "Granulation and characterization of fine powders and investigation of transient bubble behaviors in coarse particle systems", PhD dissertation, West Virginia Unviersity, Morgantown (1995).

Verloop, J. and Heertjes, P.M., "Shock waves as a criterion for the transition from homogeneous to heterogeneous fluidization", Chem. Engng. Sci., 25, 825-832 (1970).

Visser, J., "An Invited review : Van der Waals and other cohesive forces affecting powder fluidization", Powder Technol., 58, 1-10 (1989).

Wong, A.C.Y., "Use of angle of repose and bulk densities for powder characterization and the prediction of minimum fluidization and minimum bubbling velocities", Chem. Engng. Sci., 57, 2635-2640 (2002).

Wu, S.Y. and Baeyens, J., "Effect of operating temperature on minimum fluidization velocity", Powder Technol., 67, 217-220 (1991).

Xie, H.Y., "The role of interparticle forces in the fluidization of fine particles", Powder Technol., 94, 99-108 (1997). 
Yamazaki, R., Ueda, N., and Jimbo, G., "Mechanism of incipient fluidization in fluidized bed at elevated temperature", J. Chem. Eng. Japan, 19(4), 251-257 (1986).

Yates, J.G., "Effects of temperature and pressure on gas-solid fluidization", Chem. Engng.Sci., 51 (2), 167-205 (1996). 
APPENDICES 


\section{APPENDIX A}

\section{Calculation of Original Aeration Data}

The following examples are given based on the data from EXP1-17 (Starch 1, weight $\left.=946.2 \mathrm{~g}, \mathrm{H}_{\mathrm{mf}} / \mathrm{D}=1.5\right)$. The original data from the aeration experiment are bed height $(H)$ and pressure drop $(\Delta \mathrm{P})$ at various gas velocity. When the bed surface is fluctuating in the region above $\mathrm{U}_{\mathrm{mb}}, \mathrm{H}$ is taken as the average value between the highest and lowest height reached in the fluctuation. These original data are displayed in column A, B, and C of Table A.1.

\section{Excess pressure drop}

The procedure for excess pressure drop calculation is as the following.

a. A linear regression is performed on the data that shown a linear correlation on the plot of pressure drop against gas velocity in the range of $0<U<U_{m f}$. For this set of data, the regression equation is:

$$
\Delta \mathrm{P}(\mathrm{U})=16624 \mathrm{U}
$$

with $\Delta \mathrm{P}$ in $\mathrm{Pa}$ and $\mathrm{U}$ in $\mathrm{cm} / \mathrm{s}$. The linear regression is done by Excel regression function which is graphically shown in Figure A.1.

b. The hypothetical pressure drop as a function of temperature, $\Delta P_{h}(U)$, is calculated based on Eq. (A.1) and the results are listed in column D of Table A.1.

c. The excess pressure drop is calculated as:

$$
\Delta \mathrm{P}^{*}(\mathrm{U})=\Delta \mathrm{P}_{\mathrm{h}}(\mathrm{U})-\Delta \mathrm{P}_{\text {eq }}
$$


For these data, $\Delta \mathrm{P}_{\text {eq }}=1200 \mathrm{~Pa}$ (see Figure A.1). The calculation is performed for gas velocities data in the region of $U>U_{m f}$.

The results are in column E of Table A.1.

\section{Number of powder layers}

For this set of data, the number of powder layers is:

$$
\mathrm{N}=\frac{\mathrm{H}_{\mathrm{mf}}}{\mathrm{d}_{\mathrm{p}}}=\frac{15 \mathrm{~cm}}{\left(15 \times 10^{-4}\right) \mathrm{cm}}=10000
$$

\section{Powder tensile stress}

By dividing column E in Table A.1 with the number of powder layer, the powder tensile stress is obtained as those listed in column $F$ in Table A.1.

\section{Powder Strain}

The powder strains are calculated for the gas velocities between $\cup_{m f}$ and the gas velocity that makes the maximum expansion (it is the region bordered by the bold line in Table A.1). It is calculated as:

$$
\mathrm{S}=\frac{\mathrm{H}-\mathrm{H}_{\mathrm{mf}}}{\mathrm{H}_{\mathrm{mf}}}
$$

For this data set, $H_{m f}=15 \mathrm{~cm}$. The powder strains are those in column $G$ in Table A.1. 
Table A.1. Original data from EXP1-17

\begin{tabular}{|c|c|c|c|c|c|c|}
\hline A & B & C & D & $E$ & $F$ & G \\
\hline $\mathrm{U}(\mathrm{cm} / \mathrm{s})$ & $\mathrm{H}(\mathrm{cm})$ & $\Delta \mathrm{P}(\mathrm{Pa})$ & $\Delta \mathrm{P}_{\mathrm{h}}(\mathrm{Pa})$ & $\Delta \mathrm{P}^{*}(\mathrm{~Pa})$ & $\Delta \mathrm{P}^{* *}(\mathrm{~Pa})$ & $S(-)$ \\
\hline 0.400 & 25.90 & 1201 & 6669 & 5469 & 0.550 & \\
\hline 0.370 & 26.00 & 1207 & 6131 & 4931 & 0.490 & \\
\hline 0.340 & 26.15 & 1193 & 5578 & 4378 & 0.440 & \\
\hline 0.300 & 26.25 & 1199 & 5009 & 3809 & 0.380 & \\
\hline 0.250 & 27.05 & 1189 & 4130 & 2930 & 0.320 & 0.80 \\
\hline 0.230 & 26.50 & 1192 & 3829 & 2629 & 0.260 & 0.77 \\
\hline 0.210 & 25.7 & 1196 & 3524 & 2324 & 0.230 & 0.71 \\
\hline 0.190 & 25.2 & 1189 & 3216 & 2016 & 0.200 & 0.70 \\
\hline 0.180 & 24.5 & 1186 & 2904 & 1704 & 0.170 & 0.63 \\
\hline 0.160 & 23.8 & 1183 & 2588 & 1388 & 0.140 & 0.59 \\
\hline
\end{tabular}


Table A.1. (continued)

\begin{tabular}{|c|c|c|c|c|c|c|}
\hline $\mathbf{A}$ & B & C & D & $E$ & $F$ & G \\
\hline $\mathrm{U}(\mathrm{cm} / \mathrm{s})$ & $\mathrm{H}(\mathrm{cm})$ & $\Delta \mathrm{P}(\mathrm{Pa})$ & $\Delta \mathrm{P}_{\mathrm{h}}(\mathrm{Pa})$ & $\Delta \mathrm{P}^{*}(\mathrm{~Pa})$ & $\Delta \mathrm{P}^{* *}(\mathrm{~Pa})$ & S (-) \\
\hline 0.140 & 22.3 & 1180 & 2269 & 1069 & 0.110 & 0.50 \\
\hline 0.120 & 20.9 & 1154 & 1946 & 746 & 0.070 & 0.39 \\
\hline 0.100 & 18.6 & 1118 & 1619 & 419 & 0.040 & 0.30 \\
\hline 0.080 & 15.7 & 1004 & 1288 & 88 & 0.010 & 0.10 \\
\hline 0.060 & 15.4 & 969 & 954 & 44 & 0.005 & 0.03 \\
\hline 0.040 & 15 & 600 & 616 & 0 & 0 & 0 \\
\hline 0.030 & 15 & 523 & 545 & & & \\
\hline 0.029 & 15 & 465 & 477 & & & \\
\hline 0.025 & 15 & 426 & 414 & & & \\
\hline 0.021 & 15 & 358 & 355 & & & \\
\hline 0.018 & 15 & 330 & 301 & & & \\
\hline
\end{tabular}


Table A.1. (continued)

\begin{tabular}{|r|r|r|r|r|r|r|}
\hline \multicolumn{1}{|c|}{ A } & \multicolumn{1}{|c|}{ B } & \multicolumn{1}{c|}{ C } & \multicolumn{1}{c|}{ D } & E & F & G \\
\hline $\mathrm{U}(\mathrm{cm} / \mathrm{s})$ & $\mathrm{H}(\mathrm{cm})$ & \multicolumn{1}{|c|}{$\Delta \mathrm{P}(\mathrm{Pa})$} & $\Delta \mathrm{P}_{\mathrm{h}}(\mathrm{Pa})$ & $\Delta \mathrm{P}^{*}(\mathrm{~Pa})$ & $\Delta \mathrm{P}^{* *}(\mathrm{~Pa})$ & $\mathrm{S}(-)$ \\
\hline 0.015 & 15 & 271 & 251 & & & \\
\hline 0.012 & 15 & 213 & 201 & & & \\
\hline 0.009 & 15 & 175 & 162 & & & \\
\hline 0.008 & 15 & 155 & 123 & & & \\
\hline 0 & 15 & 0 & 0 & & & \\
\hline
\end{tabular}




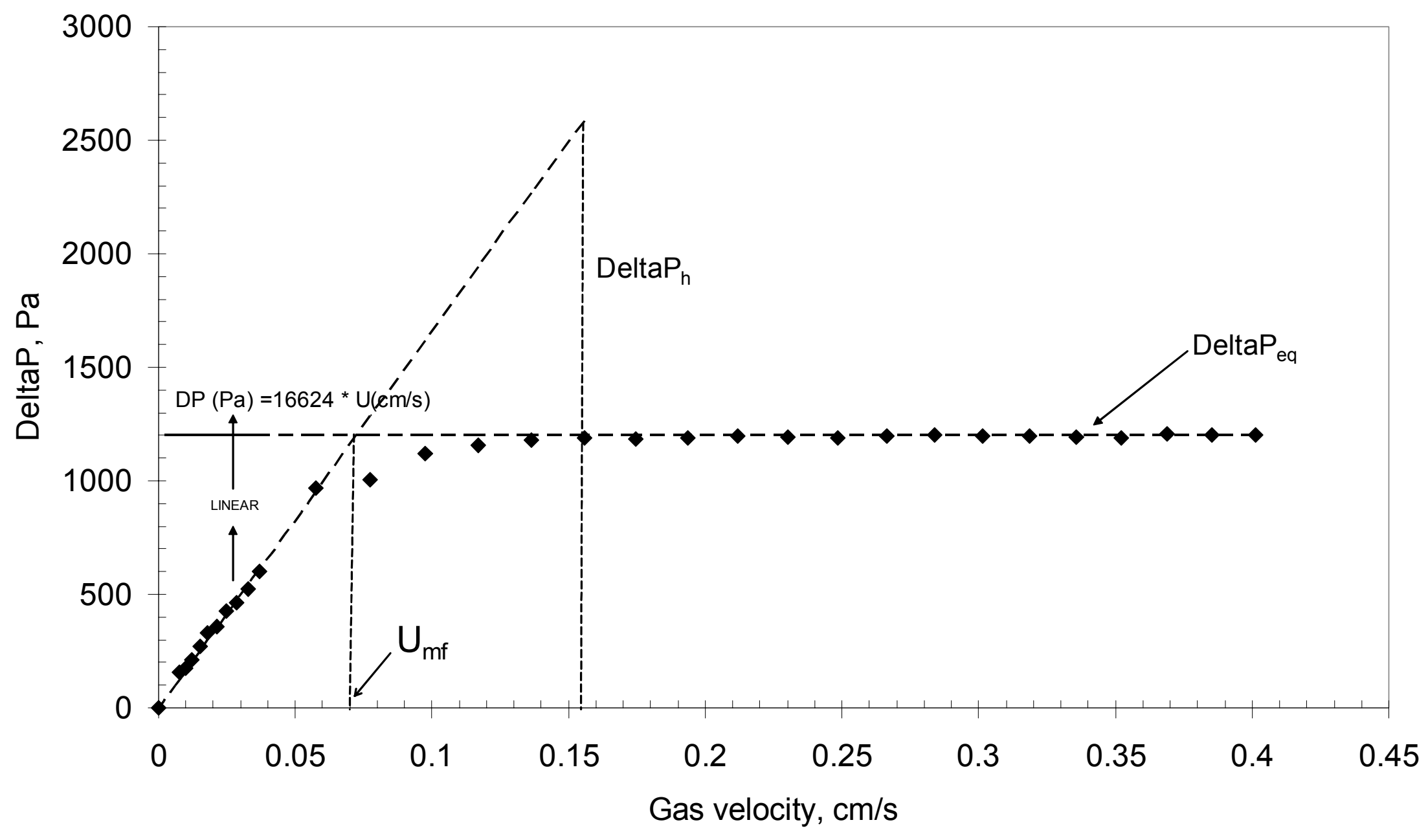

Figure A.1. Pressure drop data 


\section{APPENDIX B}

\section{Calculation of Elastic Deformation Coefficient}

The following examples are given based on the data from EXP1-17 (Starch 1, weight $\left.=946.2 \mathrm{~g}, \mathrm{H}_{\mathrm{m} f} / \mathrm{D}=1.5\right)$.

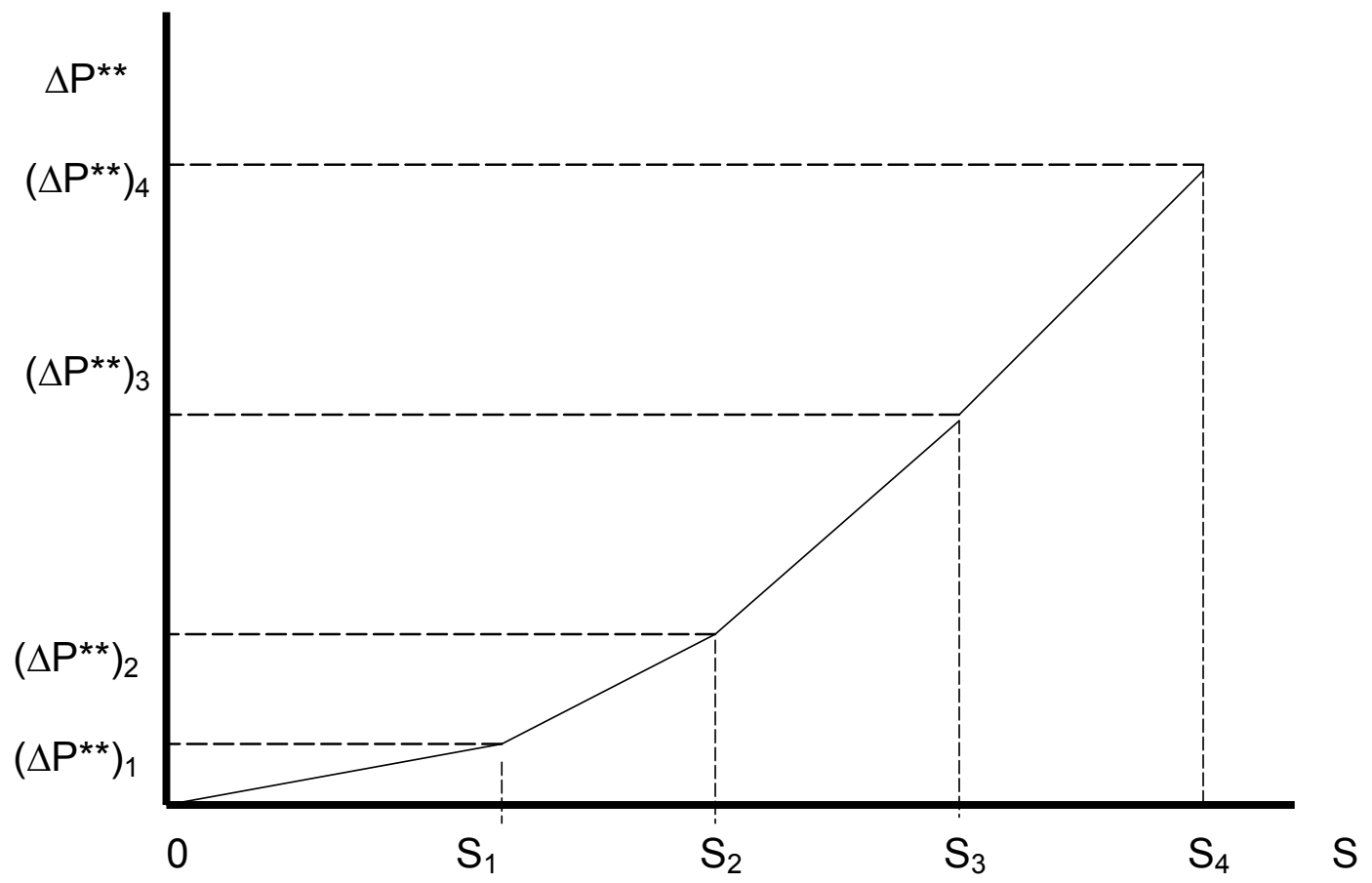

Figure B.1. Powder tensile stress curve

The average powder strain, for example in the range of $S_{2} \leq S \leq S_{3}$, is calculated as:

$$
\mathrm{S}_{\mathrm{avg}}=\frac{\mathrm{S}_{2}+\mathrm{S}_{3}}{2}
$$


Elastic deformation coefficient is defined as:

$$
\mathrm{Y}=\frac{\Delta \sigma^{*}}{\Delta \mathrm{S}}=\frac{\Delta\left(\Delta \mathrm{P}^{* *}\right)}{\Delta \mathrm{S}}
$$

This $Y$ will be calculated between several small increments of $S$ between zero to the maximum observed $S$ in the experiment. For example, for the range of $\mathrm{S}_{2} \leq \mathrm{S} \leq \mathrm{S}_{3}$, the value of $\mathrm{Y}_{3}$ is:

$$
\mathrm{Y}_{3}=\frac{\Delta \mathrm{P}_{3}{ }^{*}-\Delta \mathrm{P}_{2}{ }^{* *}}{\mathrm{~S}_{3}-\mathrm{S}_{2}}
$$

The results for this set of data are listed in Table B.1 
Table B.1. Determination of elastic deformation coefficient for data from EXP1-17

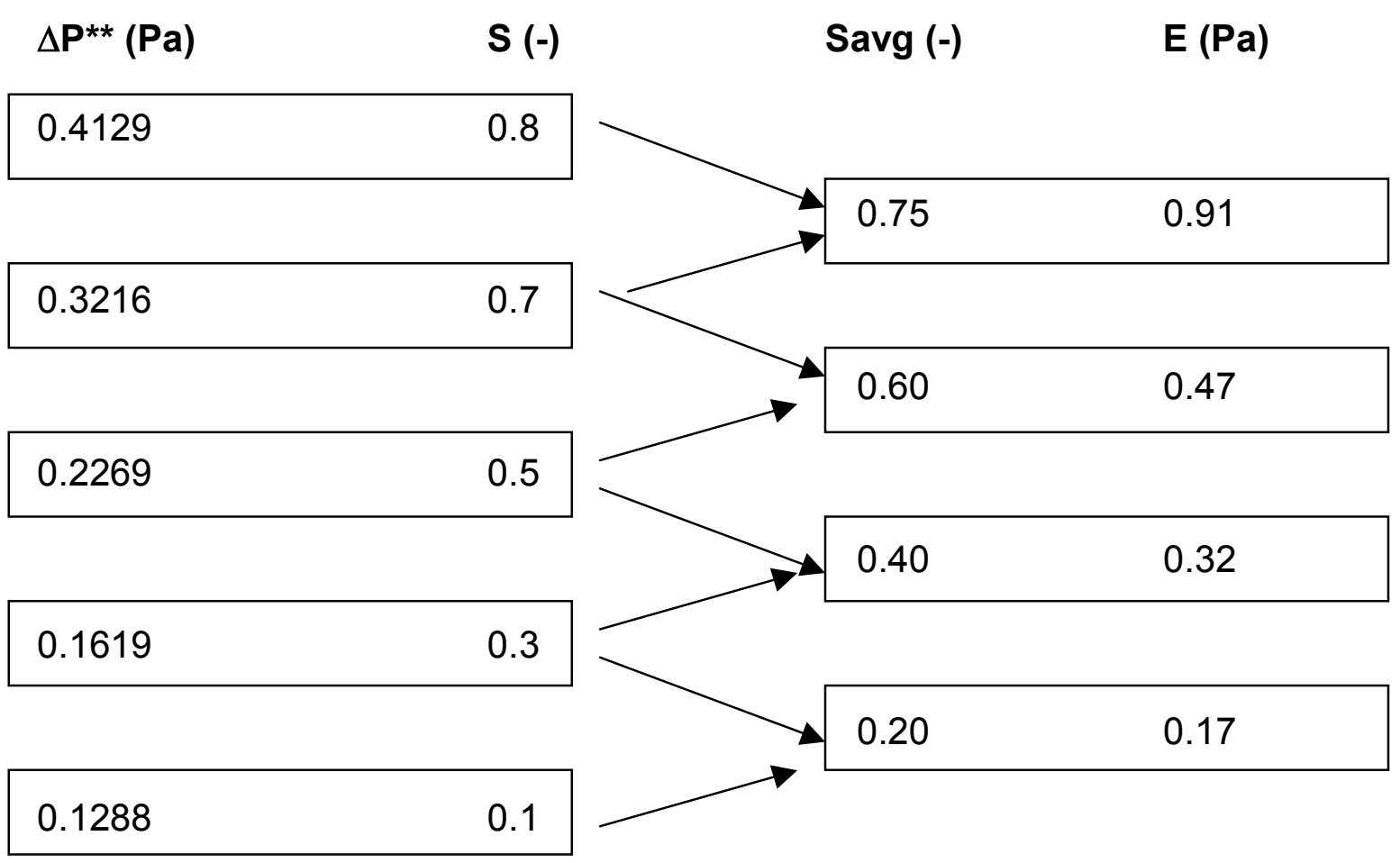




\section{APPENDIX C \\ Procedure to determine $U_{m b}$ from $Y-S$ plot}

On the Y-S data, the point of minimum bubbling point is given as a pair of $Y$ and $S$ values at which the sudden change of $Y$ value is observed. In this appendix, the procedure to determine $U_{m b}$ point from the sudden change point in $Y$-S plot is to be exemplified based on the plots of FCC catalyst at $26^{\circ} \mathrm{C}$.

The procedure is as the following :

1. Locate the point of sudden change in Y-S plot (Figure C.1). At the plot for $26^{\circ} \mathrm{C}$, this point is observed at $\mathrm{S}=0.165$.

2. From the $S-U$ plot (Figure C.2), at $S=0.165$ the corresponding $U$ value is $0.59 \mathrm{~cm} / \mathrm{s}$. This value is the intrinsic $U_{\mathrm{mb}}$ point for $\mathrm{FCC}$ catalyst at $26^{\circ} \mathrm{C}$. 


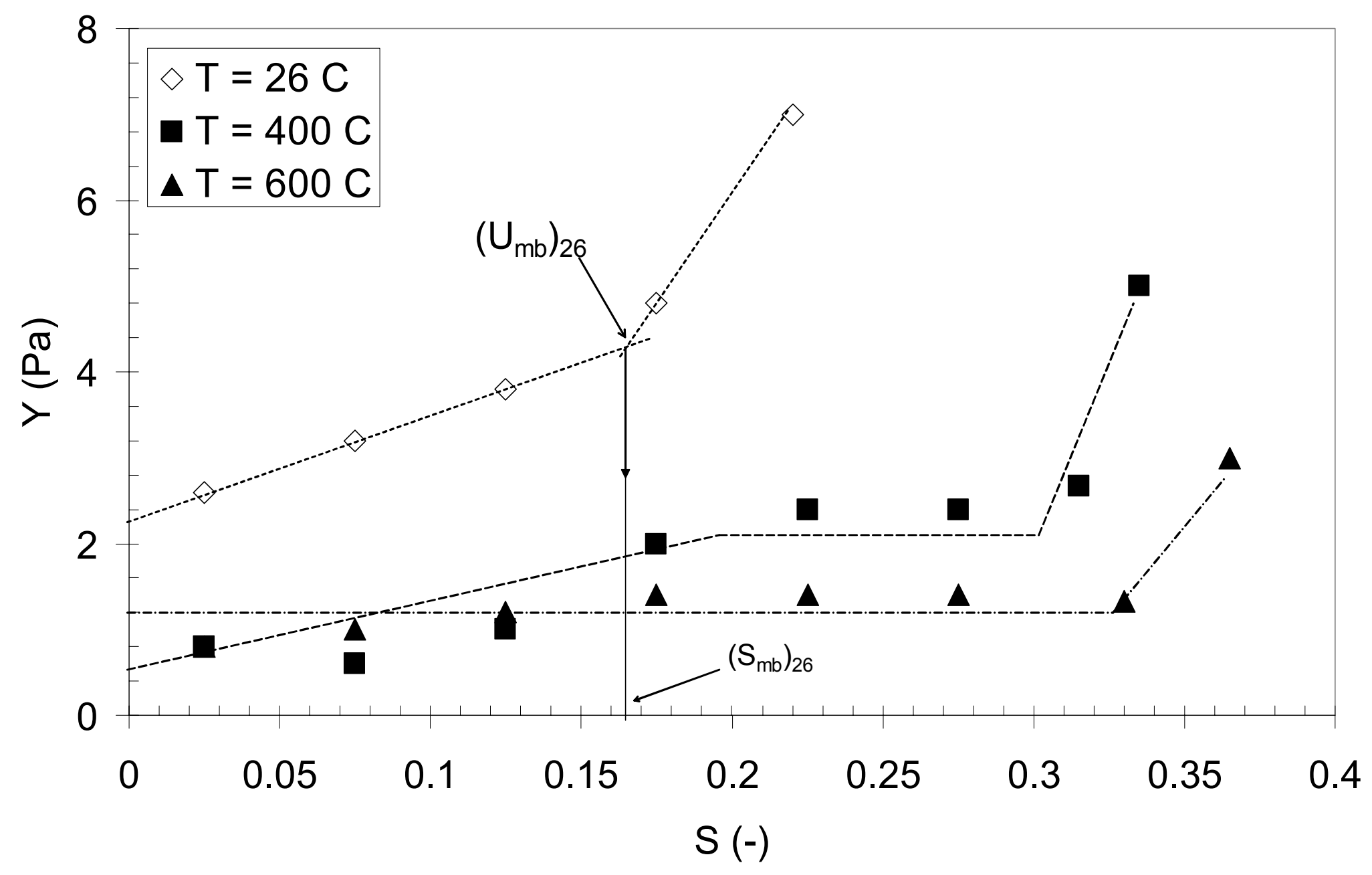

Figure C.1. The plot of elastic deformation coefficient against powder strain 


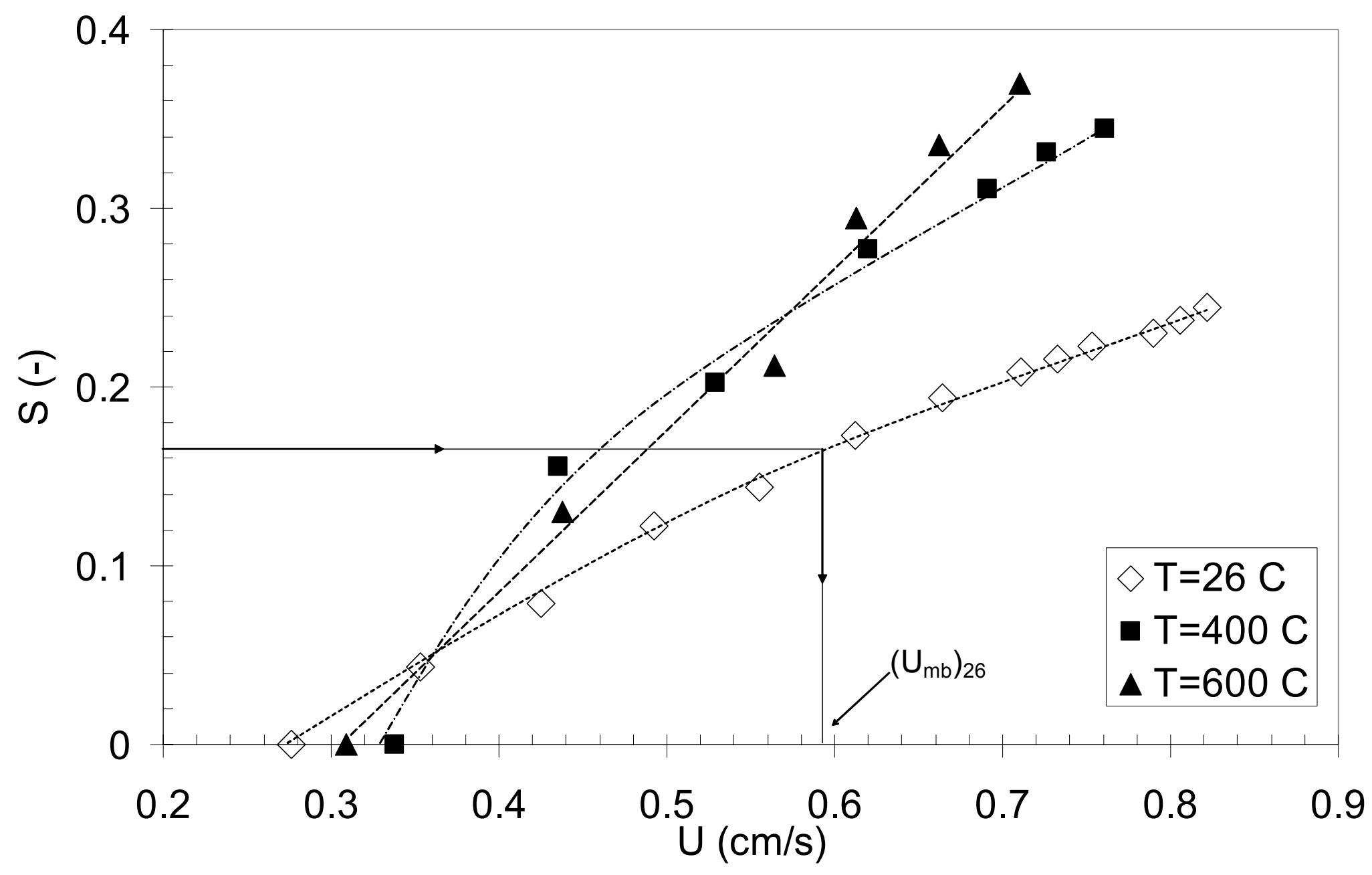

Figure C.2. The plot of powder strain against gas velocity 


\section{APPENDIX D}

\section{Analysis of variance on $\mathrm{Y}$ data}

\section{Data}

Table D.1 lists the $Y$ values of Starch 1 at fixed values of bed aspect ratio and powder strain. There are two observations on each combination of bed aspect ratio and powder strain.

Table D.1. Y data on Starch 1

\begin{tabular}{|c|c|c|c|c|c|c|}
\hline & & & Bed & ratio & & \\
\hline & & 1 & 1.5 & 2 & 2.5 & 3 \\
\hline & 0.2 & 0.15 & 0.18 & 0.20 & 0.18 & 0.16 \\
\hline & & 0.19 & 0.20 & 0.20 & 0.19 & 0.20 \\
\hline.$\subseteq$ & 0.4 & 0.24 & 0.22 & 0.23 & 0.24 & 0.19 \\
\hline 心 & & 0.25 & 0.23 & 0.24 & 0.19 & 0.24 \\
\hline కె & 0.6 & 0.42 & 0.43 & 0.41 & 0.37 & 0.30 \\
\hline & & 0.43 & 0.42 & 0.40 & 0.42 & 0.41 \\
\hline & 0.8 & 0.88 & 0.93 & 0.89 & 0.83 & 0.76 \\
\hline & & 0.85 & 0.94 & 0.87 & 0.94 & 0.90 \\
\hline
\end{tabular}




\section{Two-way ANOVA}

A two-way ANOVA is performed by using the statistics toolbox in MATLAB 6.5.

The output of the program is shown in Figure D.1.

\begin{tabular}{|c|c|c|c|c|c|c|}
\hline \multicolumn{7}{|c|}{ ANOVA Table } \\
\hline Source & SS & $\mathrm{df}$ & MS & $F$ & Prob $>F$ & 人) \\
\hline $\begin{array}{l}\text { Columns } \\
\text { Rows } \\
\text { Interaction } \\
\text { Error } \\
\text { Total }\end{array}$ & $\begin{array}{l}0.01027 \\
3.0348 \\
0.01027 \\
0.0285 \\
3.08384\end{array}$ & $\begin{array}{r}4 \\
3 \\
12 \\
20 \\
39\end{array}$ & $\begin{array}{l}0.00257 \\
1.0116 \\
0.00086 \\
0.00142\end{array}$ & $\begin{array}{c}1.8 \\
709.89 \\
0.6\end{array}$ & $\begin{array}{l}0.1683 \\
0 \\
0.8167\end{array}$ & \\
\hline
\end{tabular}

Figure D.1. The output of two-way ANOVA from MATLAB 6.5

Based on the ANOVA output shown in Figure D.1, it can be concluded that:

a. The F value for column (corresponding to bed aspect ratio) indicates that there is no significant difference caused by bed aspect ratio on $Y$ value measurement (in 95\% confidence interval). 
b. The $F$ value for row (corresponding to powder strain) implies that there is significant effect of powder strain on $\mathrm{Y}$ values (in 95\% confidence interval).

c. The $F$ value for interaction does not indicate significant interaction between bed aspect ratio and powder strain (in 95\% confidence interval).

\section{Box plot}

The statistical information of the data (Starch 1 ) is summarized in the box plot shown in Figure D.2. The plot is generated by statistics toolbox in MATLAB 6.5.

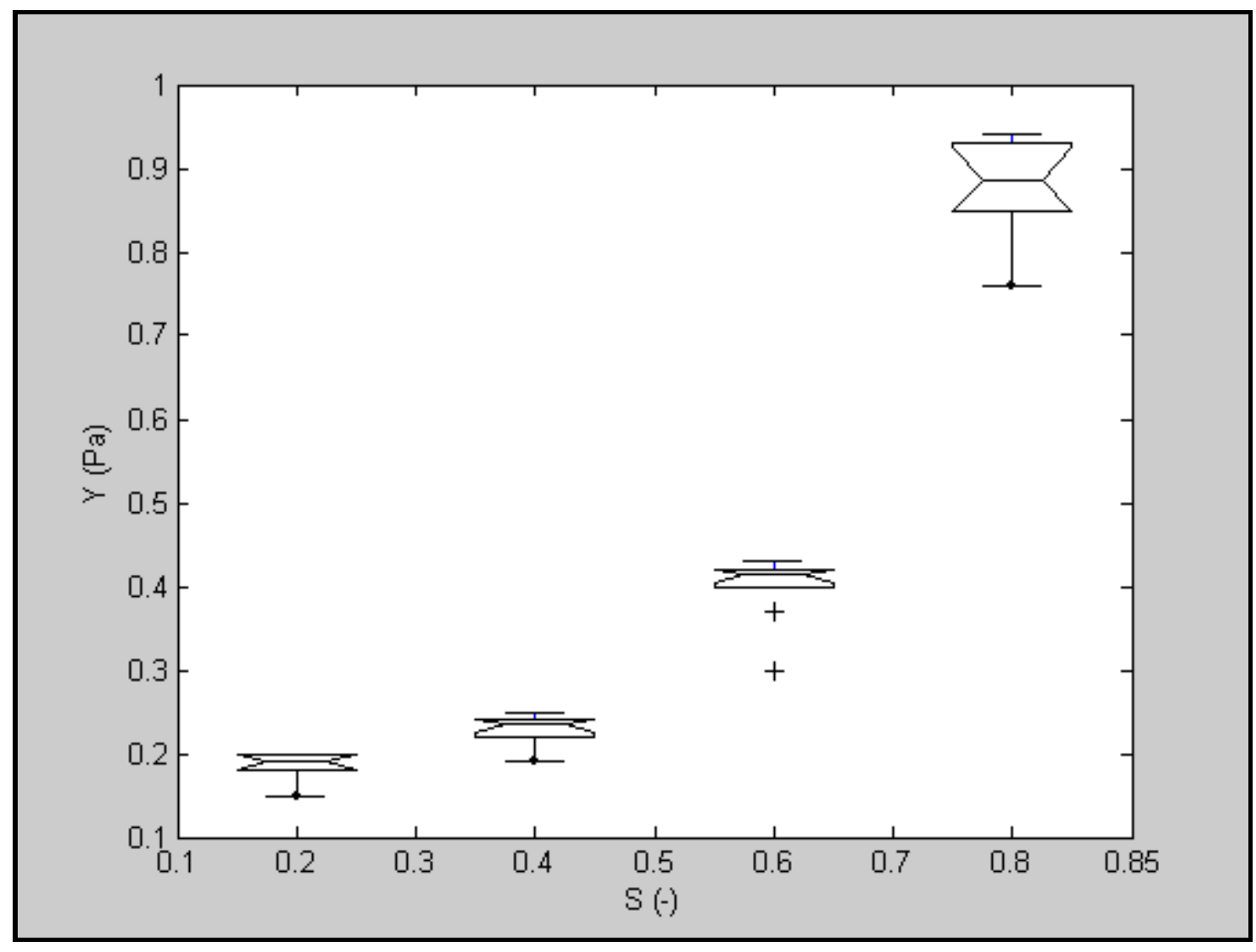

Figure D.2. Box plot for Starch 1 data from MATLAB 6.5 